\title{
THE FATIGUE CHARACTERISTICS OF FRICTION STIR WELDED STIFFENED PANEL STRUCTURE
}

\author{
By \\ HEESUCK, JUNG \\ B.Eng

\begin{abstract}
A thesis submitted to
the Faculty of Graduate Studies and Research

in partial fulfillment of

the requirements for the degree of

Master of Applied Science

Ottawa-Carleton Institute for

Mechanical and Aerospace Engineering

Department of

Mechanical and Aerospace Engineering

September, 2007
\end{abstract} \\ Carleton University \\ 1125 Colonel By Drive, Ottawa, ON, CANADA K1S 5B6
}

Copyright $\Theta 2007$ by Heesuck Jung

All rights reserved. 


$\begin{array}{ll}\begin{array}{l}\text { Library and } \\ \text { Archives Canada }\end{array} & \begin{array}{l}\text { Bibliothèque et } \\ \text { Archives Canada }\end{array} \\ \begin{array}{l}\text { Published Heritage } \\ \text { Branch }\end{array} & \begin{array}{l}\text { Direction du } \\ \text { Patrimoine de l'édition }\end{array} \\ \begin{array}{l}\text { 395 Wellington Street } \\ \text { Ottawa ON K1A ON4 }\end{array} & \begin{array}{l}\text { 395, rue Wellington } \\ \text { Ottawa ON K1A ON4 } \\ \text { Canada }\end{array}\end{array}$

Your file Votre référence ISBN: 978-0-494-33653-3 Our file Notre référence ISBN: 978-0-494-33653-3

NOTICE:

The author has granted a nonexclusive license allowing Library and Archives Canada to reproduce, publish, archive, preserve, conserve, communicate to the public by telecommunication or on the Internet, loan, distribute and sell theses worldwide, for commercial or noncommercial purposes, in microform, paper, electronic and/or any other formats.

The author retains copyright ownership and moral rights in this thesis. Neither the thesis nor substantial extracts from it may be printed or otherwise reproduced without the author's permission.
AVIS:

L'auteur a accordé une licence non exclusive permettant à la Bibliothèque et Archives Canada de reproduire, publier, archiver, sauvegarder, conserver, transmettre au public par télécommunication ou par l'Internet, prêter, distribuer et vendre des thèses partout dans le monde, à des fins commerciales ou autres, sur support microforme, papier, électronique et/ou autres formats.

L'auteur conserve la propriété du droit d'auteur et des droits moraux qui protège cette thèse. $\mathrm{Ni}$ la thèse ni des extraits substantiels de celle-ci ne doivent être imprimés ou autrement reproduits sans son autorisation.
In compliance with the Canadian

Privacy Act some supporting forms may have been removed from this thesis.

While these forms may be included in the document page count, their removal does not represent any loss of content from the thesis.
Conformément à la loi canadienne sur la protection de la vie privée, quelques formulaires secondaires ont été enlevés de cette thèse.

Bien que ces formulaires aient inclus dans la pagination, il n'y aura aucun contenu manquant.

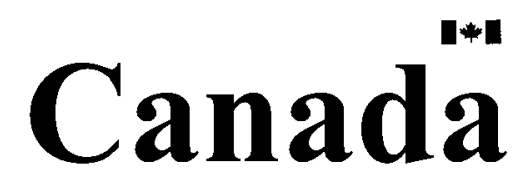




\begin{abstract}
Friction Stir Welding (FSW) is an advanced welding technology for joining materials using friction energy alone.

In this thesis, the FSW process was reviewed, and compared with other joining methods. In particular, the FSW process is considered as a manufacturing process for airframe structures. To this end a lap joint specimen was developed to represent the stiffened panel of an aircraft skin and its associated stiffener. The materials used in this test program were $2024-\mathrm{T} 3$ as the skin and $7075-\mathrm{T} 6$ as the stiffener. The skin and stiffener were joined using FSW.
\end{abstract}

In the test program the static strength of FSW stiffened panel structures fabricated from 2024-T3 and 7075-T6 were compared with values from the reference literature. In addition, 20 fatigue test specimens classified into 5 groups according to the existence of a tool pin hole and the welding sequence. The welding sequences considered were: Single Pass, Double Pass (Type I) and Double Pass (Type II). S-N curves, fatigue crack growth rate data and metallurgical analysis were investigated and presented for the five groups of FSW specimens. It was found that the pin plunge and removal locations were key crack initiation points for specimens with discontinuous welding. However, the Double Pass (Type II) welding specimens with continuous welding showed outstanding fatigue life. 


\section{ACKNOWLEDGEMENTS}

I would like to thank to my supervisor, Professor R.Bell and co-supervisor, Professor X.Wang for their guidance, support and patience during my study.

Also, I want to thank to Dr. A.Merati, Institute for Aerospace Research, National Research Council (NRC) of Canada for his support of test specimens and SEM pictures.

Finally, I appreciate my family for their patience during my study. 


\section{TABLE OF CONTENTS}

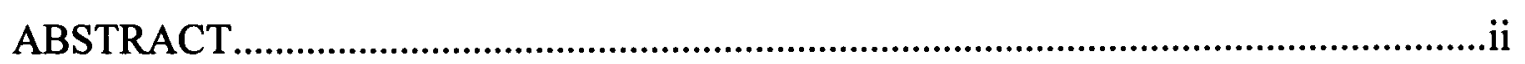

ACKNOWLEDGEMENTS.................................................................................. ii

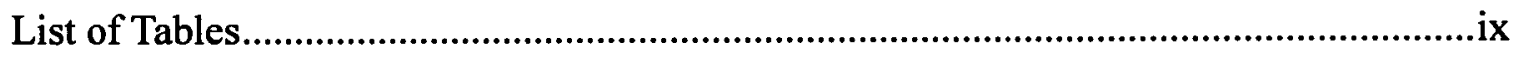

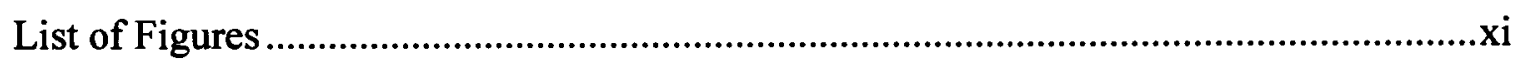

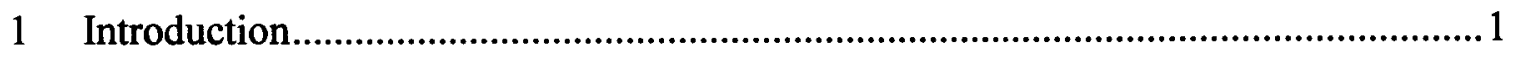

1.1 Background ………..................................................................................... 1

1.2 Overview of Friction Stir Welding (FSW) ................................................... 2

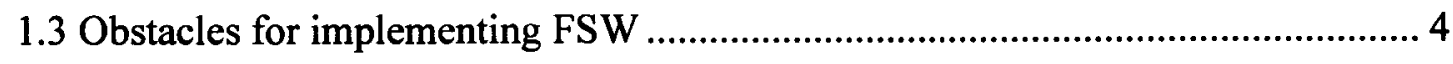

1.4 Stiffened panel structure using FSW ................................................................ 4

1.5 Main objective of this thesis .......................................................................... 6

1.6 Outline of this thesis........................................................................................

2 Literature review for Friction Stir Welding (FSW) and its application to the stiffened

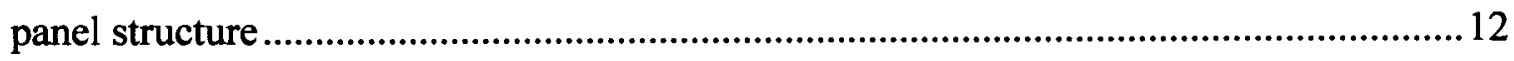

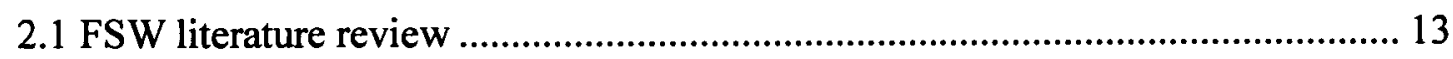




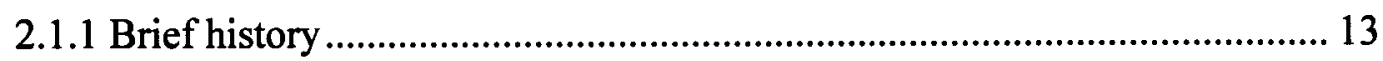

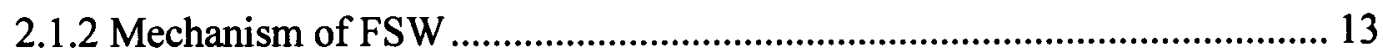

2.1.3 FSW parameters ................................................................................. 14

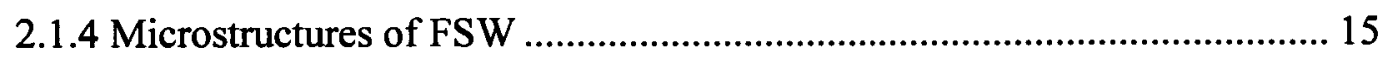

2.1.5 Advantages and disadvantages of FSW ................................................... 16

2.1.6 Possible defects of FSW joints and their cause ……………...................... 18

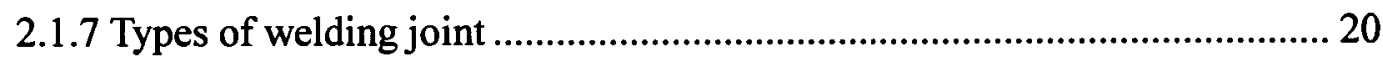

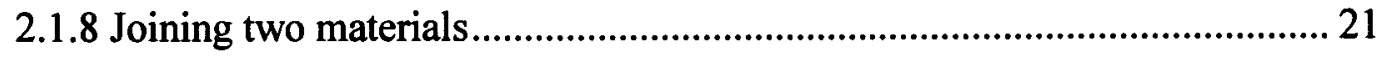

2.2 The application of FSW to stiffened panel structures........................................ 22

2.2.1 Material properties of 2024-T3 and 7075-T6 ........................................... 22

2.2.2 Brief comparison of riveting, laser welding, and FSW ............................... 23

2.2.3 Previous studies of the FSW butt and lap joint with 2024 and 7075

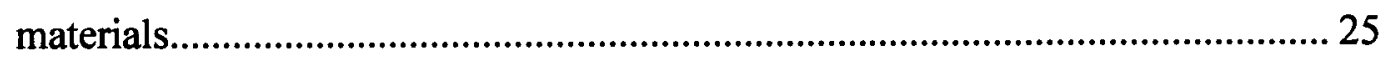

2.2.4 Static strength comparison between the riveted panel and the Friction Stir

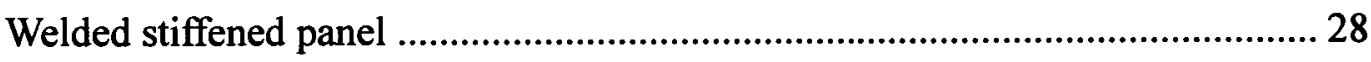

2.3 Fatigue properties of FSW joints .................................................................. 29 
2.3.1 S-N behavior about FSW

2.3.2 Fatigue Crack Propagation (FCP) of FSW .............................................. 30

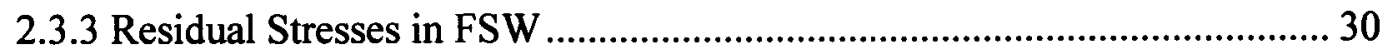

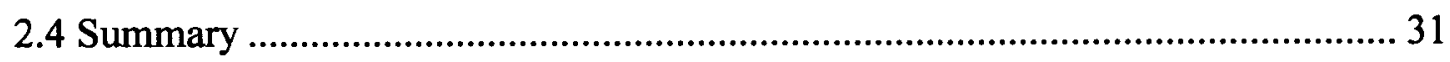

3 Experimental setup, procedure, and results ............................................................43

3.1 2024-T3 base material static tensile strength and fatigue property ...................... 43

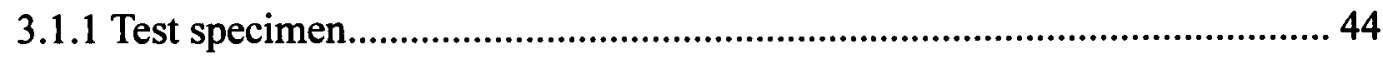

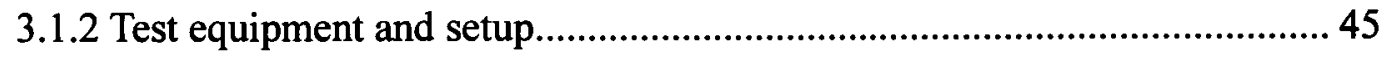

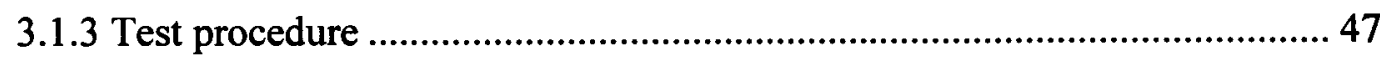

3.1.4 Static and Fatigue Test results for 2024-T3 .............................................. 47

3.2 Static tensile strength test for the FSW stiffened panel specimens ....................... 49

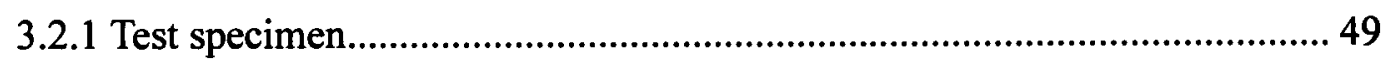

3.2.2 Test equipment and setup..................................................................... 50

3.2.3 Test procedure and results of FSW specimens.......................................... 51

3.3 The Fatigue tests of the FSW specimens........................................................... 52

3.3.1 Test specimens ..................................................................................... 52 
3.3.2 Test equipment and setup........................................................................ 54

3.3.4 The simple label system for FSW fatigue test specimens .......................... 55

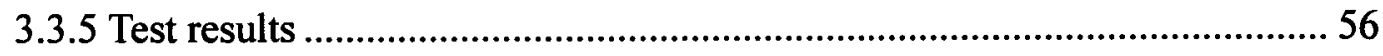

3.3.5.1 S-N curve for FSW specimens....................................................... 56

3.3.5.2 Location of surface crack initial detection..........................................58

3.3.5.3 Crack propagation ............................................................................ 60

3.3.5.4 Metallurgical analysis by scanning electron microscopy (SEM) ..... 61

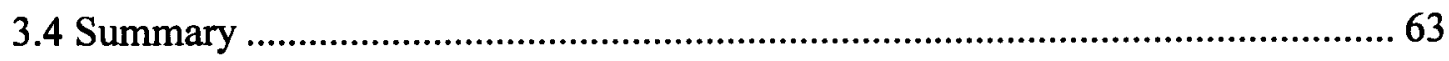

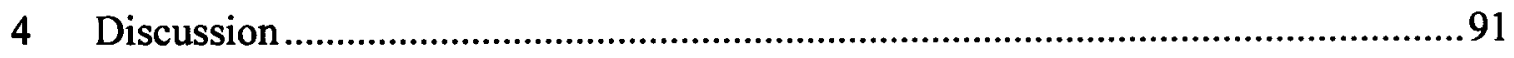

4.1 The fatigue fracture mechanism of FSW specimens............................................. 91

4.1.2 The fatigue fracture mechanism of the DP FSW specimens with tool pin

hole

4.1.3 The analysis of the fatigue behavior of the SP and DP FSW specimens with tool pin hole 94

4.1.4 The fatigue fracture mechanism of the SP and DP FSW specimens without tool pin hole 95 
4.1.5 The analysis of the fatigue behavior of the SP and DP FSW specimens

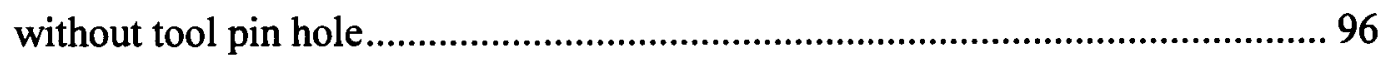

4.2 The fatigue crack propagation rate of the FSW specimens........................... 96

4.2.1 The fatigue crack propagation rate comparison between 2024-T3 base

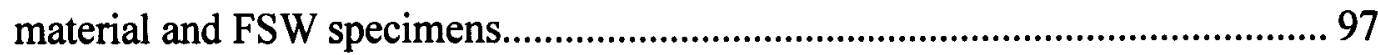

4.2.2 The fatigue crack propagation rate comparison according to the existence of tool pin hole 98

4.3 The metallographic analysis of FSW fatigue test specimens 98

4.4 Summary 99

5 Conclusions 108

APPENDIX 110

REFERENCES 115 


\section{List of Tables}

$\underline{\text { Table }}$

Description

Page

TABLE 2.1. Microstructure characteristics 33

TABLE 2.2. The chemical and mechanical properties of 2024-T3 and 7075-T6

aluminum 34

TABLE 2.3. Mechanical properties of 1" thick butt joints in 2024-T351/7075-

T7351 plates 35

TABLE 3.1. Stress ratio and representative load description 65

TABLE 3.2. The mechanical properties between experimental 2024-T3 aluminum and references. 66

TABLE 3.3. The width and thickness of FSW specimens for the tensile strength test. 67

TABLE 3.4. The mechanical properties between SP and DP(Type I) FSW specimens and 2024-T3 specimen .68 
TABLE 3.5. The test load levels and categorized specimens 69

TABLE 3.6. The label and number of FSW fatigue specimens and their fracture cycles 70

TABLE 3.7. The average crack propagation rate 71 


\section{List of Figures}

Figures

Description

$\underline{\text { Page }}$

Fig. 1.1. Welding speed and weldable aluminum type ................................. 8

Fig. 1.2. Material distribution at Airbus A340-600 fuselage .......................... 9

Fig. 1.3. Material distribution at Airbus A380 .............................................. 9

Fig. 1.4. Friction Stir Welding (FSW) process .............................................. 10

Fig. 1.5. A stiffened panel structure sample.................................................11

Fig. 2.1. Schematic drawing of friction stir welding ..................................... 36

Fig. 2.2. Microstructure classification of FSW ........................................... 37

Fig. 2.3. Change from Resistant Spot Welding system .................................. 38

Fig. 2.4. Joint configurations for friction stir welding.................................... 39

Fig. 2.5. Tension Test Results of FSW and Riveted Panels............................. 40

Fig. 2.6. S-N curves of base material, FSW weld, laser weld and MIG weld for 6005 AL-T5 
Fig. 2.7. Fatigue crack growth kinetics in air (left) and $3.5 \% \mathrm{NaCl}$ (right) through the base metal, HAZ, and weld nugget. 42

Fig. 3.1. 2024-T3 base material dimensions. 72

Fig. 3.2. 2024-T3 base material fatigue test with $\mathrm{R}=0.1,60 \mathrm{~Hz}$, Laboratory-air 73

Fig. 3.3. Static tensile test Single Pass (SP) specimen 74

Fig. 3.4. Static tensile test Double Pass (DP) specimen (Type I) 74

Fig. 3.5. Developing the stiffened panel structure specimens from original welded part 75

Fig. 3.6. Test specimen installed MTS 1 inch extensometer 76

Fig. 3.7. FSW Static Tensile Test Results with SP and DP 77

Fig. 3.8. Difference of DP Type I and II 78

Fig. 3.9. FSW test specimen configuration layout provided by NRC-IAR (Ottawa) 79

Fig. 3.10. The pictures of representative categorized sample 80

Fig. 3.11. The S-N curves for all specimens. 81

Fig. 3.12 The S-N curves for SP/DP(Type I)/DP(Type II) with tool pin hole..... 82 
Fig. 3.13 The S-N curves for the SP specimens with tool pin hole versus the SP specimens without tool pin hole 83

Fig. 3.14 The S-N curves for the DP(Type I,II) specimens with tool pin hole versus the DP specimens without tool pin hole 84

Fig. 3.15. Crack initiation location of Single Pass welded specimens ................ 85

Fig. 3.16. Crack initiation place in the categorized group except single pass with tool pin hole 86

Fig. 3.17. The representative crack monitoring sample of SP 87

Fig. 3.18. The representative crack monitoring sample of DP 88

Fig. 3.19. The SEM pictures of the SP with tool pin hole with $20 \mathrm{ksi}$ (SP_P_20 (1)) 89

Fig. 3.20. The SEM pictures of the DP (Type I) specimen with tool pin hole with $20 \mathrm{ksi}($ DP1_P_20 (5)) 90

Fig. 4.1. The overlaid schematic of the graphic model and SEM picture for the SP specimen. 102

Fig. 4.2. The SEM pictures of DP I and DP II 103 
Fig. 4.3. The fracture section view of SP/DP

Fig. 4.4. Defects in the FSW samples............................................................... 105

Fig. 4.5. The representative SEM pictures of DP (Type II) with tool pin hole.. 106 Fig. 4.6. The representative SEM pictures of DP (Type II) without tool pin hole 


\section{CHAPTER 1}

\section{Introduction}

This thesis describes an experimental test program to evaluate Friction Stir Welding (FSW) as a manufacturing process to replace riveting as a joining process in airframe construction. In particular, the fatigue performance of the welded skin-stringer lap joints is investigated, with the view to improving the damage tolerance performace of this process.

\subsection{Background}

As a result of the high competition in the aerospace industry, many companies are trying to reduce manufacturing costs by making their parts simple and implementing sophisticated design for less labour costs. At the same time, major aircraft assembly companies want to improve structural efficiency and cost effectiveness for their airframe structures. Thus, many new technologies such as adapting advanced materials and improving manufacturing processes have been developed.

In fact, some of new technologies were already implemented to get better cost 
effectiveness and structural performance. Friction stir welding (FSW) is a good example of a new manufacturing process because it can improve the welding speed 10 times higher than the conventional auto riveting machine (Murphy et al. 2006) Fig. 1.1 and it costs only 17 cent( $(\phi)$ per (USD) foot while riveting costs over 20 dollars (USD) per foot (Horschel 2007).

In addition, FSW can weld some of $2 \times x x$ and $7 x x x$ high strength aluminum series alloys, which were regarded as non-weldable materials, by other welding techniques such as fusion welding and laser welding. Since these high strength aluminum series are frequently used in airframe structures, FSW has high potential to replace riveting in many parts such as stiffened panel structures. For example, Fig. 1.2 and Fig. 1.3 illustrate how many $2 \times x x$ and $7 \times x x$ series were used in the Airbus commercial airplanes. Thus, if FSW can be used in many different parts in airframe structures, it can contribute to the cost savings and structural efficiency dramatically.

However, some doubt regarding the damage tolerance of welded components in airframes initiated the study of this thesis. To address the damage tolerance of welded aluminum components, this thesis will investigate the structural performance of FSW components. This is part of a comprehensive program on the use of FSW in airframe structures including tensile tests, metallurgical studies, and fatigue tests.

\subsection{Overview of Friction Stir Welding (FSW)}

One advanced manufacturing process used in airframe structure design is friction stir welding, invented by TWI (The Welding Institute) in 1991(TWI 2006). FSW is a 
welding system normally used for joining two metallic materials using only friction energy. (See Fig. 1.4) Though FSW was introduced only one and half decades ago, its applications vary from the Delta rocket fuel tank in NASA to MAZDA RX-8 in the automotive industry (The communications Department of the Boeing company 1998; Aluminum Now Online 2003).

The benefits of FSW can be categorized by 3 main aspects. First, from the metallurgical point of view, FSW is a solid phase process, which means that the welded material doesn't melt. Thus, friction stir welded parts have low distortion, are less porous, and have better microstructures. Also, this process can be used to weld not only similar materials but dissimilar materials, such as different high strength aluminums or even completely different materials, for instance, aluminum and steel. Secondly, FSW can be called a green technology since it can weld the work pieces without producing any harmful gas or toxic liquids. Finally, FSW can reduce the overall consumable energy of welded objects by weight saving, which implies that FSW can remove non-essential parts in the structure such as bolts, nuts, etc. Also, the FSW process itself uses less energy consumption. For example, FSW can consume only $2.5 \%$ energy for welding compared with laser welding (Mishra and Ma 2005).

Although FSW has these advantages, it has been used only in limited applications because i) a FSW machine is not portable due to its large size, ii) strong clamping forces during the welding process induce undesirable residual stress, and iii) the brittleness of the welded zone of welded objects increases abruptly (Ericsson et al. 2007). More details about the advantages and disadvantages about FSW will be explained in 
section 2.1.5.

\subsection{Obstacles for implementing FSW}

Though FSW has shown many advantages in both practical and experimental applications, a comprehensive testing program must be carried out before FSW components can be widely used in airframe structures. To date, applications of FSW process have been partially approved whenever it was required. Therefore, even if many academic and industrial studies have shown that FSW process is better than the previous welding processes, FSW must demonstrate its outstanding welding properties with widely acceptable practical applications such as a stiffened panel structure (see Fig. 1.5. for a stiffened panel structure sample).

The FSW material property tests under static conditions were carried out in various forms such as coupon and stiffened panel tests. In addition, simple fatigue coupon tests using a UTM (Universal Tension Test Machine) were carried out using various materials to make S-N curves as representative welding characteristics. However, it is necessary to make a more specific case-study such as stiffened panel fatigue tests to approve the FSW process as a widely acceptable general welding process.

\subsection{Stiffened panel structure using FSW}

The main reason for choosing the stiffened panel structure is that it has been widely used in many industries including the aerospace industry, because the geometry of 
stiffeners can increase the overall damage tolerance strength of the structure with relatively low weight. Also, panel structures without stiffeners or doublers are apt to bend easily and are weak in buckling.

To attach stiffeners or doublers to a panel, a joining technique is required. The most common joining technique of a panel and stiffeners or doublers is riveting, where a mechanical fastener joins two plates by inserting a circular pin. However, riveting takes too much time for preparing the material, is expensive in terms of labour cost, and reduces the fatigue characteristics of material induced by stress concentration nearby the rivet holes. Also, the additional attachments such as rivets, nuts and bolts increase the weight of the structure. Therefore, the welding technique appears to be a good alternative joining method.

For example, to weld a plate and stiffeners with $6 \mathrm{xxx}$ aluminum, the laser welding technique was used and initially showed good welding properties. However, many aircraft structures were made by high strength aluminum materials, such as $2 \mathrm{xxx}$ or $7 \mathrm{xxx}$, which cannot be welded using the previous fusion welding including laser welding, because of a hot-cracking and liquation-cracking problem - a partial melting of HAZ (Heat Affected Zone) area (Qian and Lippold 2003; Ir Sjoerd et al. 2006). Thus, FSW is considered to be the only method to weld $2 \mathrm{xxx}$ and $7 \mathrm{xxx}$ aluminum materials because FSW can weld these materials without problems because it is a solid state process, which means FSW can weld the materials at relatively low temperatures.

However, the application of FSW to a stiffened panel structure has to consider 
the following three major challenges. First, the welding quality of FSW heavily depends on the welding parameters such as the welding rotational speed, the welding transverse speed, and so on. Therefore, the optimization of welding parameters is important. Secondly, the welding of dissimilar materials is more complex than that of a single material. Lastly, the lap joint welding between a skin plate and stiffeners has a totally different mechanism compared to butt joint welding. Those three elements have effects on each other, so, an integrated investigation is required.

\subsection{Main objective of this thesis}

The main objective of this thesis could be summarized as investigating the fatigue characteristics of FSW stiffened panel structures with a 2024-T3 skin and a 7075T6 stiffener for the purpose of widening FSW applications to the general stiffened panel structure in airframe structures. Thus, the literature review about FSW, the stiffened panel structure, and general fatigue characteristics were conducted. Moreover, the fatigue tests of FSW stiffened panel structures, with or without a tool pin-hole under different welding conditions, were carried out. Therefore, the optimized FSW welding conditions can be proposed and the fatigue characteristics about the FSW stiffened panel structure under different load levels are revealed. Those results could be used as a design reference when FSW is applied to a stiffened panel structure. 


\subsection{Outline of this thesis}

This thesis is divided into five chapters. Chapter 2 of this thesis is the literary review about FSW and its application to stiffened panel structures. The former consists of brief history, mechanism, welding parameters, microstructures, advantages and disadvantages, defects and their cause, welding of dissimilar materials, and fatigue crack propagation in FSW. The latter is composed of static tensile strength of stiffened panel structure and comparison with results of the riveted case with the same configuration.

Chapter 3 describes the test procedure and conditions including details and specific categorizations about specimens, test parameters and conditions. Also, this chapter presents the test results and comparison of each test. The test data showed the static and fatigue characteristic of each categorized sets of FSW specimens.

Chapter 4 discusses the test results and attempts to explain the differences in fatigue performance between specimens in terms of welding procedures and material properties.

Chapter 5 gives conclusions and summarizes the overall results and analysis, and suggests recommendations for future work. 


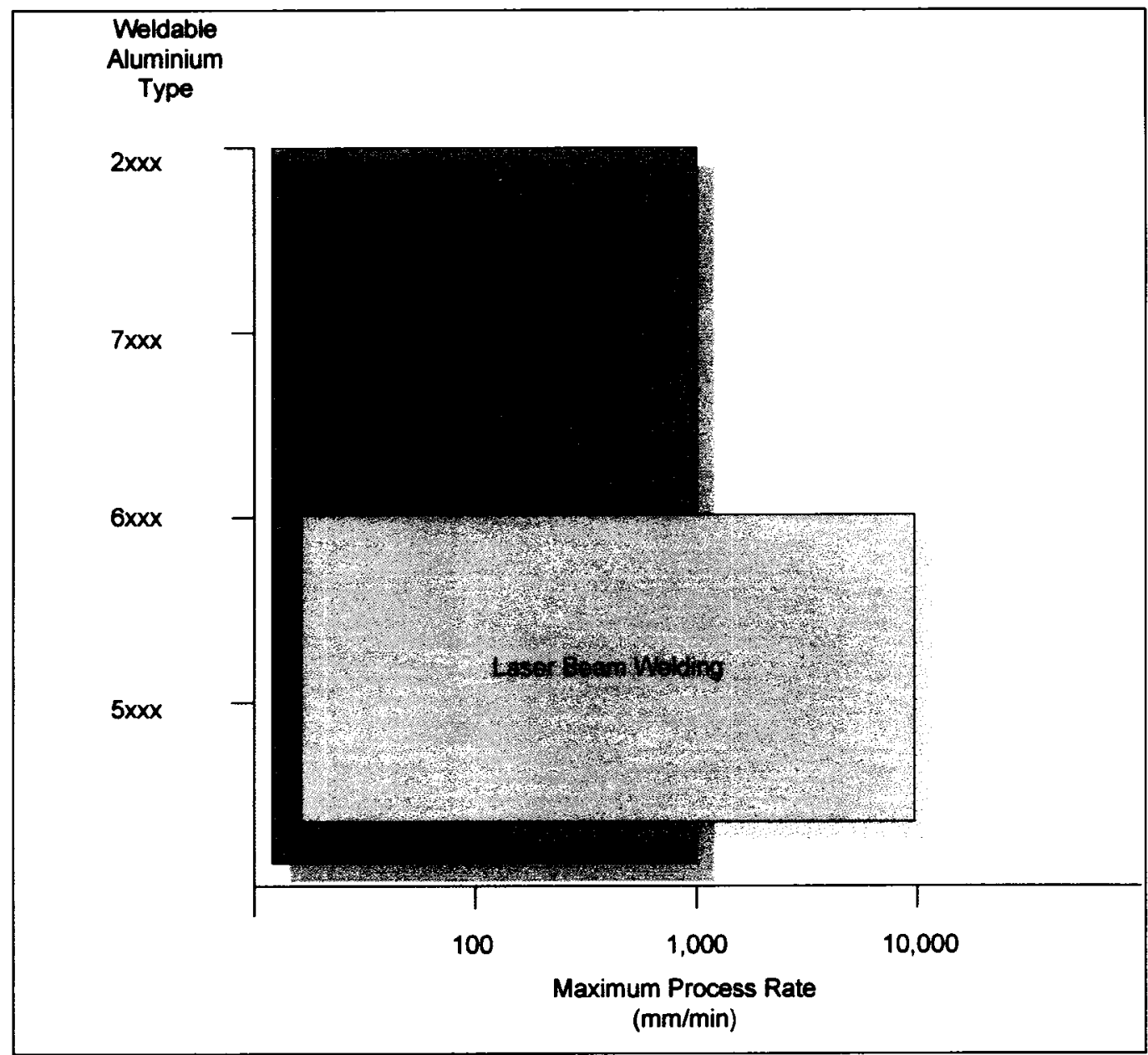

Fig. 1.1. Welding speed and weldable aluminum type

The chart was re-generated by the data from the reference

(Murphy et al. 2006) 


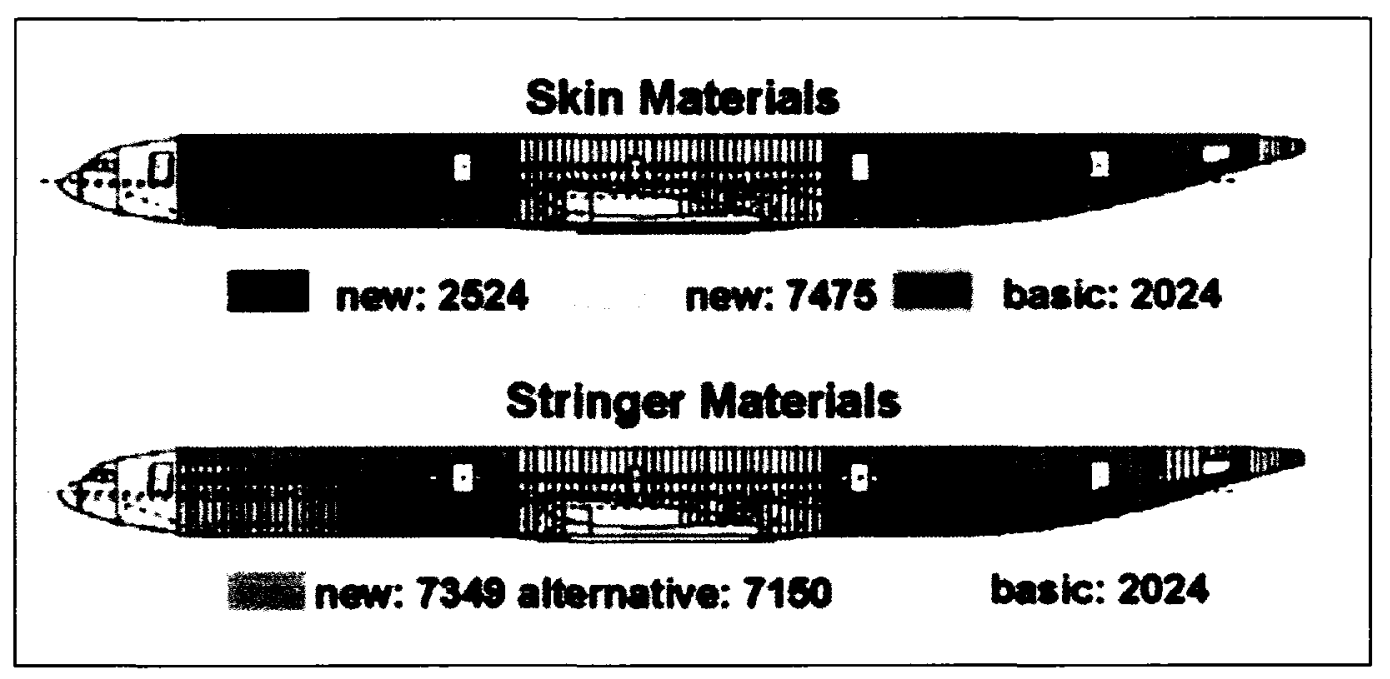

Fig. 1.2. Material distribution at Airbus A340-600 fuselage

(Schmidt et al. 2003)

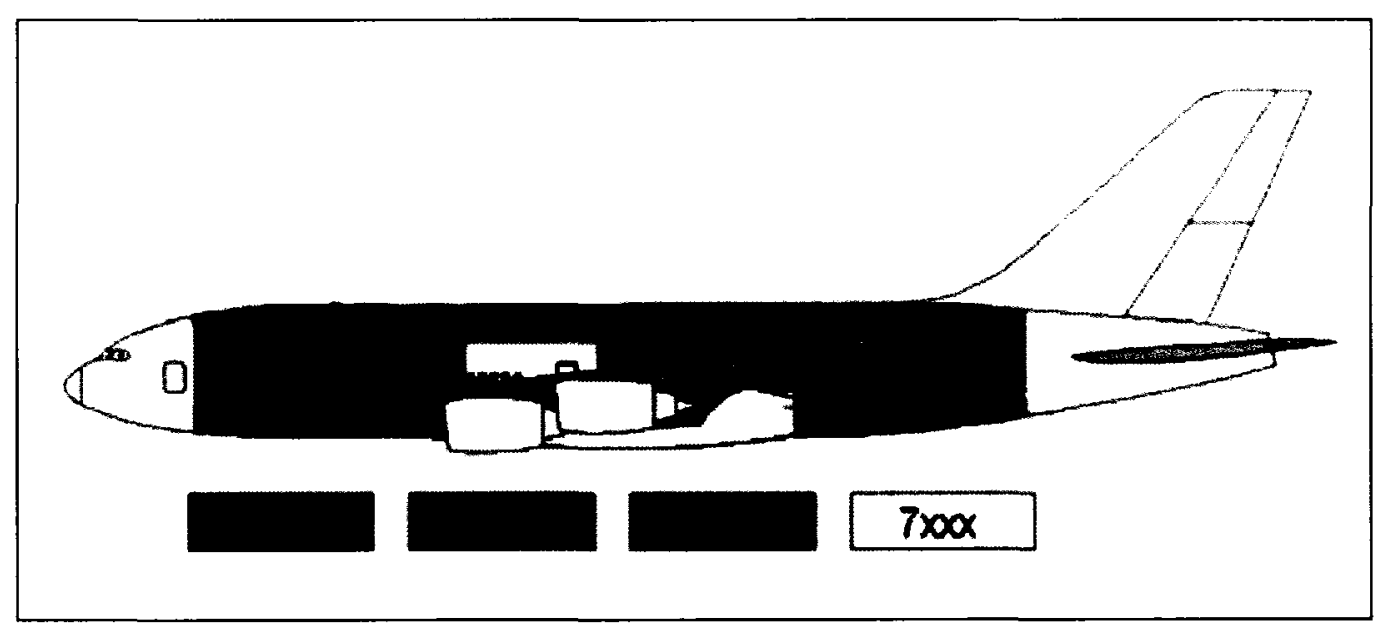

Fig. 1.3. Material distribution at Airbus A380

(Schmidt et al. 2003) 


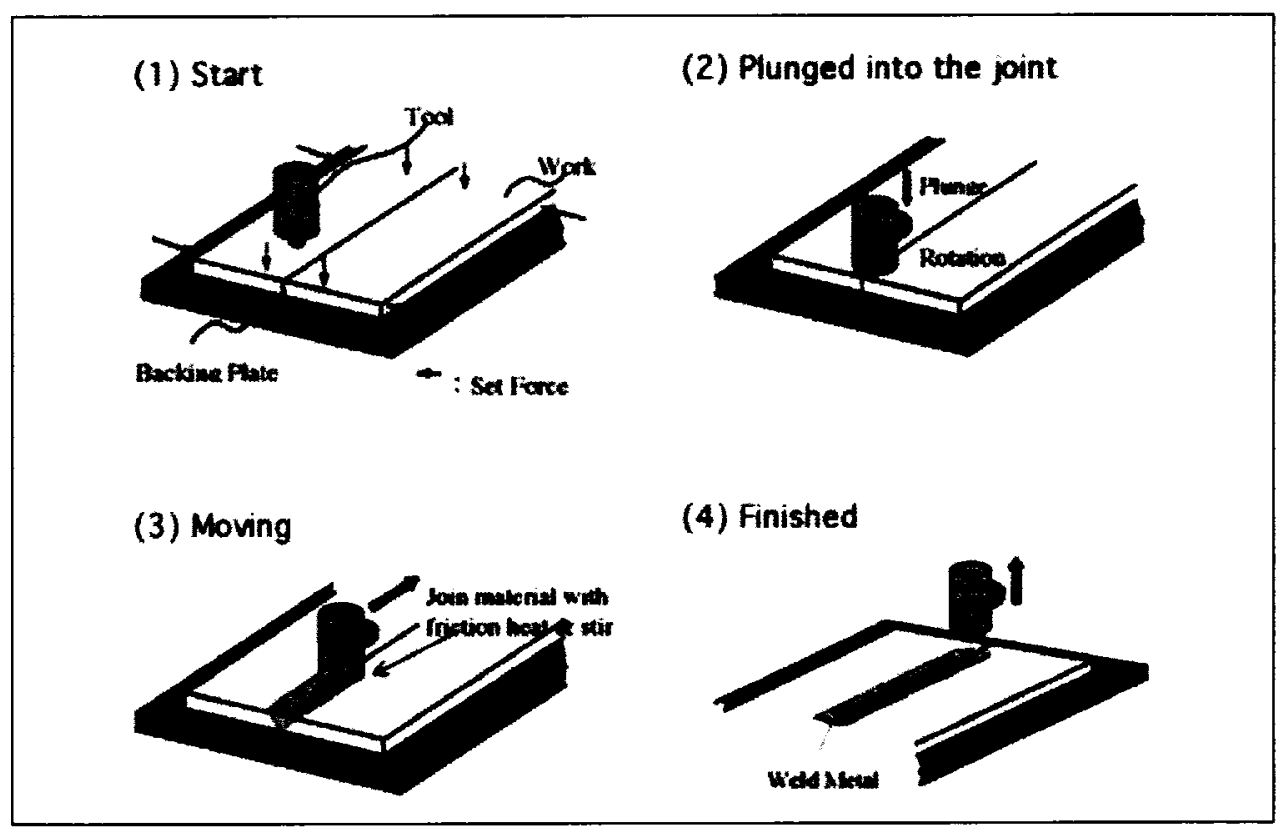

Fig. 1.4. Friction Stir Welding (FSW) process

(Hitachi-rail 2007) 


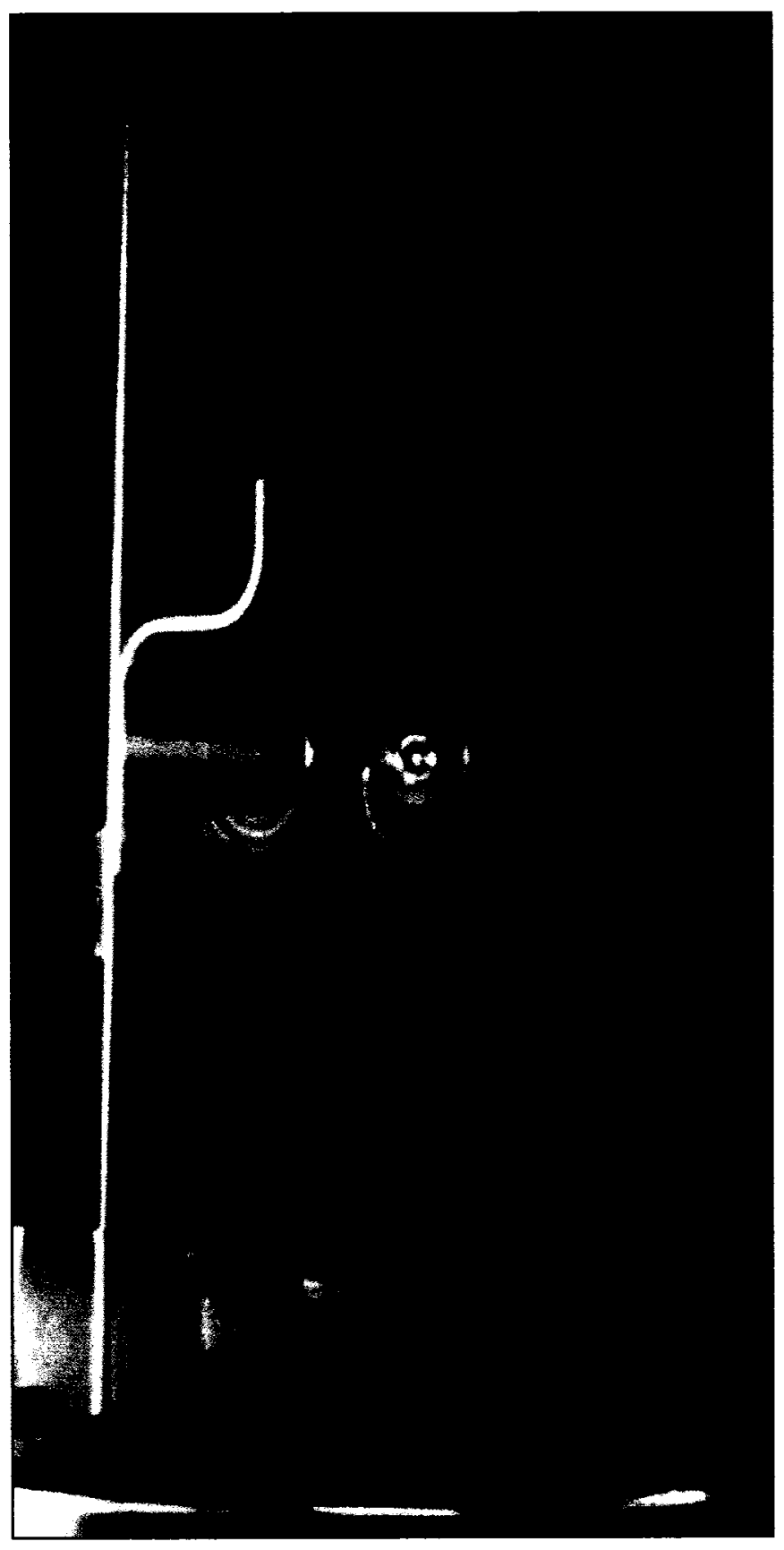

Fig. 1.5. A stiffened panel structure sample 


\section{CHAPTER 2}

\section{Literature review for Friction Stir Welding (FSW) and its application to the stiffened panel structure}

In this chapter, the features of Fiction Stir Welding are discussed. The brief history, mechanism, welding parameters, and microstructures are outlined to obtain a general understanding of FSW. In addition, the advantages and disadvantages of FSW, possible defects and their causes, and welding joints including butt and lap are highlighted. Also, joining two materials with FSW focused on 2024-T3 and 7075-T6 aluminum is discussed.

The second part of chapter 2 consists of the application of FSW to a stiffened panel structure. In this work, 2024-T3 and 7075-T6 aluminum material properties are investigated since those materials are used in the test specimens. Moreover, the merits and demerits of riveting, laser welding, and FSW are compared since those joining techniques have been widely used in airframe assembly. Also, the static tensile strength comparison between riveted and FSW stiffened panels are given as a reference. 
The last part of this chapter describes the fatigue characteristics and the crack propagation of FSW components. Their results are used in chapter 3 to compare the test results of the current study according to the categorized specimens.

\subsection{FSW literature review}

\subsubsection{Brief history}

The FSW/FSP (Friction Stir Welding/ Friction Stir Process) is a process invented by TWI (The Welding Institute) in 1991 and has been used for various applications such as the structure of an airframe, the fuel tank of a rocket, and so on. This process can weld high strength aluminum materials which had been regarded as non-weldable materials heretofore. Also, due to vigorous studies involving FSW, this process has widened its applications from shipbuilding to the automotive industry, and has high potential to replace current electric resistance spot welding by Friction Stir Spot Welding (FSSW).

\subsubsection{Mechanism of FSW}

The core of the mechanism of FSW is very simple. A rotating tool set, consisting of a pin and shoulder, is plunged into the contacting surface of sheets or plates to be joined and travels along the upper common contact line Fig. 2.1 (Mishra and Ma 2005). To do this, proper pressure should be maintained between the surface of the shoulder and the welded surface. The welded area is heated by the friction energy. To achieve the best welding quality, the surface ratio of shoulder and pin should be constant and the pressure 
between the surface of the material and the shoulder should be controlled precisely. In addition, the vertically inserted tool set has to be tilted a certain small angle and the tool pin should be plunged into the material sufficiently to prevent the lack of welding.

\subsubsection{FSW parameters}

There are many parameters that affect the quality of FSW. However, tool rotation rate and tool traverse speed are the most important parameters. These parameters can be classified by 3 different criteria according to their characteristics (Mishra and Ma 2005). Also, each category may be divided into more detailed sub-categories as given below.

1) Tool geometry

- Geometry of Shoulder

- Shape of Pin (number of flutes, geometry of pin, etc)

- Type of Pin mechanism (Kumar et al. 2005)

$\checkmark \quad$ Fixed pin; no moving parts

$\checkmark$ Retractable pin; consist of two parts; a shoulder and a pin, which move independently each other

$\checkmark$ Self-reacting; consist of two shoulders. Positioning of the upper shoulder is controlled by the positioning of the spindle head while the positioning of the lower shoulder is controlled by the independent pin actuator

2) Welding parameters

- Tool rotation rate 
- Tool traverse rate

- Tilt angle

- Preheating and cooling

3) Joint design

- Butt welding

- T butt welding

- Lap welding, etc

In section 2.2 .4 , a practical example of FSW is provided which gives typical parameters.

\subsubsection{Microstructures of FSW}

Because of the friction energy generated between the shoulder and the material surface when the tool is rotated, the relatively high-temperature and the intensive plastic deformation, the microstructure and mechanical properties of the welded material can change. For example in 7075Al-T651, there exist 3 distinct zones after FSW. Fig. 2.2 illustrates these 3 zones as: nugget zone, thermo-mechanically affected zone (TMAZ) and heat affected zone (HAZ). Moreover, the temperature, grain size, and remarks for each zone are explained in the Table 2.1.

The interesting thing is that the tensile strength of the nugget zone showed a significant difference between the top and bottom (close to the backing plate). This comes from the fact that the microstructure of both areas has totally different shapes even though both areas are the same nugget zone vertically. It has been shown that the cooling 
effect of backing plate made the bottom of nugget zone denser than the top of nugget zone (Pao et al. 2005).

Also, the HAZ has the lowest strength (minimum hardness) due to significantly coarsened precipitations and the development of the precipitate-free zones (PFZs). Thus, during tension loading, strain concentrates in the HAZ, so the low-strength HAZ can locally elongate to high levels of strain (12-14\%), and finally result in necking and fracture, whereas the nugget zone experiences only $2-5 \%$ strain because of the recrystallized dense microstructure. Therefore, fracture almost always occurred in the HAZ (Mishra and Ma 2005).

\subsubsection{Advantages and disadvantages of FSW}

\subsubsection{Advantages}

The biggest advantage of FSW is that it can make it possible to weld some high strength aluminum alloys such as $2 \mathrm{xxx}$ or $7 \mathrm{xxx}$. Also, many researchers have shown that FSW can weld not only the same kind of alloys but also dissimilar alloys, even different materials such as steel and aluminum alloys, magnesium and aluminum alloys, and so on.

Considering the industrial aspect, FSW can remove many auxiliary systems like filler material feeding system or gas supplying system Fig. 2.3. Thus, this simplicity can contribute to increasing the overall DFMA (Design for Manufacturing and Assembly) performance. In addition, the cost and weight effectiveness of FSW is better than the 
other joining methods in airframe structures as the FSW can remove many unnecessary components like bolts, nuts, and so on in the welded parts.

Many other benefits can be classified as follows according to the literature (Mishra and Ma 2005).

1) Metallurgical benefits

- Solid phase process

- Low distortion of work piece

- Good dimensional stability and repeatability

- No loss of alloying elements

- Excellent metallurgical properties in the joint area

- Fine microstructure

- Absence of cracking (under ideal conditions)

- Replace multiple parts joined by fasteners

2) Environmental benefits

- No shielding gas required

- No surface cleaning required

- Eliminate grinding wastes

- Eliminate solvents required for degreasing

- Consumable materials saving, such as rugs, wire or any other gases

3) Energy benefits

- Improved materials use (e.g., joining different thickness) allows reduction in weight

- Only $2.5 \%$ of the energy needed for a laser weld 
- Decreased fuel consumption in light weight aircraft, automotive and ship applications

\subsubsection{Disadvantages}

Though there are many advantages, FSW has been used in limited areas because of the following major obstacles.

- Normally, the FSW system is not portable.

- Specially designed fixtures are needed to hold the specimen tightly enough and this leads to the residual stress.

- The back plate should be supplied.

- After welding, the corrosion resistance is low.

- The brittleness of the material increases.

- In general case, the tool pin hole is left if the ordinary tool pin is used.

- Only limited joint geometry can be welded.

\subsubsection{Possible defects of FSW joints and their cause}

The principal defects in the FSW joints can be categorized as the following; incomplete filling, incomplete penetration, and root discontinuities. These defects can be detected by the non-destructive ultrasonic method or by scanning electron microscopy (SEM) to evaluate the welding quality. They are summarized as follows (Ghidini et al. 2005): 
- Incomplete filling

After welding, the welded part is not completely filled with material because the temperature is too hot or too cold.

- Incomplete penetration

In this case, the tool profile has not fully penetrated, and so the welding is incomplete.

- Root discontinuities

This can be defined as imperfection of the welding or an oxide in the welded area. This defect should be checked by SEM because this root discontinuity can affect the fatigue performance dramatically.

These defects also can be called root flaws and can occur by improper welding parameters. The fatigue life of these welds with defects can be 30-80 times shorter than that of defect-free welds, and the fatigue load level in an S-N curve has decreased from 120.6 $\mathrm{MPa}$ for defect-free welds to $54.7 \mathrm{MPa}$ for defected welds at $2 \times 10^{6}$ cycles since the root flaws can be regarded as crack initiation sites (Zhou et al. 2006).

Another concern about the application of FSW to a general structure is a "kissing bond" defect. A kissing bond is defined as the incomplete mixing of two metallic parts in the atomic level after welding or joining. Though the contact surface of the two parts seems to be close and looks like they have mixed well, the kissing bond results in low static strength, low impact strength, and low fatigue life since the atomic level of bonding is not enough for the two parts. The kissing bond defect can be a potential major issue in 
applying FSW to a specific structure since it can not be detected by a general nondestructive method like X-ray or ultrasonic testing (Oosterkamp et al. 2004; wikipedia 2007).

\subsubsection{Types of welding joint}

The most widely used weld joint configurations for FSW are butt joints and lap joints. However, it is possible to weld other joint configurations as can be seen in Fig. 2.4. Also, it is very important to recognize that butt and lap joint welding with FSW has a huge difference in mechanism and strength compared to other welding methods. For instance, both the rotating reaction of the tool pin and the vertical pull-up reaction between the upper and lower materials by material flow are the main factors to determine welding quality in a lap joint while the welding quality of a butt joint may heavily depend on the rotation reaction of the tool pin solely.

Furthermore, the welding efficiency, defined as the ratio of the ultimate tensile strength of the FSW joint to that of the base (parent) material is a common parameter used to check weld properties. In the general, the welding efficiency of butt joint tensile strength varies about 70 90\% (Kumar et al. 2005). However, the joining efficiency of the lap joint ranges about $65 \% \sim 85 \%$, even $40 \%$ in the case of two different materials (Ericsson et al. 2007).

Moreover, another weakness in lap-joints of dissimilar materials was reported by Ir Sjoerd et al. 2006. In their work, part of the softer metal is pulled up into the stronger 
metal, thereby reducing the effective thickness of the higher strength sheet and thus the strength of the joint. Other aspects of the geometry of the interface can also be of great importance, in some cases leading to stress concentrations and weak joints.

\subsubsection{Joining two materials}

There are many notable approaches to apply FSW to various materials including plastics. Nevertheless, the main criteria of the application for FSW can be divided into 3 sections. The first section is the simple welding with the same material. The second section is the welding of dissimilar material such as 2024-T3 and 7075-T6 aluminum. Even though two dissimilar materials are the same aluminum, it's very hard to weld two dissimilar materials since the material properties are completely different. The last section represents the welding of completely different materials, for example, the welding of steel and aluminum, aluminum and titanium and so on. In this thesis, the second section was focused on because the test specimens for the experiments were made of 2024-T3 and 7075-T6 which are frequently used in the airframe structure design.

The general concepts of FSW were discussed in section 2.1., therefore in the remainder of this chapter, the detail applications of FSW to the stiffened panel structure will be discussed. 


\subsection{The application of FSW to stiffened panel structures.}

Since the test specimens in this thesis were made of 2024-T3 as the skin and 7075-T6 as the stiffener, the chemical composition and mechanical properties of these materials were studied. Some of these data will be used as a reference to compare the tensile strength test results of 2024-T3 base material in chapter 3. Also, brief descriptions of rivet and laser welding are introduced to compare alternative methods with FSW.

Though the applications of laser welding and FSW in the airframe structure have many benefits compared to rivets, they cannot replace all the riveted structure since their capability cannot fulfill the requirements of the durability and damage tolerance in the airframe structure. Therefore, the progressive application of laser welding and FSW into airframe structure manufacture will progress gradually because each joining method (laser welding, FSW, and rivets) has its strength and weakness respectively as can be seen in section 2.2.2.

In the last part of this section, the static strength comparison between riveted and FSW stiffened panel will show that the stiffened panel structure of FSW has about 5\% higher strength than that of a riveted joint.

\subsubsection{Material properties of 2024-T3 and 7075-T6}

The chemical composition and mechanical properties of 2024-T3 and 7075-T6 are summarized in the Table 2.2(a) and Table 2.2(b) respectively. Though these 2xxx and 
$7 \mathrm{xxx}$ materials have been widely used in airframe structures for their high strength, weight saving, and good damage tolerance characteristics, these materials are regarded as difficult to weld materials because of hot-cracking and liquidation problems. Thus, the usage of these high strength materials is limited to certain structures (Ir Sjoerd et al. 2006).

\subsubsection{Brief comparison of riveting, laser welding, and FSW}

\subsubsection{Riveting}

In general, riveting is one joining method of many unthreaded fastener joining methods. A rivet itself consists of a head, shank and foot made from a deformable material in common cases. The rivet inserted into a properly prepared aligned hole in the joined parts and normally the foot parts are deformed to semi-spherical shape at room temperature with a machine or hammer in order to hold the parts together. However, some rivet techniques use hot-temperature to deform the foot of the rivet and these techniques are used in the steel structure of buildings or bridges (Messler, Jr. 2004).

Although the material properties are not main concerns in riveting while the material properties like the deformation by heat are regarded as main concerns in the welding and riveting can be used for different materials, riveting has been widely applied to many structures especially in airframe structures. However, the cost of preparing the joined materials by drilling appropriate holes is high and the holes in the joined materials can be a main source for crack initiation. 


\subsubsection{Laser beam welding (LBW)}

Though the laser beam welding (LBW) technique has been used for many years, it can be only applied in the limited airframe structures since it cannot be fully guaranteed that this welding technique would have low distortion in relatively thin sheets. However, the recent LBW technique can be successfully applied to the airframe structures with relatively low distortion comparing with other welding techniques, using a small focused heat source produced by a fast and high heat intensity laser beam (Murphy et al. 2006). In addition, this promising LBW technique can contribute to the reduction of the manufacturing cost and the minor weight reduction in the aerospace applications. The best example of LBW technique is the welding of T-joint like skin-to-stringer or skin-toclip joints (Schmidt et al. 2003).

The current LBW can weld airframe structures such as $6 \mathrm{xxx}$ aluminum, which is used in some commercial aircraft by Airbus, but a few restrictions still remain. For example, meticulous surface cleaning in the LBW applied areas to remove surface oxide films. Also, welded components should be strictly clamped to remove the possibility of the small diameter laser beam getting through the joint setup gaps. Moreover, non-portable equipment, precise optical alignment, and huge electrical power and water cooling systems make LBW high cost in operation and tooling. Nevertheless, since the welding speed of LBW is so high and LBW can weld 6xxx high strength aluminum, LBW has a high potential to replace some riveted parts in a big commercial aircraft (Murphy et al. 2006). 


\subsubsection{Friction Stir Welding}

Most general approaches to FSW are already mentioned in chapter 2 literature reviews. The major benefits of applying FSW in airframe structures is: i) FSW can weld $2 \mathrm{xxx}$ and $7 \mathrm{xxx}$ high strength materials that are generally regarded as non-weldable materials, ii) FSW is more cost effective and time saving than riveting. However, FSW must prove its superiority in many standard applications under the static and fatigue loading conditions. Also, the corrosion characteristics and brittleness of FSW are crucial issues to overcome.

\subsubsection{Previous studies of the FSW butt and lap joint with 2024 and 7075 materials}

\subsubsection{Butt joint}

Some experiments were carried out with 2024 and 7075 aluminum series materials in both butt and lap joints. One of them showed the mechanical properties given in Table 2.3 by testing 1 inch thick plates in the form of ; base materials (2024T351/7075-T7351/7050-T7451) and FSW butt joint welding with different equipment ( EWI-Edison Welding Institute and HB-Boeing Phantom Works) and different welding parameters. The tensile strength of FSW with 2024 and 7075 is more than $50 \%$ of the base material (7050-T7451). However, the elongation of FSW specimens was 5-6\% due to the brittleness of welding nugget (J.A.Baumann et al. 2003). 
Also, another paper (Cook et al. 2005) described the results of bend tests, tensile tests, and corrosion tests with butt joints of 0.25 inch 2024-T3 and 7075-T73 materials with varying welding parameters. The values of UTS (Ultimate Tensile Strength) range from $53.3 \mathrm{ksi}$ to $65.3 \mathrm{ksi}$.

An interesting research project regarding the tool rotating speed and welding quality in dissimilar materials welding with FSW concluded the following; "As the rotational speed becomes faster, the mechanical mixing of the material in the dissimilar welds becomes more uniform, and the single or multiple cells of the material flow with the alternative lamellae of different alloy constituents becomes rounder and more complete" (Ouyang and Kovacevic 2002). However, if the rotational speed becomes too fast, the overall welding quality will be decreased because of the high temperature due to excessive friction energy. Therefore, the optimization of welding parameters is very crucial.

\subsubsection{Lap joint}

In general, the welding mechanism of FSW in lap joints had a large difference with that of FSW in butt joints since the interface between the two dissimilar metal sheets in the lap joint makes the flow of materials more important than the microstructure (L.Cederqvist et al. 2001). Thus, the tensile stress of FSW lap joint specimens showed a lower stress level than that of FSW butt joint specimens in the most general tensile strength tests. 
The studies by L.Cederqvist et al. 2001; Ericsson et al. 2007 presented tensile strength results under various welding conditions with $2.29 \mathrm{~mm}(0.090 \mathrm{in}) \mathrm{FSW}$ lap joint specimens that consisted of 2024-T3 and 7075-T6 dissimilar materials. Their initial tests were the tensile strength tests under the same welding conditions with 9 different tool geometries and single pass welding (SP), which means one time pass welding. The second series of tests were tensile strength tests under different welding conditions with selected tool geometries and double pass welding (DP), which means that the first pass is the exact same as SP, but in the second pass the tool rotation is reversed and the tool has S/E (separation distance) toward the advancing side of the first weld. Throughout this DP procedure, the welding area has better welding efficiency than SP since both the welding width and oxide disruption are increased.

Also, while the advancing welding side in the lap joint with SP can be a weak point because the vertical material flow of the advancing side prevents the mixing of two materials, DP can improve the mixture of two materials in the advancing side of the first welding pass since the second pass can provide better welding material flow. To summarize the results of this paper, L.Cederqvist et al. 2001, showed that the failure load for SP specimens are $5.6 \sim 14.0 \mathrm{kN}$ and that of DP specimens are $14.4 \sim 23.8 \mathrm{kN}$.

In addition, the results showed that the strongest weld has the welding parameters and tool dimensions which make the least interface pull up in the retreating side. Therefore, the results suggest that the welding speed should be high, rotational speed must be low, and the length of the tool pin should be short. 


\title{
2.2.4 Static strength comparison between the riveted panel and the Friction Stir Welded stiffened panel
}

\begin{abstract}
A few studies about the static strength comparison between rivet and FSW stiffened panel specimens were reported. The maximum carrying loads of tension, compression, and shear were discussed. Two studies focused on the tensile strength tests of rivet and FSW stiffened panel specimens (Tweedy et al. 2006; Burford et al. 2006). The specimens were made of two 7075-T6 hat section shape stiffeners and a $2 \mathrm{ft}$ by $2 \mathrm{ft}$ 2024-T3 skin panel. Two stiffeners were friction stir welded with a tapered conical pin with 3 flats and each one spaced 8.0 inch on center. The welding parameters are the following.
\end{abstract}

- Spindle Rotational Speed: $1200 \mathrm{rpm}$ (rev. per min.)

- Traverse rate along the joint: $16 \mathrm{in} / \mathrm{min}$ (inch per min.)

- Downward Pressure or Normal Force of the tool : $850 \mathrm{lbs}$

The test results showed that FSW panels are about $10 \%$ stronger than riveted panels and the elongation of FSW panels is $41 \%$ less than that of riveted panels. Both tested panels were broken at the joint line and the riveted panels showed more catastrophic failure than the FSW panels. The strain-stress curves were plotted in the Fig. 2.5 (Tweedy et al. 2006). 


\subsection{Fatigue properties of FSW joints}

Though there are many parameters describing fatigue properties, S-N (stress vs. number of cycles to failure) curves and fatigue crack propagation were the main interest in this thesis since these parameters are related to the mechanical properties of FSW. So, S-N curve behavior and fatigue crack propagation (FCP) in FSW butt joints will be briefly introduced.

\subsubsection{S-N behavior about FSW}

The S-N curve is a plot which linearly connected multiple points represents stress levels versus number of cycles to failure according to the types of specimens. A sample S-N curve (using the 6005 Aluminum specimens in condition of the base material, FSW, MIG (metal inert gas) welding, and Laser Welding) showed that FSW specimens have

superior fatigue life over other welding methods at $10^{6}$ cycles and beyond as shown in Fig. 2.6. Also, this graph is plotted for the case of stress ratio (the ratio of minimum stress to maximum stress) of 0.1 since FSW specimen can demonstrate its outstanding strength at low $\mathrm{R}$ values. More detailed information on choosing the stress ratio is discussed in section 3.1.2.

To eliminate the defects in the surface of FSW specimens, milling $0.1-0.15 \mathrm{~mm}$ from top surface makes a huge positive difference in fatigue strength. Also, the compressive residual stress and the good-quality surface finish are recommended for better FSW fatigue properties (Mishra and Ma 2005). 


\subsubsection{Fatigue Crack Propagation (FCP) of FSW}

Crack growth behavior of FSW joints is affected by many factors such as load level, stress ratio, corrosion environment, microstructures, and so on. For instance, Fig. 2.7 represents the fatigue crack growth in air and $3.5 \% \mathrm{NaCl}$. This plot shows that the corrosion environment make a significant difference in the crack growth behavior of FSW. However, the strongest factor to affect the crack growth in FSW 2024-T351 joints is the weld residual stress. Though the microstructure and hardness generated small effects in the crack growth in FSW specimen, the location and orientation of FSW to the weld centerline could create a distinct difference in the fatigue crack growth of FSW (Mishra and Ma 2005).

\subsubsection{Residual Stresses in FSW}

Since the residual stresses can affect the fatigue life significantly in general material testing, it would be worth while surveying the role of residual stresses in FSW. The residual stresses in a FSW joint are the remaining stress in a part after removing the applied forces. Because compressive residual stresses can increase the fatigue life by removing relatively small tensile loads, they are used for extending the fatigue life by so called "shot-peening". Also, surface treatment and heat treatment could be used as methods for the reinforcement of fatigue characteristics of the materials using residual stresses. 
While residual stresses in fusion welding were regarded as a negative effect (because they are typically tensile) due to the deformation of welded parts, those in FSW can be a minor factor since the deformation of welded parts is relatively small because FSW can be done at low temperature. However, when FSW is applied to aluminum, the residual stresses should be carefully monitored because the heat produced by FSW can expand the whole surface due to high thermal conductivity of aluminum and the strong clamping force of the fixture for FSW may lead to unexpected residual stresses when the welded parts cool down (Ghidini et al. 2005). The presense of compressive stresses in the current specimens has a relatively minor effect because the preserve of welding defects greatly reduces the crack initiation period.

\subsection{Summary}

In this chapter, the fundamentals of FSW and its application to the stiffened panel structure with 2024-T3 skin and 7075-T6 stiffeners were discussed. Also, some test data with butt joints and lap joints were briefly reviewed. Moreover, riveting, LBW, and FSW were compared since these joining techniques were used to compensate each technique's weakness in current airframe assembly.

In the next chapter - chapter 3 , the experimental setup, test procedure, and test results for a FSW coupon specimen will be presented. Static tensile tests are carried out for the comparison with some results from the literature and references. In addition, a series of fatigue tests are performed with different welding conditions and various load levels to find out the optimized welding conditions and S-N curves. Also, crack 
propagation and fatigue characteristics are studied. 
For example, each microsturctural area of FSW has different characteristic as following table in case of 6061 Aluminum.

\begin{tabular}{|c|l|l|l|}
\hline & $\begin{array}{l}\text { Experienced } \\
\text { temperature }\end{array}$ & \multicolumn{1}{|c|}{ Grain size } & \multicolumn{1}{|c|}{ Remarks } \\
\hline HAZ & $250-350^{\circ} \mathrm{C}$ & Big as same as & $\begin{array}{l}\text { Only thermal cycle } \\
\text { base material }\end{array}$ \\
\hline TMAZ & $350-450^{\circ} \mathrm{C}$ & Medium & $\begin{array}{l}\text { Go through plastic deformation } \\
\text { No recrystallization due to } \\
\text { insufficient deformation strain }\end{array}$ \\
\hline Weld nugget & $450-500^{\circ} \mathrm{C}$ & Fine-equiaxed & $\begin{array}{l}\text { Onion ring structure } \\
\text { Recrystallization } \\
\text { Mechanical strength is high }\end{array}$ \\
\hline
\end{tabular}

Note; 1) Experienced temperature and grain size data came from (Ouyang and Kovacevic 2002)

2) Remarks information came from (Mishra and Ma 2005)

TABLE 2.1. Microstructure characteristics 
(a) The chemical composition of 2024-T3 and 7075-T6 aluminum

\begin{tabular}{|c|c|c|c|c|c|}
\hline & $\mathrm{Cu}(\%)$ & $\operatorname{Mn}(\%)$ & $\operatorname{Mg}(\%)$ & $\operatorname{Cr}(\%)$ & $\mathrm{Zn}(\%)$ \\
\hline $\mathbf{2 0 2 4 - T 3}$ & 4.4 & 0.6 & 1.5 & 0 & 0 \\
\hline 7075-T6 & 1.6 & 0 & 2.5 & 0.23 & 5.6 \\
\hline
\end{tabular}

Reference: Kaufman, J. Gilbert, Aluminum alloy database, 2004

(b) The mechanical properties of 2024-T3 and 7075-T6 aluminum

\begin{tabular}{|c|c|c|c|c|c|}
\hline & UTS & TYS & Elongation & ultimate shear & Elastic modulus \\
& (MPa) & (MPa) & $(\%)$ & (MPa) & (GPa) \\
\hline 2024-T3 & 435 & 290 & 15 & 251 & 72 \\
\hline 7075-T6 & 540 & 470 & 9 & 312 & 71 \\
\hline
\end{tabular}

Reference: Kaufman, J. Gilbert, Aluminum alloy database, 2004

TABLE 2.2. The chemical and mechanical properties of 2024-T3 and 7075-T6 aluminum 


\begin{tabular}{|c|c|c|c|c|c|c|}
\hline Trial \# & Alloys & $\begin{array}{l}\text { Location of } \\
\text { specimen }\end{array}$ & $\begin{array}{c}\text { YS } \\
\text { (ksi) }\end{array}$ & $\begin{array}{l}\text { UTS } \\
\text { (ksi) }\end{array}$ & $\begin{array}{c}\text { Elongation } \\
(\%)\end{array}$ & $\begin{array}{c}\text { Failure } \\
\text { Location }\end{array}$ \\
\hline Parent mat'l & $\begin{array}{l}2024-\mathrm{T} 351 \\
7075-\mathrm{T} 7351 \\
7050-\mathrm{T} 7451\end{array}$ & & $\begin{array}{l}50.6 \\
61.2 \\
68.2\end{array}$ & \begin{tabular}{r|}
70.8 \\
73.9 \\
77.4
\end{tabular} & $\begin{array}{l}17.5 \\
10.8 \\
13.5\end{array}$ & \\
\hline $\begin{array}{c}\text { EWI-14 } \\
150 \mathrm{rpm}, 4.5^{\prime \prime} / \mathrm{min}\end{array}$ & $2024(A) / 7075$ & $\begin{array}{l}\text { Start } \\
\text { Finish }\end{array}$ & $\begin{array}{l}38.0 \\
37.4 \\
\end{array}$ & $\begin{array}{l}56.8 \\
56.4 \\
\end{array}$ & $\begin{array}{l}6.7 \\
6.7 \\
\end{array}$ & $\begin{array}{l}\text { HAZ(7075) } \\
\text { HAZ(7075) }\end{array}$ \\
\hline $\begin{array}{c}\text { HB-141644 } \\
200 \mathrm{rpm}, 3 \% / \mathrm{min}\end{array}$ & $2024(\mathrm{~A}) / 7075$ & $\begin{array}{l}\text { Start } \\
\text { Finish }\end{array}$ & $\begin{array}{l}35.7 \\
36.5\end{array}$ & $\begin{array}{l}53.9 \\
55.0 \\
\end{array}$ & $\begin{array}{l}5.7 \\
5.6 \\
\end{array}$ & $\begin{array}{l}\text { HAZ(2024) } \\
\text { HAZ(2024) }\end{array}$ \\
\hline $\begin{array}{c}\text { HB-103720 } \\
200 \mathrm{rpm}, 4 \% / \mathrm{min}\end{array}$ & $2024(A) / 7075$ & $\begin{array}{l}\text { Start } \\
\text { Finish }\end{array}$ & $\begin{array}{l}38.9 \\
38.1\end{array}$ & $\begin{array}{l}56.1 \\
56.0\end{array}$ & $\begin{array}{l}5.3 \\
5.9\end{array}$ & $\begin{array}{l}\text { HAZ(2024) } \\
\text { HAZ(2024) }\end{array}$ \\
\hline $\begin{array}{c}\text { HB-143858 } \\
\text { 200rpm,5"/min }\end{array}$ & $2024(\mathrm{~A}) / 7075$ & $\begin{array}{l}\text { Start } \\
\text { Finish }\end{array}$ & $\begin{array}{l}39.9 \\
40.2\end{array}$ & $\begin{array}{l}57.7 \\
58.0\end{array}$ & $\begin{array}{l}5.8 \\
5.6\end{array}$ & $\begin{array}{l}\text { HAZ(2024) } \\
\text { HAZ(2024) }\end{array}$ \\
\hline
\end{tabular}

Notes: 2" extensometer, $250^{\circ} \mathrm{F} / 24 \mathrm{~h}$ age prior to testing, EWI (Edison Welding Institute), HB (Boeing-Phantom Works)

TABLE 2.3. Mechanical properties of 1 " thick butt joints in 2024-T351/7075-T7351 plates

(J.A.Baumann et al. 2003) 


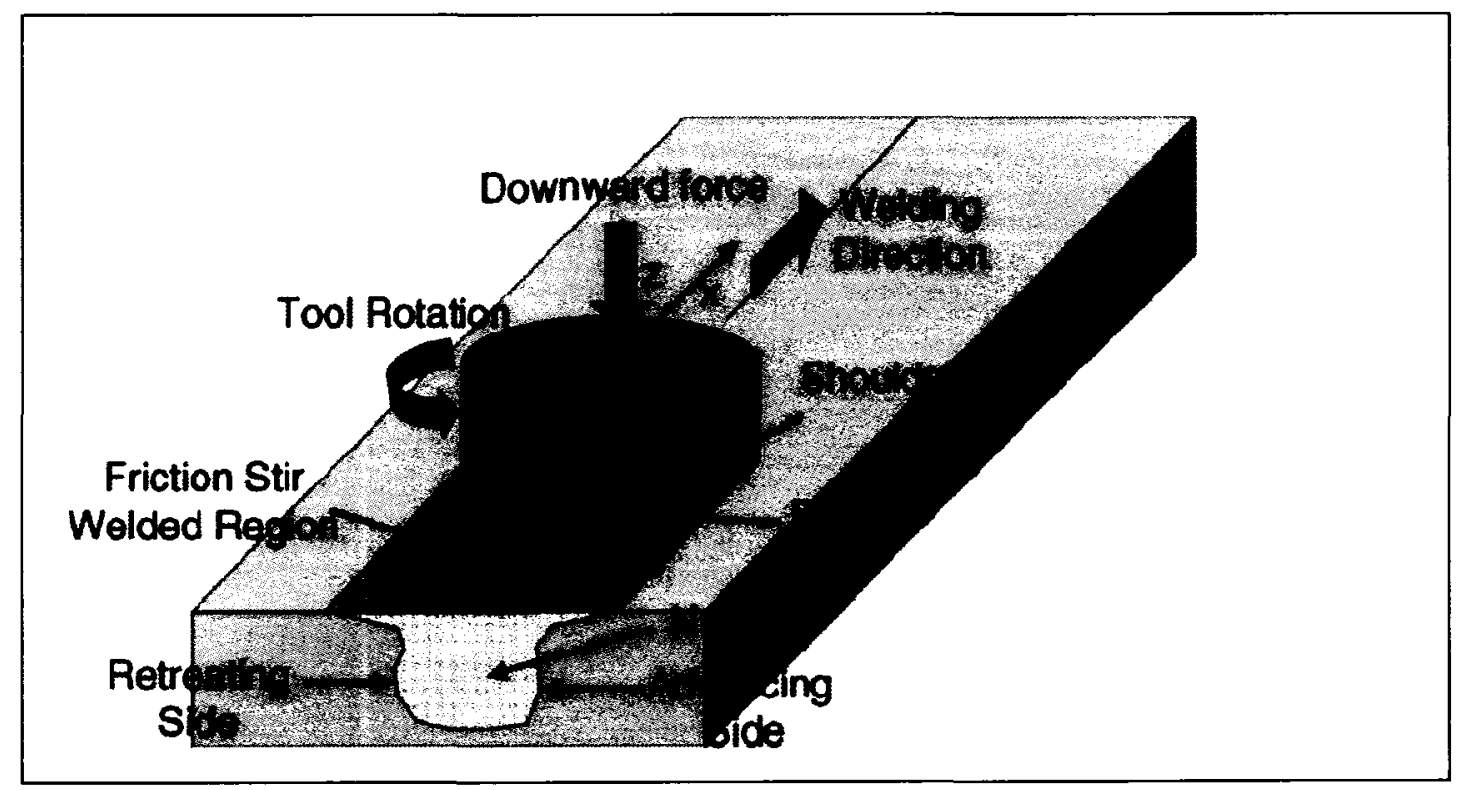

Fig. 2.1. Schematic drawing of friction stir welding

(Mishra and Ma 2005) 


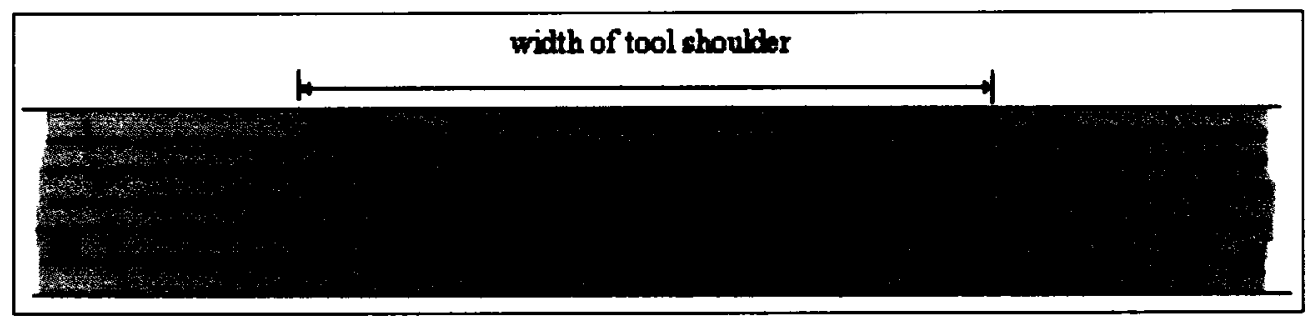

A. Unaffected material (B/M: Base Material)

B. Heat affected zone (HAZ)

C. Thermo-mechanically affected zone (TMAZ)

D. Weld nugget (Part of thermo-mechanically affected zone)

Fig. 2.2. Microstructure classification of FSW

(TWI 2007) 


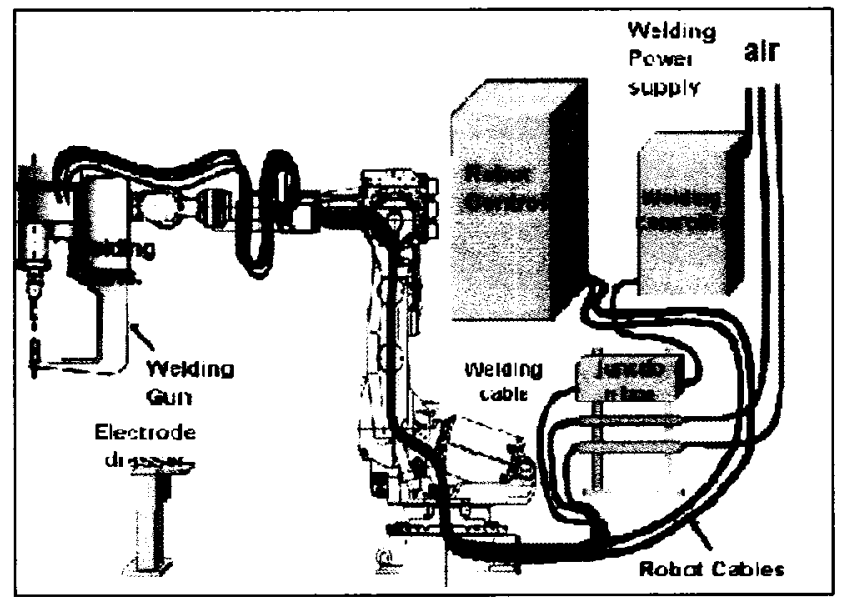

a) Resistant Spot Welding system

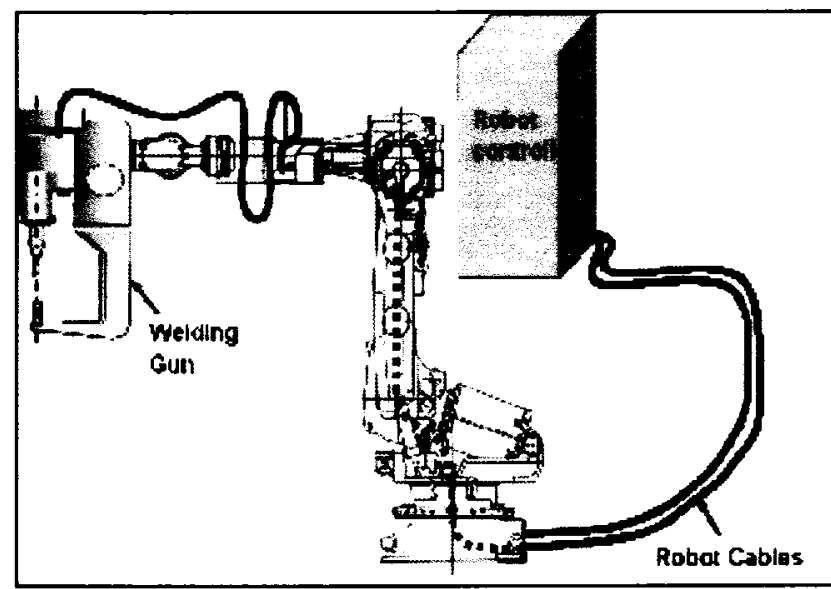

(b) Friction Stir Spot welding system

Fig. 2.3. Change from Resistant Spot Welding system

(Bhadeshia 2003)- Friction Stir Welding of Steel, Friction Stir Processing link of

Presentation of Friction Stir Welding Section 


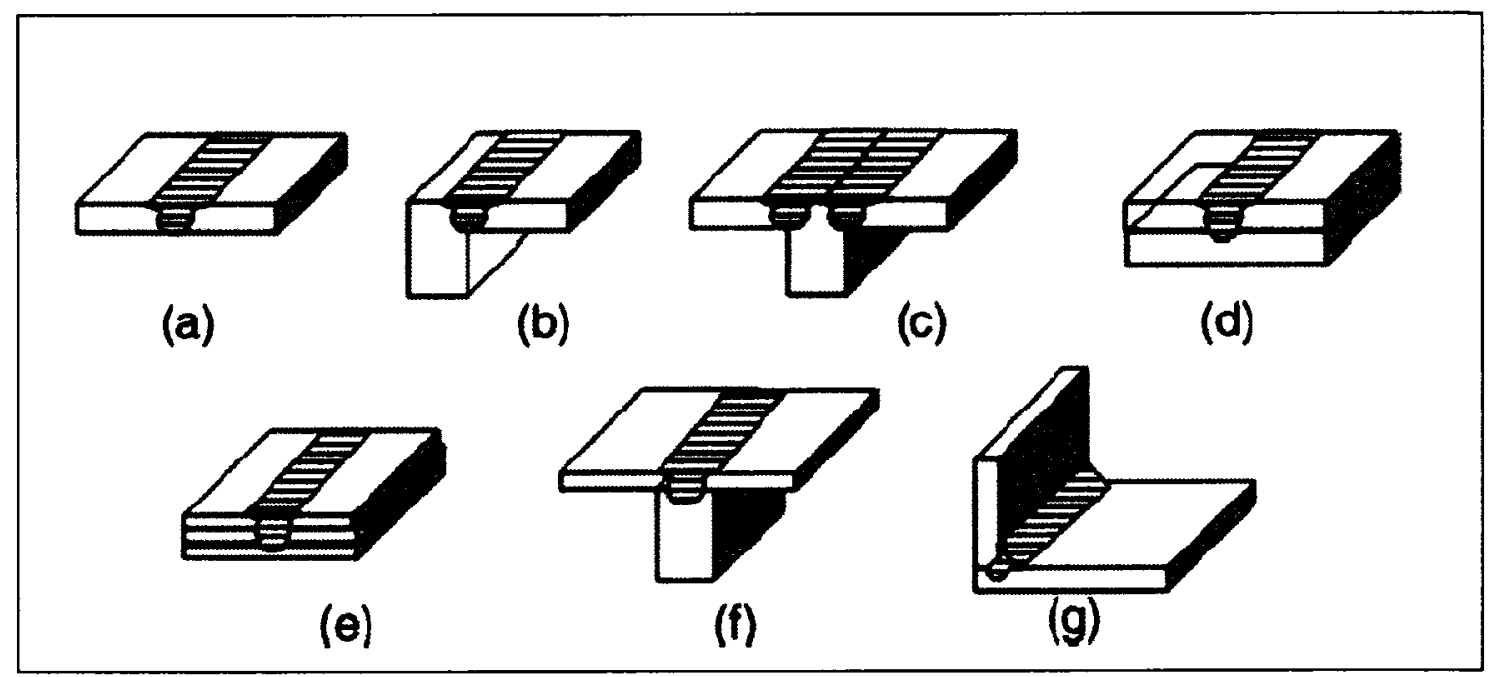

(a) Square butt, (b) edge butt, (c) T butt joint, (d) lap joint, (e) multiple lap joint, (f) T lap joint, and (g) fillet joint

Fig. 2.4. Joint configurations for friction stir welding

(Mishra and Ma 2005) 


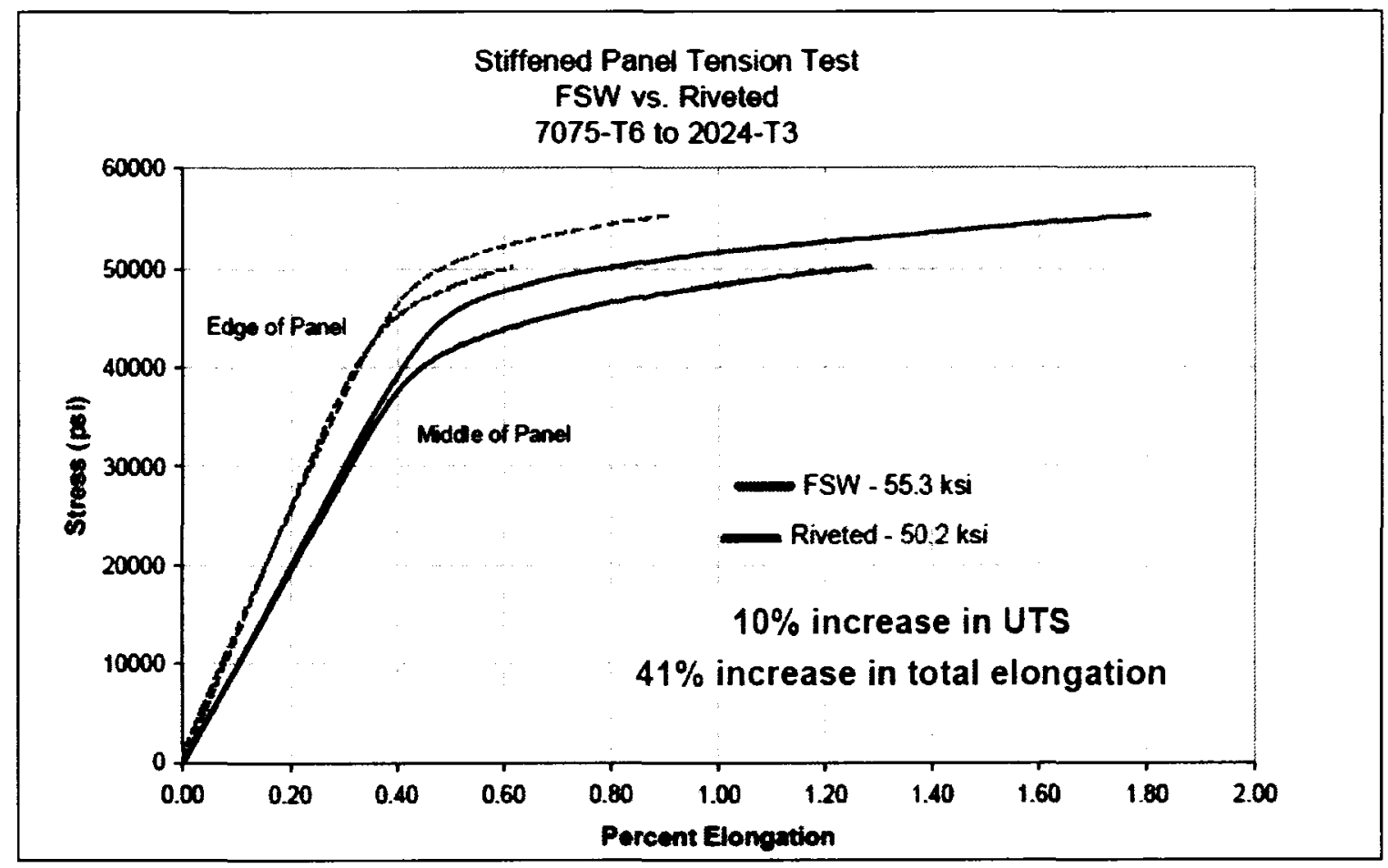

Fig. 2.5. Tension Test Results of FSW and Riveted Panels

(Tweedy et al. 2006) 


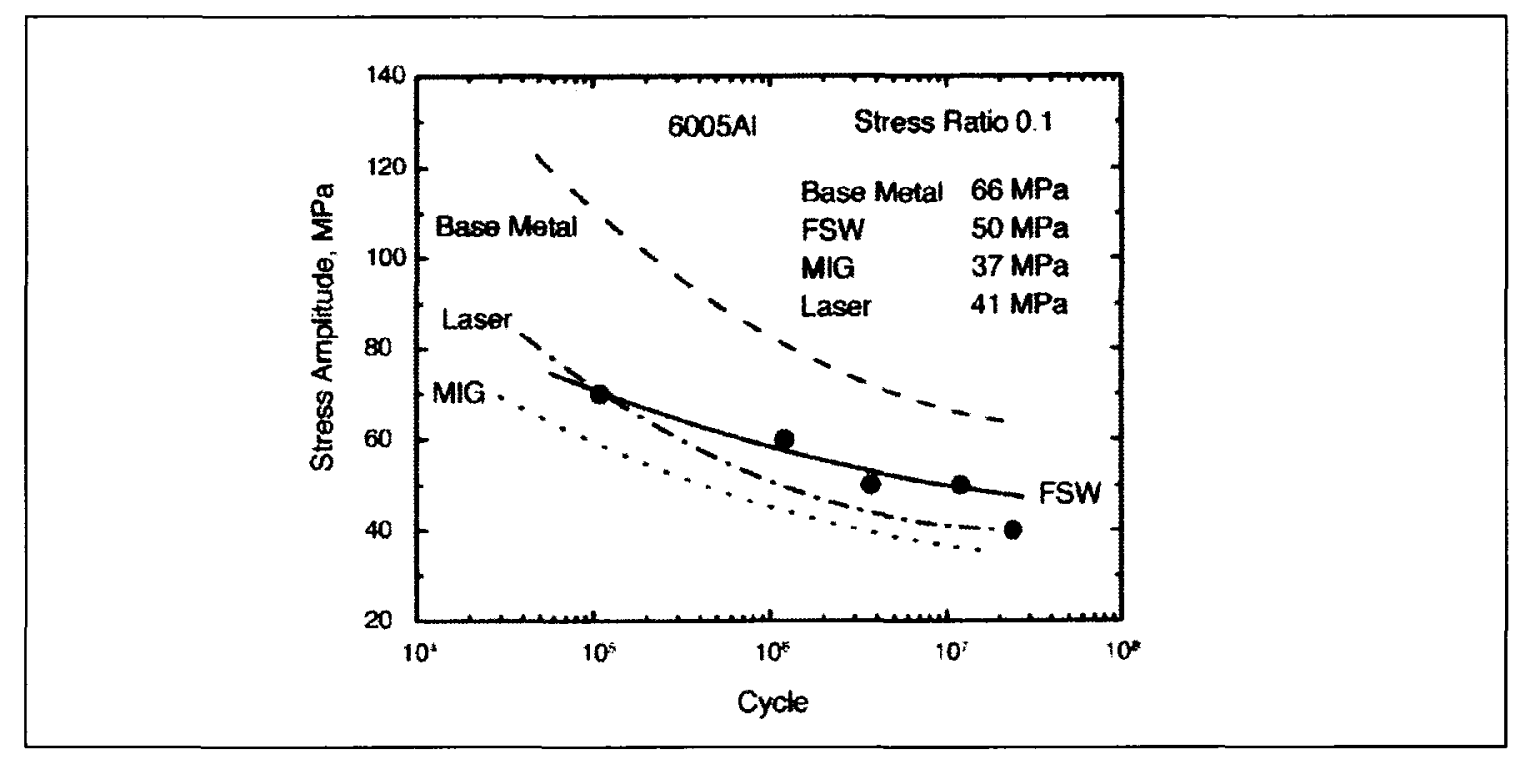

Fig. 2.6. S-N curves of base material, FSW weld, laser weld and MIG weld for 6005

\section{AL-T5}

(Mishra and Ma 2005) 


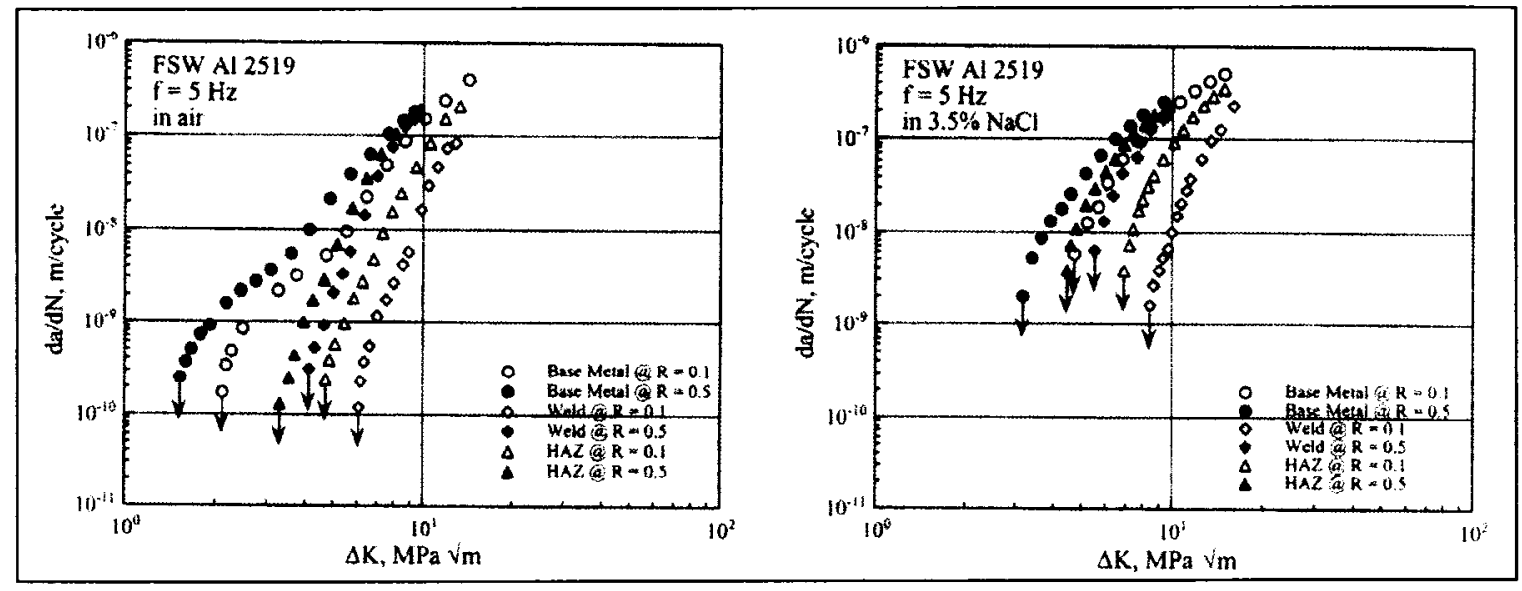

Fig. 2.7. Fatigue crack growth kinetics in air (left) and $3.5 \% \mathrm{NaCl}$ (right) through the base metal, HAZ, and weld nugget

(Pao et al. 2003) 


\section{CHAPTER 3}

\section{Experimental setup, procedure, and results}

In this chapter, the experimental setup, test procedure and results are presented. First, those of 2024-T3 base material static tensile strength and fatigue are described. Second, the static tensile strength tests of two representative single pass (SP) and double pass (DP) specimens are tested and compared with the 2024-T3 base material. Last, the fatigue tests of FSW specimens are carried out and the test specimens, experiments, and results given as S-N curves, crack locations and propagation, and SEM pictures are presented.

\subsection{4-T3 base material static tensile strength and fatigue property}

In all experiments of the FSW stiffened panel structure, 2024-T3 aluminum with $0.091 "(2.311 \mathrm{~mm})$ thickness were used for the base material which represents a main structure to endure applied loads. In a real airframe structure, it can be regarded as a skin of the fuselage or wing structures. For the stiffener, 7075-T6 aluminum with 0.064 " $(1.626 \mathrm{~mm})$ thickness was used and this specimen was designed such that the stiffener did 
not carry any real load. However, it could contribute to make the overall structure reducing the possibility of buckling and increase the strength for bending. FSW was used to join these two different aluminum materials.

Before the fatigue test of the FSW stiffened panel specimens was performed, it was necessary to obtain the mechanical properties of the 2024-T3. Thus, the static tensile strength test and the fatigue test with $20 \mathrm{ksi}$ maximum applied stress and 0.1 stress ratio (R) for 2024-T3 base material were carried out.

It should be noted that because of the dominant usage of U.S. Customary Units in the aerospace industry, U.S. Customary Units were used primarily in the thesis. However, the International System Units (SI Units) was given with U.S.Customary Units when needed.

\subsubsection{Test specimen}

The standard tensile test specimen dimensions are specified in ASTM E 8 (ASM handbook 2000). However, the objective of 2024-T3 base material static tensile strength test is to compare the mechanical properties between 2024-T3 base material and FSW stiffened panel specimen. Therefore, the test specimen of 2024-T3 base material in this static tensile strength test should be as similar to FSW stiffened panel specimen as possible. Since the maximum allowable width of MTS $810100 \mathrm{kN}$ Uniaxial Test Machine (UTM) wedge set is 3 inches, the maximum width of 2024-T3 specimen should be within 3 inches. In addition, the 2024-T3 base material specimens have to be an hour- 
glass type to prevent the crack initiation near the grip area. Therefore, the middle section width of specimen was set as 2 inches $(50.8 \mathrm{~mm})$ to maintain a reasonable radius between the test section and the 3 inch grip area. Moreover, the length of specimen is limited to 7.087 inch $(180 \mathrm{~mm})$. Therefore, the 2024-T3 base material test specimens were prepared according to the above conditions for both static tensile strength tests and fatigue test. Two 2024-T3 base material specimens (static_bm_\#1, static_bm_\#3) are used in the static test and one specimen (fatigue_bm_\#2) is used in the fatigue test. The detail dimensions for this specimen can be seen in Fig. 3.1.

\subsubsection{Test equipment and setup}

MTS 810 material testing system with 22 kips $(100 \mathrm{kN})$ hydraulic grip set was used for both static tensile strength tests and cyclic fatigue tests. The testing system consists of a load frame set with servohydraulic actuator, FlexTest SE Plus controller, and Multipurpose Testware software. The calibrations of the 22kips (100 kN) loadcell, linear variable differential transformer (LVDT), and MTS axial extensometer were carried out before the beginning of the experiments.

The first specimen (static_bm_\#1) was used for the static tensile strength test and the second specimen (fatigue_bm_\#2) for the fatigue test at $20 \mathrm{ksi}$ was tested without additional instrumentation. However, the third specimen (static_bm_\#3) for the static tensile strength test was carried out with the MTS axial extensometer since the first specimen tensile strength test using LVDT, which measured the displacement from cross head to cross head, indicated more elongation than the specimen itself. Thus, the static 
tensile strength test using the third specimen used a MTS 1 inch axial extensometer to measure elongation more accurately and was compared to the results with that of the static tensile strength test without the extensometer.

To evaluate the fatigue performance of 2024-T3 base material, the cyclic fatigue test was carried out using the second specimen (fatigue_bm_\#2). Before performing the fatigue test, the maximum applied load, test frequency, and stress ratio $(\mathrm{R}=$ minimum applied load/maximum applied load) were determined. The test frequency was chosen as $10 \mathrm{~Hz}$.

Since the 2024-T3 plate is a high strength aluminum, the fatigue test with $20 \mathrm{ksi}$ maximum applied stress may reach run-out condition, however, $20 \mathrm{ksi}$ is a reasonable load level to compare the fatigue characteristics with FSW specimens since the fatigue limit of FSW lap-joint specimen may be much less than that of 2024-T3 base material.

The stress ratio (R) should be chosen according to the objective of the test. The details regarding test objectives and stress ratio are summerized at Table 3.1. Therefore, $0<R<1$ was used for the general uniaxial tensile fatigue test. $R=0.1$ is recommended for comparative purposes (ASM handbook 2000). Another reason for using $\mathrm{R}=0.1$ is that FSW fatigue properties show its superior fatigue characteristic at the lower $\mathrm{R}$ value. The fatigue crack growth rate comparison between the base material and the FSW specimen with $\mathrm{R}=0.8$ and $\mathrm{R}=0.1$ showed that $\mathrm{FSW}$ has faster fatigue crack growth rate than the 6061-T3 base material (Schmidt et al. 2001). Therefore, $R=0.1$ was used for the 2024-T3 base material fatigue test for the purpose of comparing the test results with that of the FSW fatigue test specimens. 
To summarize, the 2024-T3 base material fatigue test used the following parameters.

- Stress ratio $(\mathrm{R}=0.1)$

- Maximum load level (20 ksi)

- Test frequency $(10 \mathrm{~Hz})$

\subsubsection{Test procedure}

Before the test, the thickness and the width of the specimens were measured and used to calculate the applied force and the calculated force was input to the MTS material testing system. Then, the testing system was set to zero position with high-pressure condition (3000 psi). The specimen was loaded to the testing parameters and the static tensile strength test or the cyclic fatigue test was carried out. The values of loads and displacements for each step were measured by the system automatically using the same control software used for both the static tensile strength test and the cyclic fatigue test. The Basic Testware module was used for the static tensile strength test and the Multipurpose Procedure Test (MPT) module was used for the cyclic fatigue test.

\subsubsection{Static and Fatigue Test results for 2024-T3}

Two static tensile strength tests were carried out. The first specimen (static_bm_\#1) was tested under displacement control and the third specimen (static_bm_\#3) was tested under strain control to compare their results to the reference 
literature. Since the specimen is aluminium, the yield stress can be obtained by the matching point between the strain-stress curve and the extension of $0.2 \%$ offset line of the strain-stress curve's linear region. The simple comparison of mechanical properties was summarized in the Table 3.2.

Since the dimensions of the static specimens (static_bm_\#1, static_bm_\#3) are shorter and wider comparing to the general coupon specimen used in the tensile strength test defined in ASTM standard, some deviation may exist between the test results and the references. Considering this variation, it is believed that the test setup, procedure, and results are satisfactory because the test results and the values from references are quite similar.

The cyclic fatigue test with the second specimen (fatigue_bm_\#2) was carried out at 20 ksi maximum applied stress, $R=0.1$, and $10 \mathrm{~Hz}$ frequency. The test ran over $1,800,000$ cycles without a surface crack and failure (run-out condition). The results was acceptable since the aluminum alloy reference given in Fig. 3.2 showed that 2024-T3 aluminum can be a run-out condition even under a more severe load ( The datum of $\mathrm{R}=0.1$, and frequency $=60 \mathrm{~Hz}$ with base material not corroded - given in Fig. 3.2, show that 2024-T3 may not break under $20 \mathrm{ksi}(137.9 \mathrm{MPa})$ ).

These test results will be the basis for comparing the 2024-T3 base material to the FSW stiffened panel specimens in the static strength and fatigue properties. 


\subsection{Static tensile strength test for the FSW stiffened panel specimens}

Representative single pass (SP) shown in Fig. 3.3 and double pass (DP) with type I specimen with tool pin-hole as shown in Fig. 3.4 were used for the static tensile strength test to compare the test results with 2024-T3 base material.

\subsubsection{Test specimen}

One SP specimen (NRC part \#.43-3) and one DP specimen (NRC part \#.48-1) with tool pin-hole were used for the static tensile strength test. Both specimens are approximately 3 in $(76 \mathrm{~mm})$ width and 7.5 in $(190 \mathrm{~mm})$ length. The 2024-T3 skin plate was 0.091 in $(2.311 \mathrm{~mm})$ thickness and the $7075-\mathrm{T} 6$ stiffener was 0.062 in $(1.626 \mathrm{~mm})$ thickness. Detail dimensions are given in Table 3.3.

In the case of SP, referring to Fig. 3.3, the friction stir welding started from left to right and stopped at $1 / 3$ of the specimen width ( 3 inches) and the tool pin was pulled out from the specimen to leave a tool pin hole intentionally, then, the tool pin was moved horizontally a third without welding to generate unwelded area. After that, the tool pin was plunged into 7075-T6 specimen surface to continue to weld. Those procedures were repeated several times for one large plate which was cut into 3 inch wide specimens so that each specimen has one tool pin hole as shown in Fig. 3.5. In the case of DP, all the procedures were repeated one more time. In other words, first welding started from left to right exactly the same as SP except that it started approximately $8 \mathrm{~mm}$ downward vertically as shown in Fig. 3.4. After finishing the first weld, the tool pin moved upward 
and started to weld from right to left for second FSW pass. By doing so, DP specimens had a larger welding area than SP specimens and this large welding area should give the DP a better tensile strength than SP.

In both SP and DP cases, the tool pin rotated counterclockwise. Thus, the lower part of welding line is referred to as the advancing side and upper part as the retreating side in case of SP. Also, both perimeter sides of the specimen weld are advancing sides in case of DP (Type I). The detail descriptions of DP specimen (Type I) and DP specimen (Type II) were given in section 3.3.1.

\subsubsection{Test equipment and setup}

The same MTS 810 material testing system was used for the FSW static tensile strength test. In addition, MTS axial extensometer was used for the control of strain rate and the measurement of strain values. The extensometer was installed near the FSW welding area and measured the strain values of the region for the SP or DP welding area as shown in Fig. 3.6.

The test was carried out by the strain rate control using the MTS axial extensometer up to the failure of the specimen. Applied loads, displacements of LVDT, and strain values from the extensometer were recorded in small time steps. For the calculation of applied load, only 2024-T3 plate area was used due to the assumption that 7075-T6 plate does not contribute the real load carrying capacity. 


\subsubsection{Test procedure and results of FSW specimens.}

The test procedure for the FSW static tensile strength test is the exact same procedure with that of 2024-T3 base material. The same material testing system and extensometer were used.

After the test, strain-stress curves for SP and DP were plotted as shown in Fig. 3.7. Moreover, the mechanical properties (yield stress, tensile stress, and maximum elongation) and comparison with 2024-T3 base material with the extensometer test [the $3^{\text {rd }}$ specimen (static_bm_\#3) in previous static tensile test] results were given in the Table 3.4 .

The welding efficiency, defined as the ratio of the ultimate tensile strength of the FSW joint to that of the base (parent) material, based on tensile stress for 2024-T3 base material is $77 \%$ for SP and $80 \%$ for DP with a tool pin-hole. Since the welding nugget has low elongation, the overall maximum elongations for a SP and a DP weld specimens are approximately one tenth compared to 2024-T3 base material. Besides, tensile stress of FSW SP and DP specimens are about 22kips (100 MPa) lower than that of 2024-T3 base material since the tested FSW SP and DP specimens have a tool pin-hole which may cause a tensile strength drop due to the stress concentration. 


\subsection{The Fatigue tests of the FSW specimens}

The purpose of these tests is to identify the fatigue lives with or without a tool pin-hole. It is almost impossible to weld a part continuously without tool pin-hole since the tool pin-hole exists whenever FSW tool is withdrawn. Thus, the identification of the fatigue characteristics with a tool pin-hole can help the applications of FSW to practical airframe design especially in the durability and damage tolerance analysis.

Moreover, since the application of single pass (SP) welding with one direction could not generate enough welding area to satisfy required durability characteristics in general, double pass (DP) welding with different directions was developed as mentioned at the literature in the section 2.2.3.2 (Lap joint). However, no experimental tests were carried out to compare the fatigue life of SP and DP with or without a tool pin hole. Therefore, this work will carry out fatigue life and the crack propagation rate tests on SP and DP specimens with and without pin holes.

\subsubsection{Test specimens}

The fatigue tests of FSW specimens with previously described welding procedures were carried out under various load levels. All FSW fatigue test specimens were categorized to 4 different groups as the following. However, DP had two different types (Type I and Type II) of FSW specimens defined by the welding procedure. Double pass welding types (I and II) are defined the below. 
Referring to Fig. 3.8, DP specimens have two different types. DP specimens (Type I) start the welding from left to right at the first welding pass. After finishing the first welding pass, the tool pin moves upward vertically (retreat side direction of specimens) and starts second welding pass from right to left.

DP specimens with type II also start their welding from left to right at the first welding pass. However, after finishing first welding pass, tool pin moves downward vertically (advanced side direction of specimens) and starts the second welding pass from right to left. The rotation of the tool pin of both DP specimens (Type I and Type II) is counterclockwise.

The main difference of type I and II of DP specimens is the perimeters of both end sides of the welding section. Since the perimeters of DP specimens (Type I) are both advancing sides, both perimeters can be the weak regions for a crack initiation. However, the perimeters of DP specimens (Type II) are both retreating sides and are relatively stronger than the advancing sides. Also, the strength of the overlapped area of DP specimens (Type II) can increase a little since that area is the mixture of two advancing sides.

The detail test load levels and categorized specimens are given in the Table 3.5. All Friction Stir Welded specimens were provided by the National Research Council Institute for Aerospace Research in Ottawa [NRC-IAR (Ottawa)] and fabricated using a MTS ISTIR machine at NRC-IAR (Montreal). The FSW specimen layout description was given in the Fig. 3.9. 


\subsubsection{Test equipment and setup}

The test system was the same as the static tensile strength test described in section 3.2.2. The only difference was the change of the software module from monocyclic to multi-cyclic system for fatigue testing. All test parameters were the same as the previous 2024-T3 base material fatigue test (section 3.1.2). The stress ratio (R) was set to 0.1 and sine wave was used for the command signal. Specimens were tested under 4 different maximum stress levels of 20/15/12/10 ksi. Test frequency was set to $5 \mathrm{~Hz}$ for all fatigue tests of FSW stiffened panel structure specimens to ensure that the maximum loads were obtained during each cycle.

To measure the crack propagation, a microscope with digital meter and supporting stand were installed on the MTS 810 UTM material test system. The digital meter can measure the cracks with the precision of $0.01 \mathrm{~mm}(0.00039 \mathrm{inch})$.

\subsubsection{Test procedure}

Before testing, the thickness and width in the welding center line of all specimens were measured. These data were used to calculate the applied force in the MTS UTM material testing machine.

For example, to calculate the applied force for the specimen that has $20 \mathrm{ksi}$ stresses in the center section of 2024-T3 base material, the conversion factor 6.895 $\mathrm{MPa} / \mathrm{ksi}$ was used. In addition, a stress can be defined as the ratio of applied force over applied area. Therefore, the applied force is 
applied force $(N)=20 \mathrm{ksi} \times 6.895 \mathrm{MPa} / \mathrm{ksi} \times$ applied area $\left(\mathrm{mm}^{2}\right)$

Applied area $=$ thickness $\times$ width of 2024-T3

The applied force from the above equation represented the maximum force and the minimum force could be calculated by multiplying 0.1 to the maximum force since the stress ratio should be 0.1 .

All fatigue tests finished when the specimen broke completely. However, the fatigue test was stopped regularly to measure the crack propagation using the microscope.

\subsubsection{The simple label system for FSW fatigue test specimens}

Since the number of FSW fatigue test specimens is twenty, it is difficult to distinguish each specimen. Therefore, a simple label system was devised. First, the identification of specimens consisted of a label name and a specimen number. For instance, SP_P_20 (1) represented the label name (SP_P_20) and the specimen number (1). For the label name, the first word, SP, DP1, and DP2 - mean welding conditions (Single Pass, Double Pass (Type I), Double Pass (Type II) respectively). The second, 'P' stands for having "tool pin hole" and ' $\mathrm{C}$ ' stands for continuous welding. The third, number represented the load level. Therefore, all fatigue test specimens could be expressed as in the Table 3.6.

All the FSW fatigue specimens can be categorized into 5 different groups. Each group has 4 specimens which were tested under different stress levels of 20/15/12/10 ksi. 
However, all specimens were tested under the same condition, for instance, the same frequency, stress ratio ( $R=0.1$ ), and so on except stress level. Representative pictures of each specimen type and the illustrated view of a specimen for defining the terms of weld detail locations are shown in Fig. 3.10.

\subsubsection{Test results}

The results can be summarized as follows;

First, all fatigue test results were summarized in an S-N curve plot. The DP (Type II) without tool pin hole specimens showed outstanding fatigue life compared to other categorized specimens.

Second, the initial surface crack detection was depicted. Most categorized groups except the SP specimens with tool pin hole have the similar initial surface crack location while the SP specimens with tool pin hole specimens have several different initial surface crack locations.

Third, the crack propagation was described for each categorized groups. The SP and DP specimens with tool pin hole showed a similar crack propagation process and SP and DP specimens without tool pin hole showed also similar crack propagation process.

Last, the metallurgical analysis by scanning electron microscopy (SEM) explained the crack development at both welding pullout region and welding plunge region.

3.3.5.1 S-N curve for FSW specimens 
All specimens were tested up to the failure of the specimens except DP_C_10 (20) since this specimen was a run-out condition which meant the specimen did not break at over $4 \times 10^{6}$ cycles. The failure cycles of each specimen was recorded and given in Table 3.6.

The S-N curve (applied stress versus number of cycles when specimen broke) was plotted in Fig. 3.11 as $\log -\log$ scale. The 3 categorized groups with tool pin hole [SP_P_20 (1) DP2_P_10 (12)] showed relatively small deviation of the failure cycle according to the load level, 2 categorized groups without tool pin hole [SP_C_20 (13) DP2_C_10 (20)] showed the large deviation of the failure cycles respectively. Moreover, the fatigue lives of the DP (Type II) specimens without tool pin hole group showed much longer fatigue lives than those of others.

The SP/DP (Type I)/DP (Type II) with tool pin hole S-N curves were extracted from Fig. 3.11 and plotted separately in Fig. 3.12 to compare each other. While SP specimens showed shorter fatigue life than others, DP (Type II) showed longer fatigue life than DP (Type I) in the 20/15 ksi cases and shorter life than DP (Type I) in the 12/10 ksi cases.

Also, the S-N curves for the SP specimens with tool pin hole versus the SP specimens without tool pin hole and the S-N curves for the DP specimens with tool pin hole versus the DP specimens without tool pin hole were given in the Fig. 3.13, Fig. 3.14 respectively. Though the S-N curves for SP specimens with/without tool pin hole did not show a significant difference, the S-N curves of DP specimens with/without tool pin hole 
showed a significant difference. These results can be deduced from the fact that the SP specimens might have a high possibility to possess defects after FSW and the DP specimens could have better fatigue life than SP specimens by removing the defects and increasing the strength due to a wider welding area caused by the second pass.

In case of DP specimens, there is no significant difference in fatigue life between DP (Type I) specimens and DP (Type II) specimens when they have a tool pin hole since the major factor to determine the fatigue lives of the specimens is the stress concentration near the $1^{\text {st }}$ and $2^{\text {nd }}$ tool pin hole pullout position. So, the fatigue life of DP specimen (Type II) without tool pin hole showed outstanding fatigue lives compared to the DP (Type I and Type II) specimens with tool pin hole. The details will be discussed further in Chapter 4.

3.3.5.2 Location of surface crack initial detection

Since two plates (2024-T3 and 7075-T6) were welded together, all surface cracks could only be monitored from the backside of the weld of 2024-T3 plate because the cracks were initiated at the interface between the front side of 2024-T3 and the bottom side of 7075-T6 and propagated to the back of the weld of 2024-T3 due to the cyclic loading which affected only 2024-T3 load carrying plate.

The SP specimens with tool pin hole [SP_P_20 (1) SP_P_10 (4)] had 3 different locations of surface crack initial detection while other specimens had the same location of the surface crack initial detection. The two specimens [SP_P_20 (1), SP_P_15 
(2)] have the same location of surface crack initial detection near the lower part of the tool pin pullout hole and the specimen [SP_P_12 (3)] has its location of surface crack initial detection near the upper part of the tool pin pullout hole. However, the specimen [SP_P_10 (4)] has its location of surface crack initial detection near the upper part of the welding tool pin plunge position into the specimen. The exact locations were described in the Fig. 3.15.

All DP specimens (Type I) with tool pin hole [DP1_P_20 (5) DP1_P_10 (8)] started their initial surface cracks at the lower part of $1^{\text {st }}$ pass tool pin pullout hole trace, while all DP specimens (Type II) with tool pin hole [DP2_P_20 (9) DP2_P_10(12)] started their initial surface cracks at the upper part of $1^{\text {st }}$ tool pin pullout hole trace. The details of DP specimen (Type I and Type II) were already mentioned in section 3.3.1.

In the case of continuous welding i.e. 'without tool pin hole', all surface cracks were detected at the center of the specimen and propagated to both ends. In particular, the locations of initial surface crack detection of SP continuous [SP_C_20 (13) SP_C_10 (16)] were at the advancing side of tool pin hole trace, while the locations of initial surface crack detection of DP (Type II) continuous [DP2_C_20 (17) DP2_C_10 (20)] were at the upper part of $1^{\text {st }}$ tool pin hole trace. All detail locations were depicted in the Fig. 3.16.

Most surface cracks of SP with tool pin hole, SP without tool pin hole, and DP without tool pin hole had only one single crack, while most surface cracks of DP (both Type I and Type II) with tool pin hole had multiple surface crack locations. 
The representative crack monitoring samples for SP [SP_P_20(1)] and DP [DP1_P_20(5)] were shown in Fig. 3.17 and Fig. 3.18

\subsubsection{Crack propagation}

In the general case, both tips of a surface crack propagate in different directions with increasing the length of the crack. Therefore, the cracks in the SP/DP without tool pin hole followed the above general rule. However, the cracks in SP/DP with tool pin hole developed differently. First, whether the crack developed in the tool pin pullout point or the tool pin plunge point, the crack mainly propagated to the surface of the welded side since the center section of the specimen was strong unwelded 2024-T3 base material. Then, it propagated along the weld until it reached the side of the specimen. After that, the other tip of crack propagated to the unwelded 2024-T3 base material. Lastly, the specimen was broken when the uncracked area was too small to carry the load or the propagated crack reached another propagating crack which had initiated at a different position.

The surface crack growth for all specimens was measured by an optical microscope with a digital meter. The maximum accuracy is $0.01 \mathrm{~mm}$. All measurements were recorded when the maximum applied load was applied to the specimen because the crack could be clearly measured at the maximum crack opening. In addition, half of the total crack length was used for the calculation of the surface crack propagation rate. Also, the primary crack, which was normally an initial crack, was used to calculate the surface crack propagation rate in case of multiple surface cracks in DP (both Type I and II) with 
tool pin hole.

The crack propagation of 17 specimens was measured and that of 3 specimens could not be measured since the crack propagation in 2 SP specimens without tool pin hole was too fast to be measured and in 1 DP specimen without tool pin hole a run-out condition was reached.

The average crack propagation rate for each specimen is summarized in the Table 3.7. Also, the individual plots of the crack length versus the cycles for all cases were added in the Appendix Fig.A-1 Fig.A-4. Because the crack propagation cycles are quite different in each case, all plots were plotted individually. In addition, the crack length of $75 \mathrm{~mm}$ represents the fracture of the specimen since the specimen length is 3 inch (almost $75 \mathrm{~mm}$ ). Further discussion will be presented in Chapter 4.

3.3.5.4 Metallurgical analysis by scanning electron microscopy (SEM)

All SEM pictures were taken at the NRC-IAR (Ottawa) facility. One specimen from each group tested at $20 \mathrm{ksi}$ [SP_P_20 (1), DP1_P_20 (5), DP2_P_20 (9), SP_C_20 (13), SP_C_20 (13), DP2_C_20 (17)] were analysed together with 3 specimens of each group tested at $10 \mathrm{ksi}$ with tool pin hole [SP_P_10 (4), DP1_P_10 (8), DP2_P_10 (12)]. In addition, 2 specimens of each group tested at $15 \mathrm{ksi}$ without tool pin hole [SP_C_15 (14), DP2_C_15 (18)] and a specimen tested at $12 \mathrm{ksi}$ with tool pin hole [SP_P_12 (3)] were also analysed using SEM.

The SEM pictures of the SP specimen with tool pin hole tested at $20 \mathrm{ksi}$ 
[SP_P_20 (1)] showed that both the tool pin pullout hole and the tool pin plunge hole were crack initiators. However, the tool pin pullout hole position of the surface crack of the bottom of the weld of 2024-T3 was detected and propagated to the fracture, while the crack of the tool pin plunge position did not fully develop to the bottom of the 2024-T3 plate as shown in Fig. 3.19.

The SEM pictures of the DP (Type I) specimen with tool pin hole tested at $20 \mathrm{ksi}$ [DP1_P_20 (5)] showed that both the $1^{\text {st }}$ tool pin pullout position and the 2 nd tool pin pullout position were crack initiators. But, the surface crack of the $1^{\text {st }}$ tool pin pullout position on the 2024-T3 the bottom of the weld was detected and propagated to the fracture, while the $2^{\text {nd }}$ tool pin pullout position did not fully develop as a surface crack, Fig. 3.20. Also, this surface crack propagated as several independent surface cracks at first and coalesced into one large surface crack.

The SEM pictures of the DP (Type II) specimen with tool pin hole tested at 10 ksi [DP2_P_10 (12)] showed similar results with DP (Type I) [DP1_P_20 (5)] as described before. Both $1^{\text {st }}$ and $2^{\text {nd }}$ tool pin pullout positions were crack initiators and the $1^{\text {st }}$ tool pin pullout position developed a surface crack primarily with multi cracks.

The SEM pictures of the SP specimen without tool pin hole tested at $15 \mathrm{ksi}$ [SP_C_15 (14)] showed a repeated tool mark in the fracture surface. A close look of this tool mark showed that this mark was generated by the tool pin and induced the crack initiators. The details are discussed in section 4.1.4. 
The SEM pictures of DP (Type II) specimen without tool pin hole tested at $15 \mathrm{ksi}$ [DP2_C_15(18)] showed that the crack started in the middle of the specimen facture section and propagated to the both side end of specimen at the similar rate. No special tool mark was found.

The SEM pictures of SP specimen with tool pin hole tested at $12 \mathrm{ksi}$ showed a unique shape in the fracture section of the specimen. It showed many tool pin marks in the fracture section which are similar to those detected in the SP without tool pin hole specimens. Also, this surface crack location was different than other SP specimens with tool pin hole. More details are explained in section 4.3.

\subsection{Summary}

In this chapter, the experimental setup, procedure, and results of 2024-T3 (base material) and the FSW specimens were described in detail. First, the experiments to obtain the static tensile and fatigue strength of 2024-T3 were described to compare the results to both the reference handbooks and the test results of FSW specimens. The experimental results of the static tensile strength of 2024-T3 showed that there are no significant differences with the reference handbook. Second, the static tensile strength tests for FSW specimens were carried out for both a SP (single pass) specimen and a DP (double pass, Type I) specimen respectively. The comparison of the mechanical properties between FSW specimens and 2024-T3 was summarized in the section 3.2.3.

Last, the fatigue tests for twenty FSW specimens were carried out at four load 
levels and five categorized welding conditions. DP without tool pin hole showed outstanding fatigue performance as compared with other categorized FSW specimens. Also, the study of the crack propagation of FSW specimens indicated that the FSW specimens without tool pin hole showed faster crack propagation rate than others although the total life is longer, because of the longer initiation life.

In the next chapter, the fatigue fracture mechanism of, the fatigue crack propagation rate of, and the metallographic analysis of FSW fatigue test specimens will be discussed. 


\begin{tabular}{|c|c|c|}
\hline $\begin{array}{c}\text { Stress } \\
\text { Ratio (R) }\end{array}$ & Loading case & Load description \\
\hline $\mathbf{R}=\mathbf{- 1}$ & Fully reversed & Rotating shaft without the overload \\
\hline $\mathbf{R}=\mathbf{1}$ & Static loading & Static loading \\
\hline $\mathbf{R}=\mathbf{0}$ & Smin $=0$ & $\begin{array}{c}\text { Pressurization and depressurization } \\
\text { of a tank }\end{array}$ \\
\hline $\mathbf{0}<\mathbf{R}<\mathbf{1}$ & Both positive & $\begin{array}{c}\text { Preloaded bolt subjected to fully } \\
\text { reversed load }\end{array}$ \\
\hline $\mathbf{R}>\mathbf{1}$ & Both negative ( with negative Sm) & $\begin{array}{c}\text { Mandrelized hole subjected to } \\
\text { fluctuating load }\end{array}$ \\
\hline $\mathbf{R}=$ & $\begin{array}{c}\text { Smax is equal to zero and Smin is } \\
\text { negative }\end{array}$ & $\begin{array}{c}\text { Mandrelized hole under fluctuating } \\
\text { load with Smax =0 }\end{array}$ \\
\hline
\end{tabular}

TABLE 3.1. Stress ratio and representative load description

(Farahmand et al. 1997) 


\begin{tabular}{|c|c|c|c|c|}
\hline & $1^{\text {st }}$ specimen & $3^{\text {rd }}$ specimen & Reference_1 & Reference_2 \\
\hline Yield stress & $39.26 \mathrm{ksi} *^{3}$ & $47.86 \mathrm{ksi}$ & $41.91 \mathrm{ksi}$ & $42.06 \mathrm{ksi}$ \\
\hline Tensile stress & $(270.71 \mathrm{MPa})$ & $(330 \mathrm{MPa})$ & $(289 \mathrm{MPa})$ & $(290 \mathrm{MPa})$ \\
\hline Max.Elongation & $(474.85 \mathrm{MPa})$ & $(480 \mathrm{MPa})$ & $(434-441 \mathrm{MPa})$ & $(435 \mathrm{MPa})$ \\
\hline Remarks & $20.56 \% * 1$ & $69.62 \mathrm{ksi}$ & $62.9-64.0 \mathrm{ksi}$ & $63.09 \mathrm{ksi}$ \\
\hline & displacement & strain control & ALCOA MILL & Aluminum alloy \\
\hline
\end{tabular}

Note;

1. Elongation was measured by internal LVDT which attached MTS 810 Uniaxial Tension Machine

(UTM) for crosshead to crosshead

2. Elongation was measured by external MTS extensometer with 1 inch displacement (max. $+50 \%$

$\min .-10 \%$ capability)

3. Not a valid yield stress due to excessive gage length

TABLE 3.2. The mechanical properties between experimental 2024-T3 aluminum and references 


\begin{tabular}{|c|c|c|}
\hline & SP(43-3) & DP(48-1) \\
\hline Width near tool pin hole & 3.03 inch $(76.860 \mathrm{~mm})$ & 2.95 inch $(74.981 \mathrm{~mm})$ \\
\hline Thickness & 0.091 inch $(2.311 \mathrm{~mm})$ & 0.091 inch $(2.311 \mathrm{~mm})$ \\
\hline
\end{tabular}

TABLE 3.3. The width and thickness of FSW specimens for the tensile strength test 


\begin{tabular}{|c|c|c|c|}
\hline & SP with tool & DP(Type I) with & Reference \\
& pin hole & tool pin hole & $47.86 \mathrm{ksi}$ \\
\hline Yield stress & $47.14 \mathrm{ksi}$ & $47.14 \mathrm{ksi}$ & $(330 \mathrm{MPa})$ \\
\hline Tensile stress & $(325 \mathrm{MPa})$ & $(325 \mathrm{MPa})$ & $69.62 \mathrm{ksi}$ \\
\hline Max.Elongation & $(370.5 \mathrm{MPa})$ & $(383.3 \mathrm{MPa})$ & $(480 \mathrm{MPa})$ \\
\hline Remarks for & NRC No. & NRC No. & 2024-T3 B/M with extensometer( $3^{\text {rd }}$ \\
\hline specimen & $(43-3)$ & $(48-1)$ & specimen $)$ \\
\hline
\end{tabular}

TABLE 3.4. The mechanical properties between SP and DP(Type I) FSW specimens and 2024-T3 specimen 


\begin{tabular}{|c|l|l|}
\hline & \multicolumn{1}{|c|}{ Single Pass (SP) } & \multicolumn{1}{c|}{ Double Pass (DP) } \\
\hline With pin-hole & $20 / 15 / 12 / 10 \mathrm{ksi}$ & $20 / 10 \mathrm{ksi}$ (Type I) \\
\hline $\begin{array}{c}\text { Without pin-hole } \\
\text { (continuous) }\end{array}$ & $20 / 15 / 12 / 10 \mathrm{ksi}$ & $20 / 15 / 12 \mathrm{ksi}$ (Type II) \\
\hline
\end{tabular}

TABLE 3.5. The test load levels and categorized specimens 


\begin{tabular}{|c|c|c|c|c|c|}
\hline \multirow[b]{2}{*}{ load (ksi) } & \multicolumn{3}{|c|}{ with tool pin hole } & \multicolumn{2}{|c|}{ without tool pin hole } \\
\hline & SP & DP(Type I) & DP(Type II) & SP_C & DP_C \\
\hline \multirow{2}{*}{20} & SP_P_20(1) & DP1_P_20(5) & DP2_P_20(9) & SP_C_20(13) & DP2_C_20(17) \\
\hline & 38749 & 50155 & 67645 & 46864 & 179263 \\
\hline \multirow{2}{*}{15} & SP_P_15(2) & DP1_P_15(6) & DP2_P_15(10) & SP_C_15(14) & DP2_C_15(18) \\
\hline & 107862 & 120117 & 186761 & 94172 & 486499 \\
\hline \multirow{2}{*}{12} & SP_P_12(3) & DP1_P_12(7) & DP2_P_12(11) & SP_C_12(15) & DP2_C_12(19) \\
\hline & 285382 & 345668 & 318628 & 210261 & 1817270 \\
\hline \multirow{2}{*}{10} & SP_P_10(4) & DP1_P_10(8) & DP2_P_10(12) & SP_C_10(16) & DP2_C_10(20) \\
\hline & 396791 & 636507 & 492657 & 718014 & $4657957^{1)}$ \\
\hline
\end{tabular}

The upper line in the cell shows the label and number of FSW fatigue specimen.

The lower line in the cell shows the failure cycles of the specimen.

Note 1) run-out condition (without failure)

TABLE 3.6. The label and number of FSW fatigue specimens and their fracture cycles 
$\Delta \mathrm{a} / \Delta \mathbf{N}$ : crack propagation length per cycle (inch/cycle)

\begin{tabular}{|c|c|c|c|c|c|}
\hline \multirow[b]{2}{*}{ load (ksi) } & \multicolumn{3}{|c|}{$\begin{array}{l}\text { crack length per a cycle with tool pin hole } \\
\text { (inch/cycle) }\end{array}$} & \multicolumn{2}{|c|}{$\begin{array}{l}\text { crack length per a cycle } \\
\text { without tool pin hole } \\
\text { (inch/cycle) }\end{array}$} \\
\hline & SP & DP(Type I) & DP(Type II) & SP_C & DP_C \\
\hline 20 & $9.06 \times 10^{-5}$ & $2.87 \times 10^{-5}$ & $26.4 \times 10^{-5}$ & too high & $75.4 \times 10^{-5}$ \\
\hline 15 & $3.31 \times 10^{-5}$ & $1.61 \times 10^{-5}$ & $4.57 \times 10^{-5}$ & too high & $8.66 \times 10^{-5}$ \\
\hline 12 & $1.10 \times 10^{-5}$ & $0.51 \times 10^{-5}$ & $1.54 \times 10^{-5}$ & $14.1 \times 10^{-5}$ & $1.02 \times 10^{-5}$ \\
\hline 10 & $1.26 \times 10^{-5}$ & $0.74 \times 10^{-5}$ & $0.39 \times 10^{-5}$ & $5.0 \times 10^{-5}$ & N/A(run-out) \\
\hline
\end{tabular}

Note

1) The values of the above table means the deviation of crack length over the deviation of cycles and can be expressed the following;

$\Delta \mathrm{a} / \Delta \mathrm{N}$ : crack propagation length per cycle (inch/cycle )

2) Two SP without tool pin hole in $20 / 15 \mathrm{ksi}$ broke within a few cycles. Therefore, they were written "too high".

3) One DP without pin hole in $10 \mathrm{ksi}$ did not break over $1,000,000$ cycles. Therefore, it was written "N/A (run-out)".

TABLE 3.7. The average crack propagation rate 


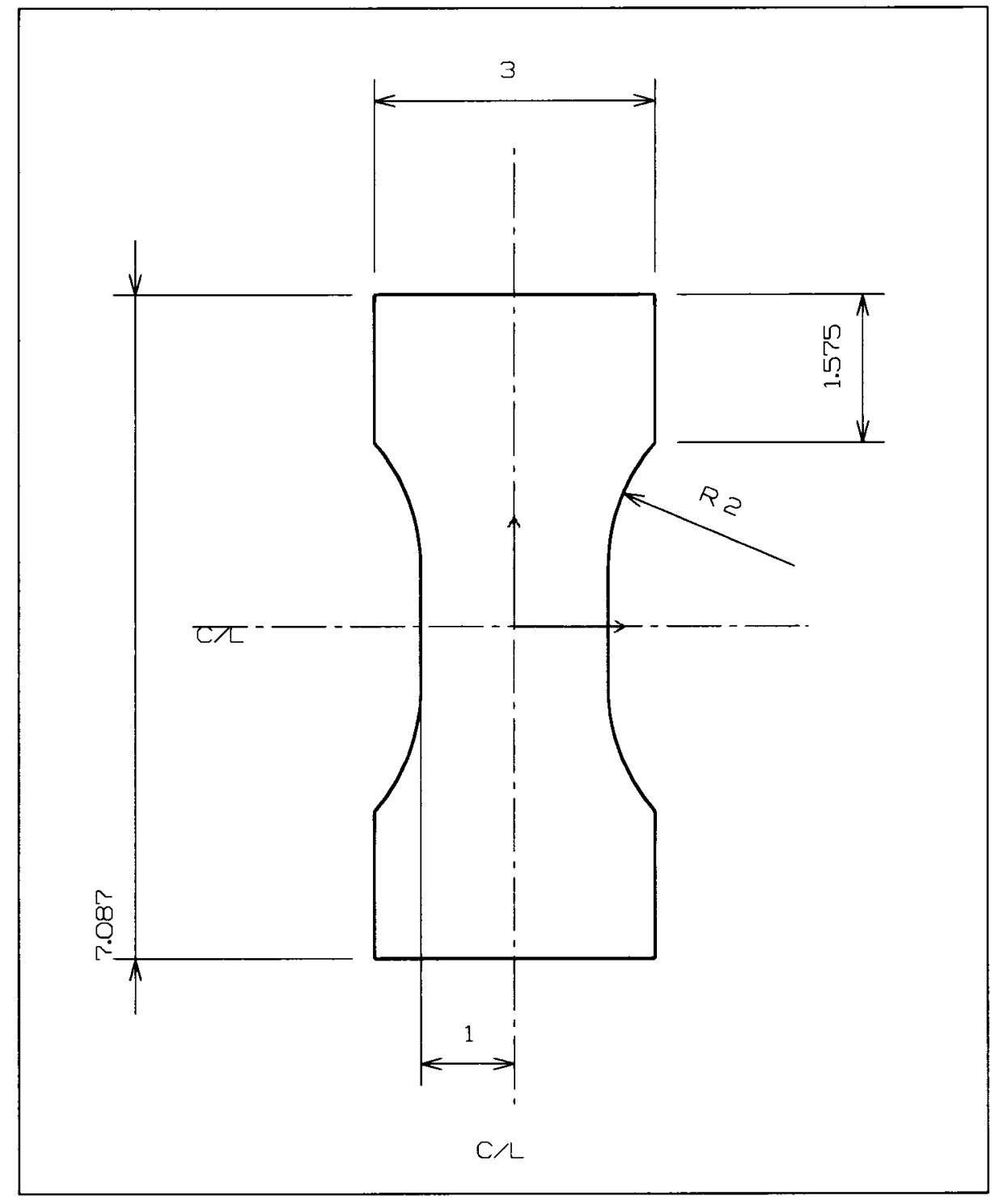

Note 1) All dimensions are inches.

2) Thickness is 0.091 in $(2.311 \mathrm{~mm})$

Fig. 3.1. 2024-T3 base material dimensions 


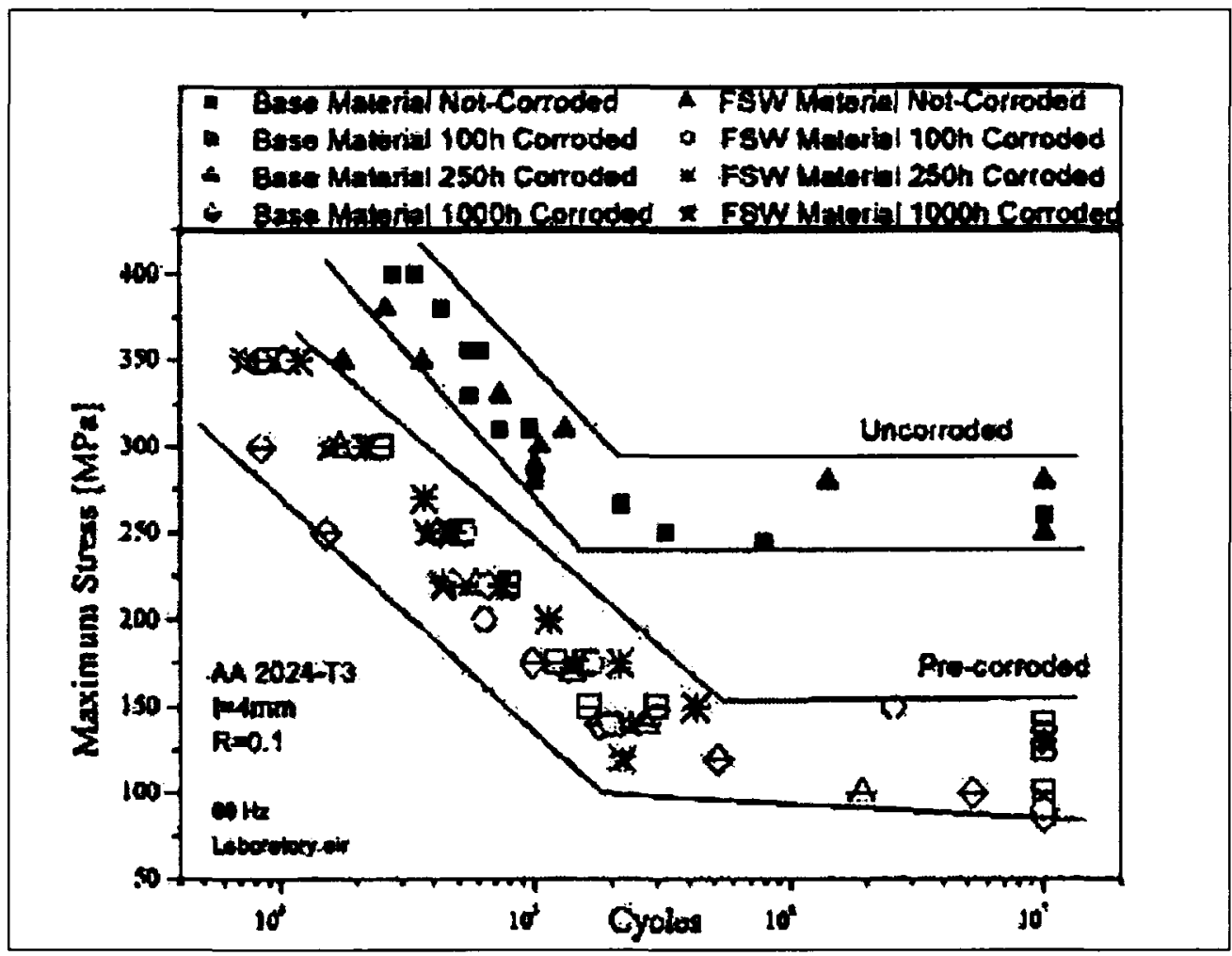

Fig. 3.2. 2024-T3 base material fatigue test with $R=0.1$, $60 \mathrm{~Hz}$, Laboratory-air (Mercado et al. 2005) 


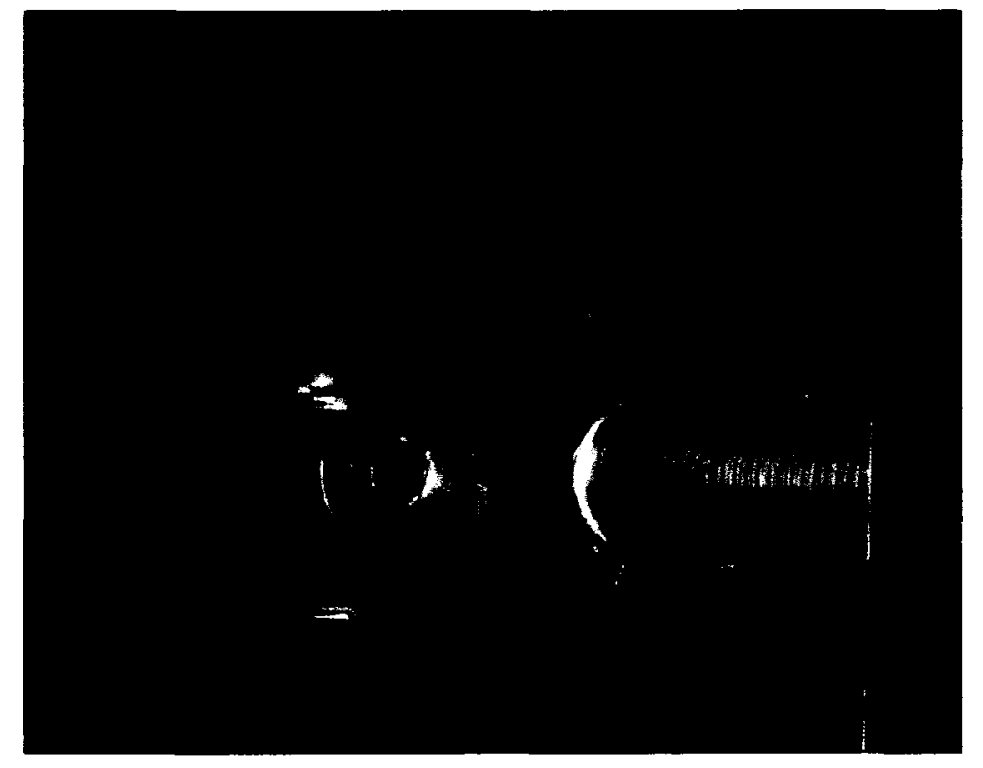

Fig. 3.3. Static tensile test Single Pass (SP) specimen

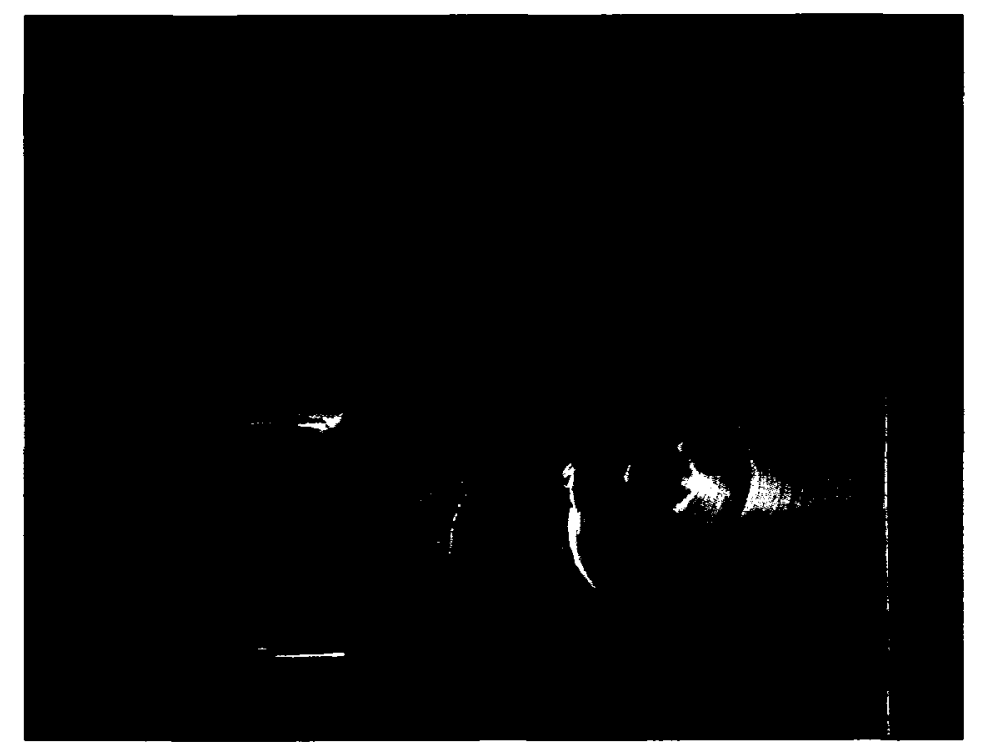

Fig. 3.4. Static tensile test Double Pass (DP) specimen (Type I) 


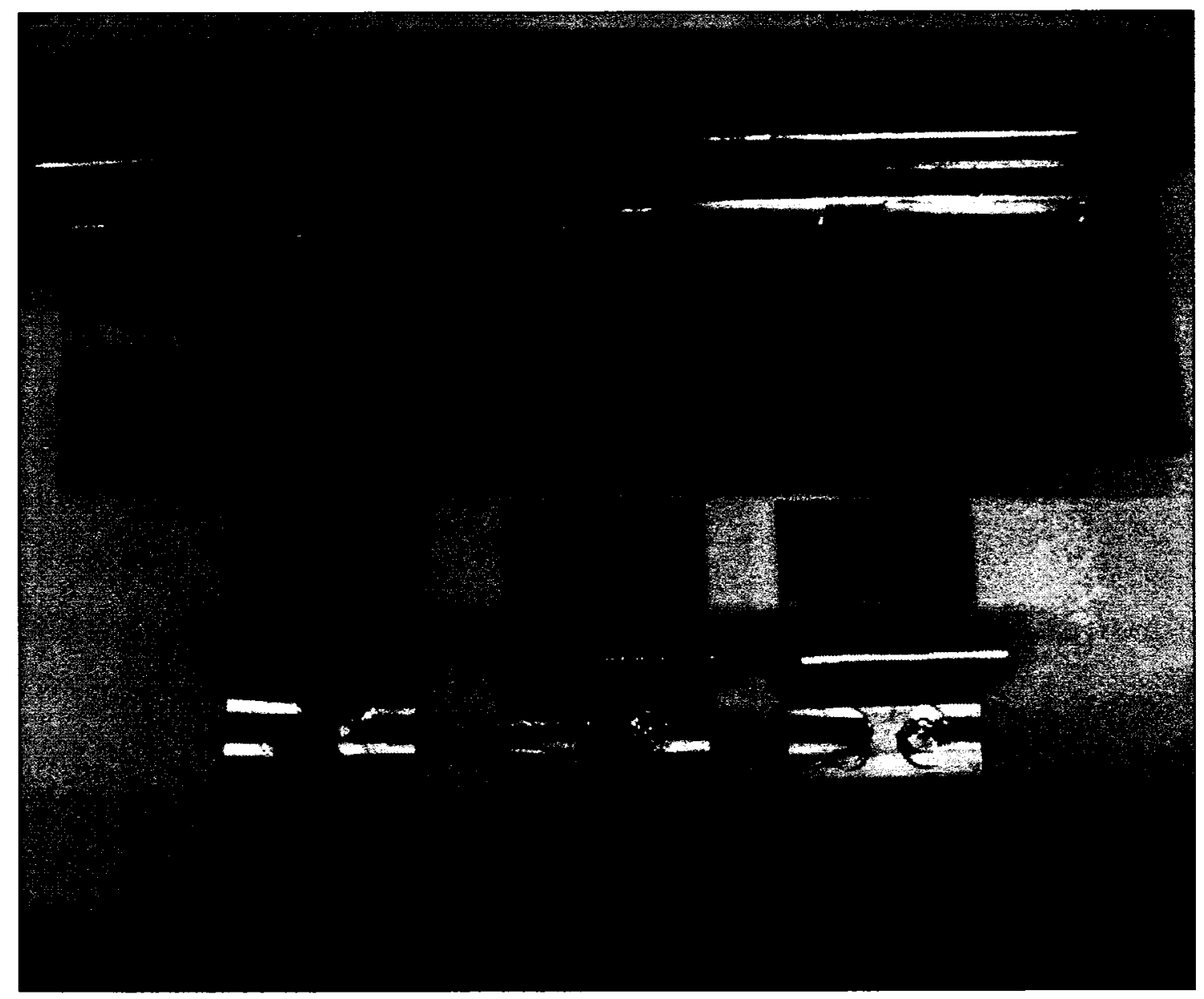

Fig. 3.5. Developing the stiffened panel structure specimens from original welded

part

(Picture from NRC-IAR (Ottawa)) 


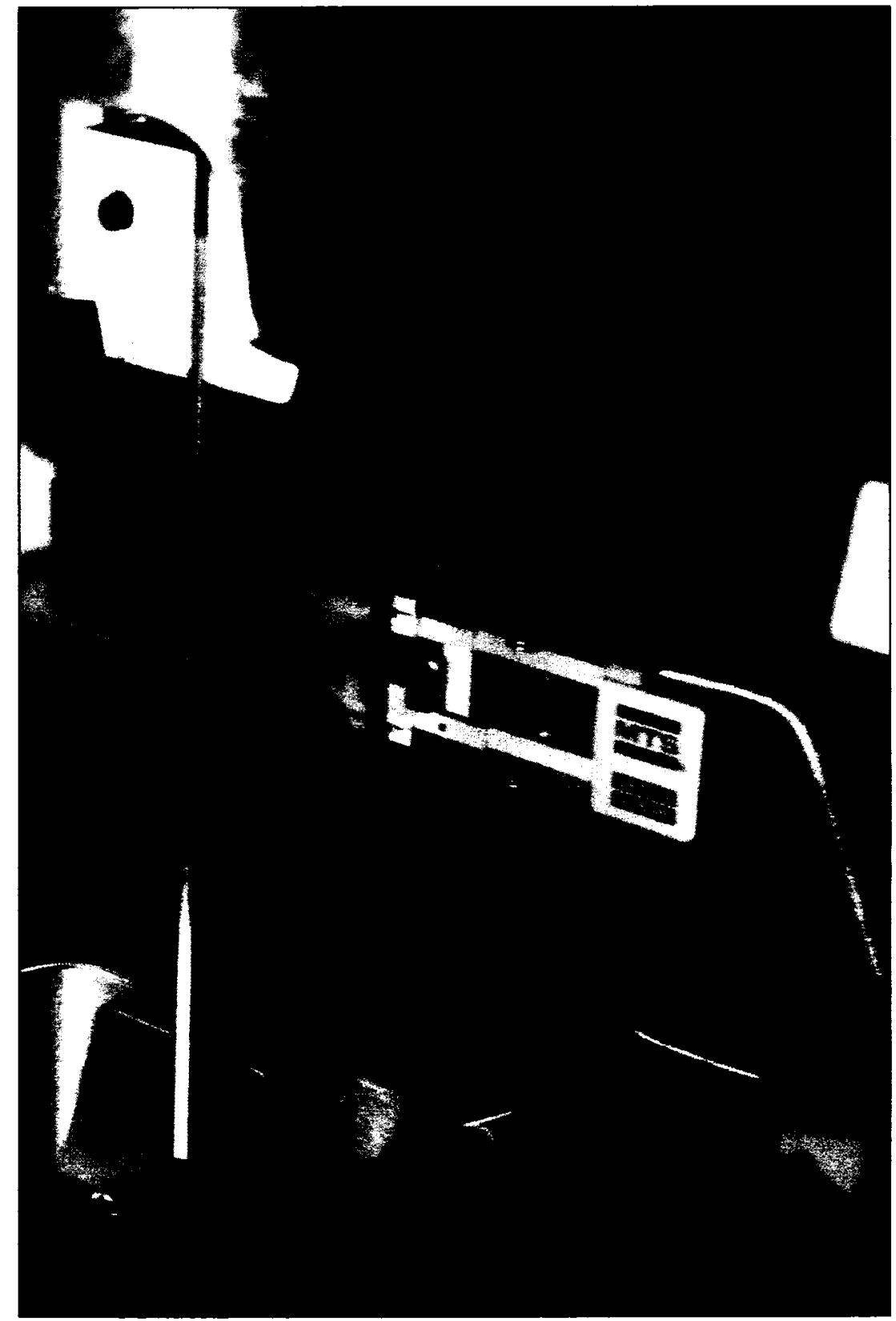

Fig. 3.6. Test specimen installed MTS 1 inch extensometer 


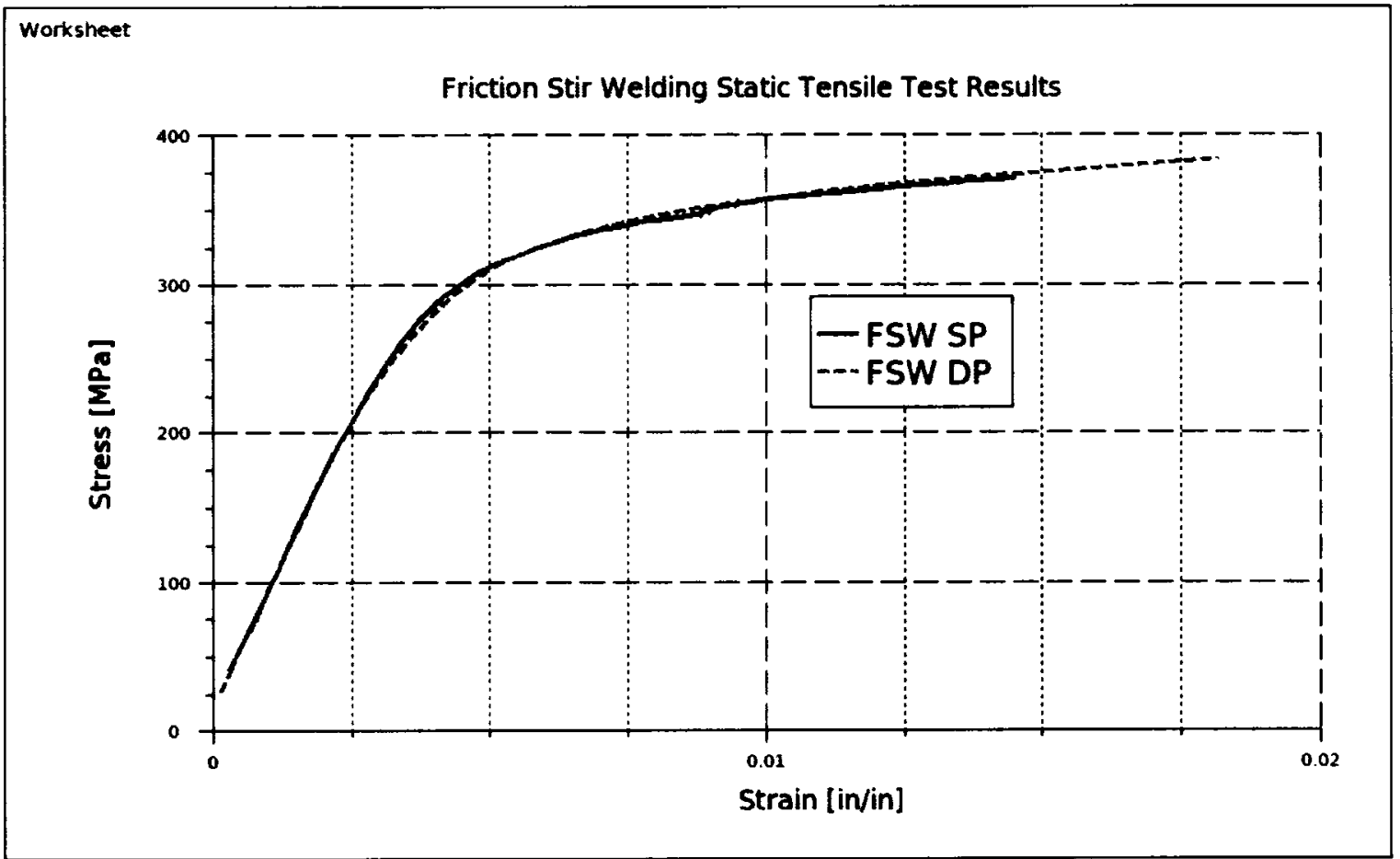

Fig. 3.7. FSW Static Tensile Test Results with SP and DP 


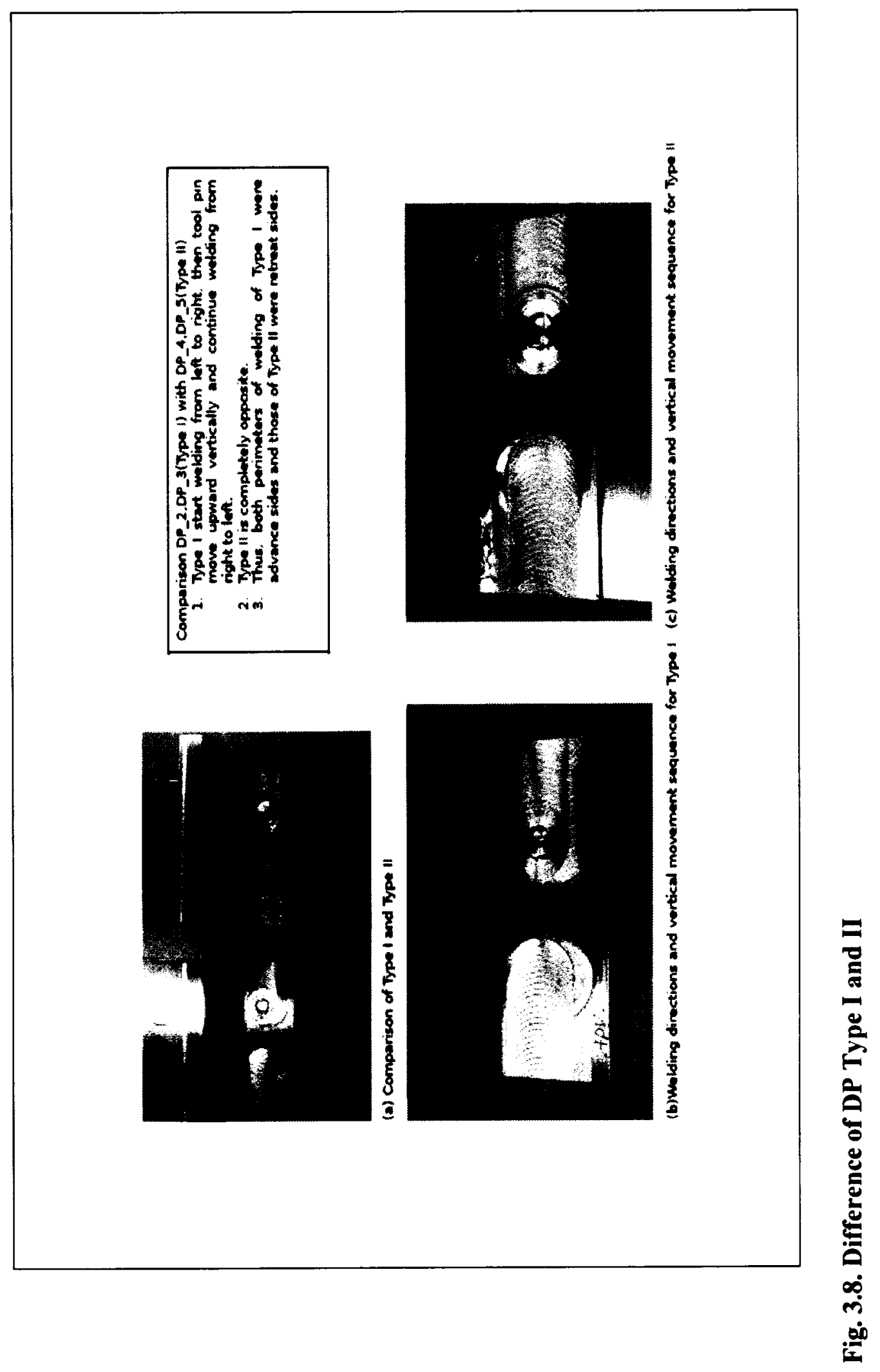

$\stackrel{\infty}{\curvearrowright}$ 


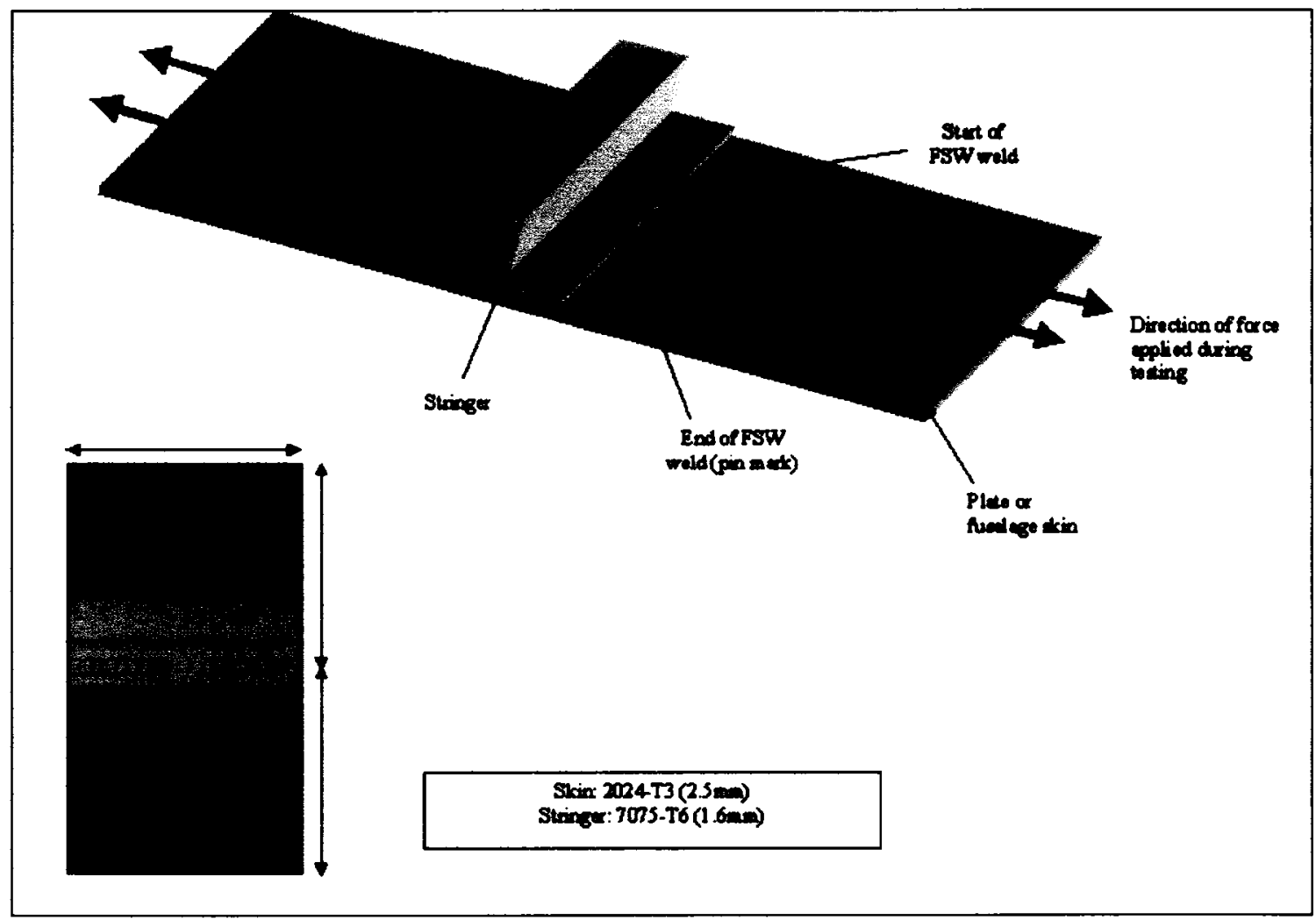

Fig. 3.9. FSW test specimen configuration layout provided by NRC-IAR (Ottawa)

The picture came from NRC-IAR (Ottawa) presentation material. 


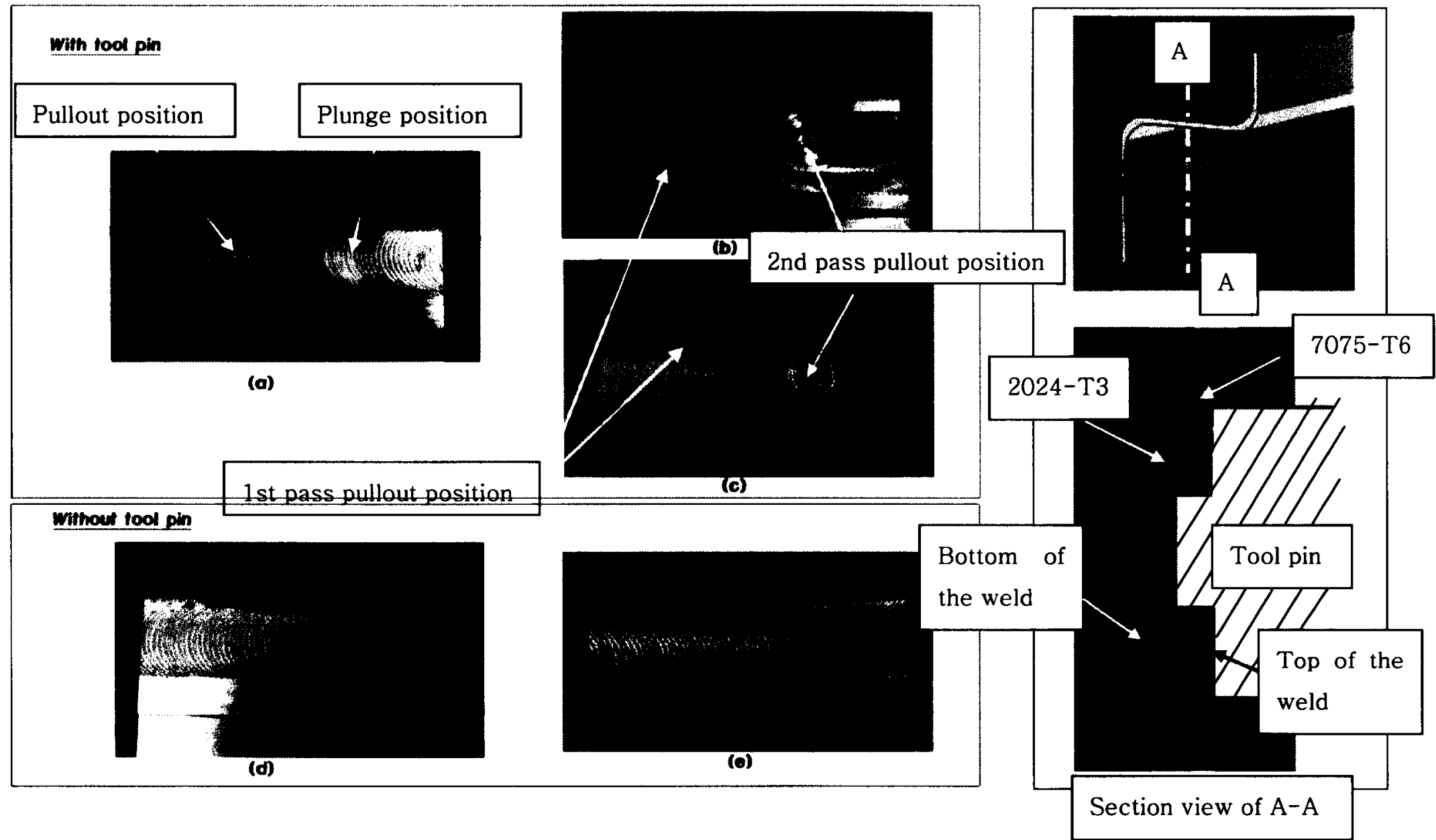

(a) Single pass with tool pin hole

(b) Double pass (Type I) with tool pin hole

(c) Double pass (Type II) with tool pin hole

(d) Single pass without tool pin hole

(e) Double pass (Type II) without tool pin hole

Fig. 3.10. The pictures of representative categorized sample 


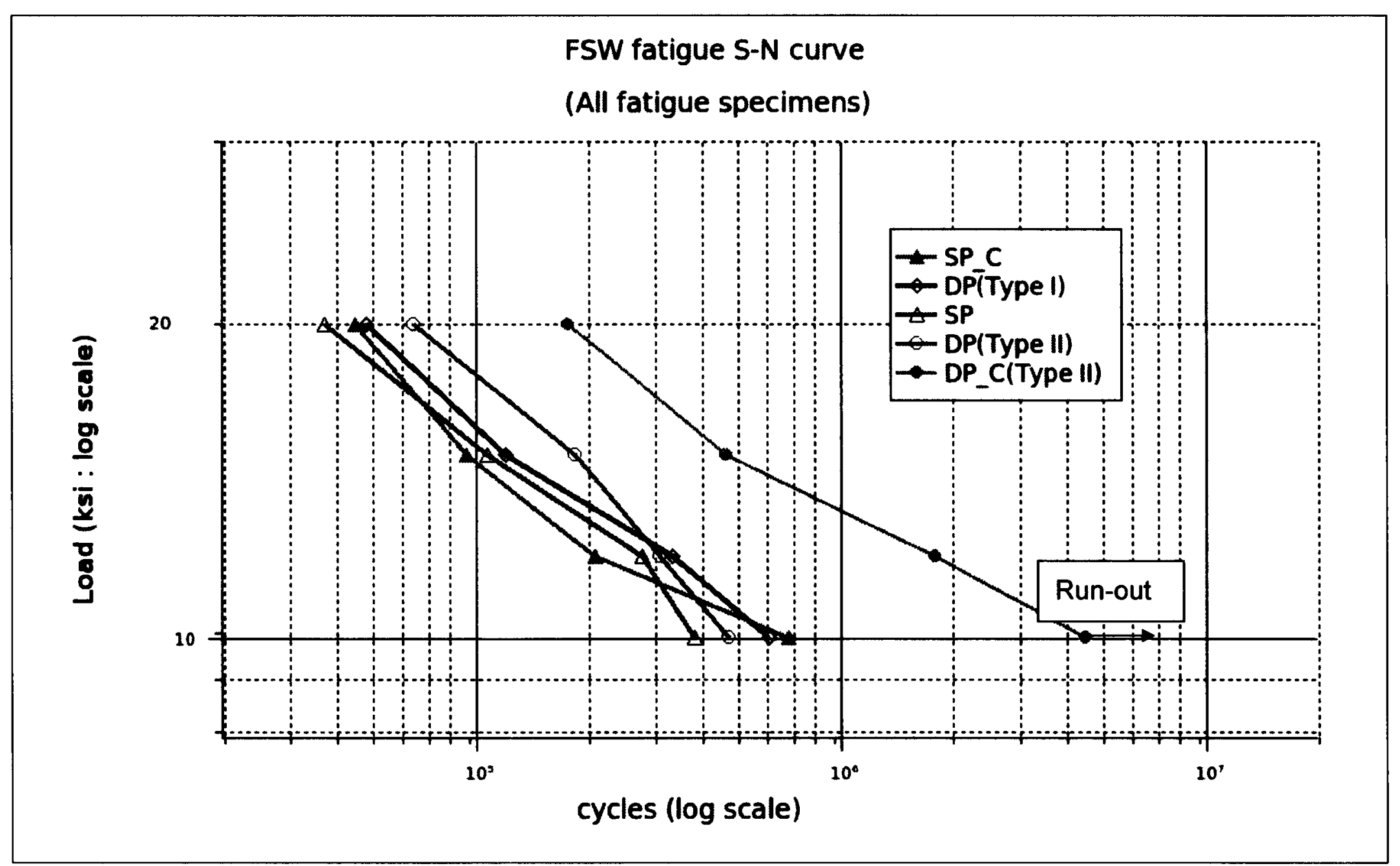

Fig. 3.11. The S-N curves for all specimens 


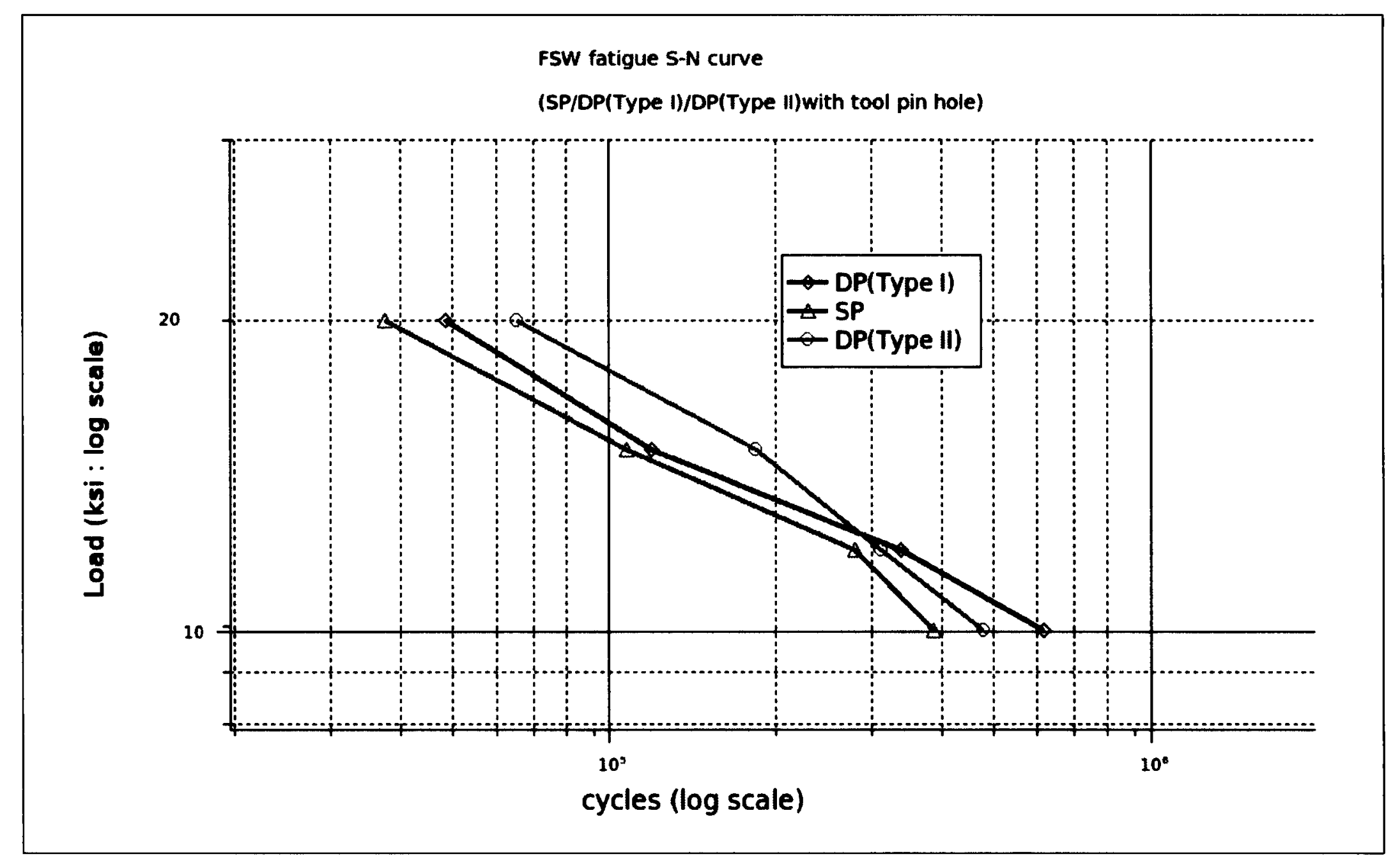

Fig. 3.12 The S-N curves for SP/DP(Type I)/DP(Type II) with tool pin hole 


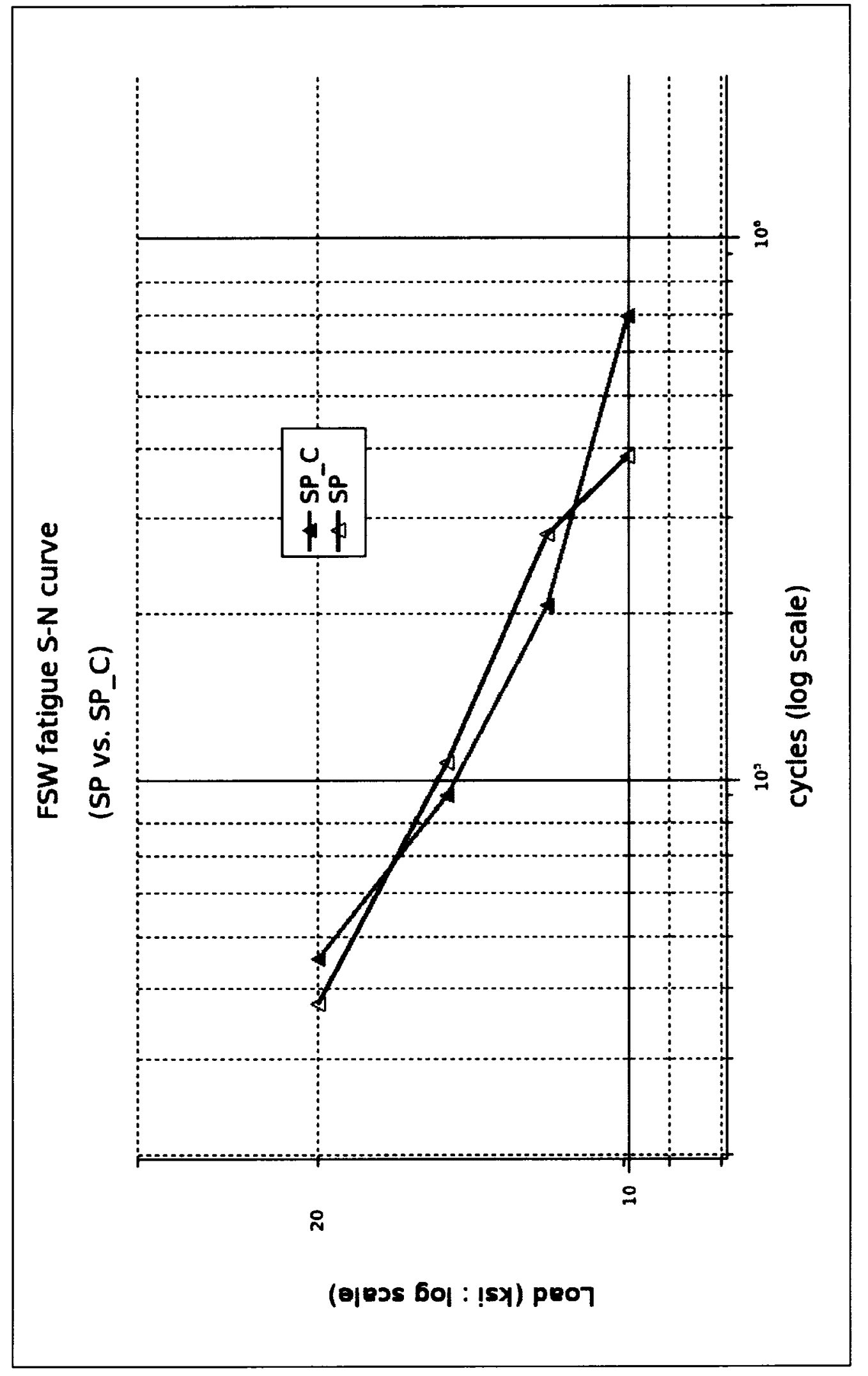

을 


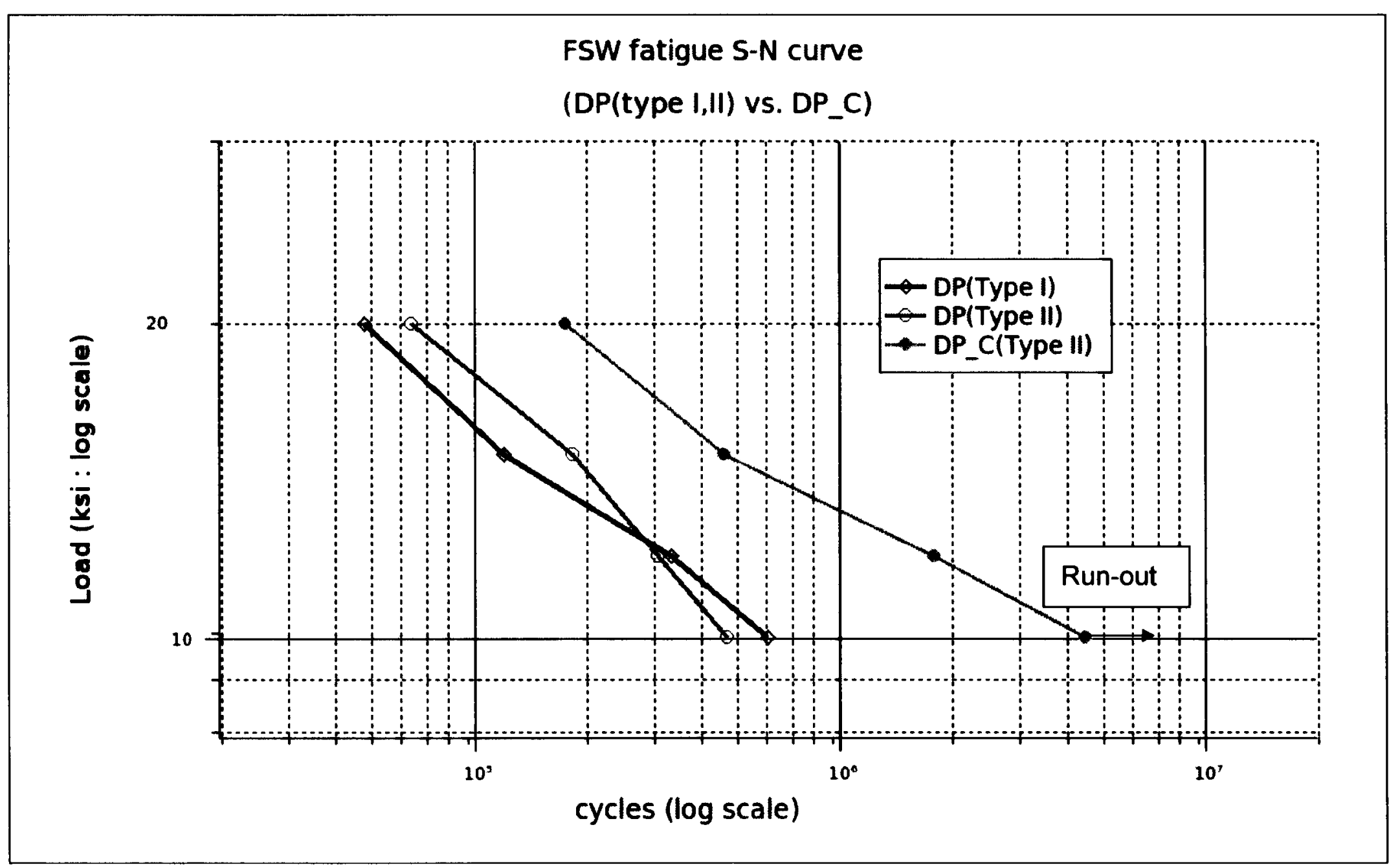

Fig. 3.14 The S-N curves for the DP(Type I,II) specimens with tool pin hole versus the DP specimens without tool pin hole 


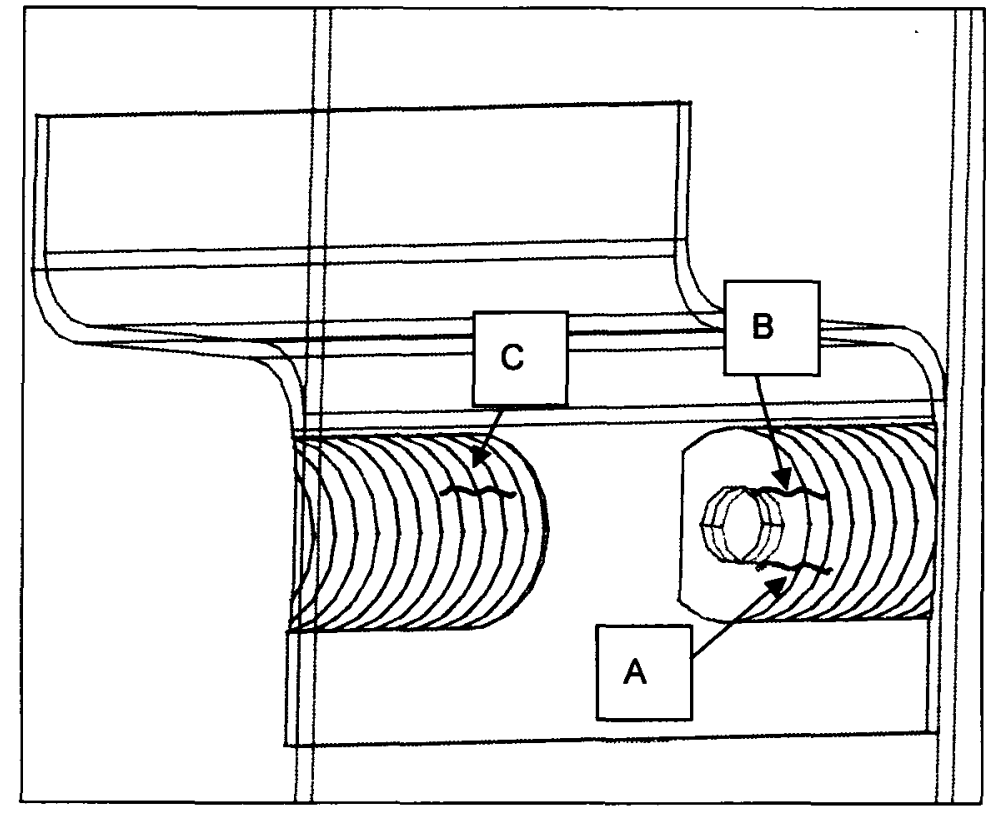

\begin{tabular}{|c|c|}
\hline Specimen Label and number & $\begin{array}{c}\text { Crack initiation } \\
\text { location }\end{array}$ \\
\hline SP_P_20(1) & A \\
\hline SP_P_15(2) & A \\
\hline SP_P_12(3) & C \\
\hline SP_P_10(4) & B \\
\hline
\end{tabular}

Fig. 3.15. Crack initiation location of Single Pass welded specimens 


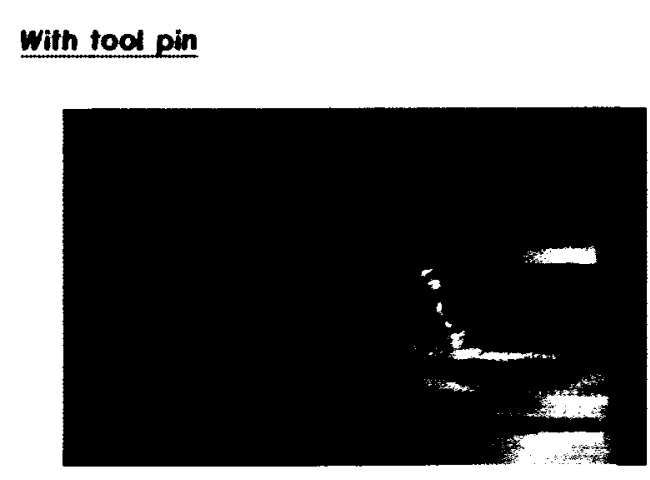

(a)

\section{Without rool pin}

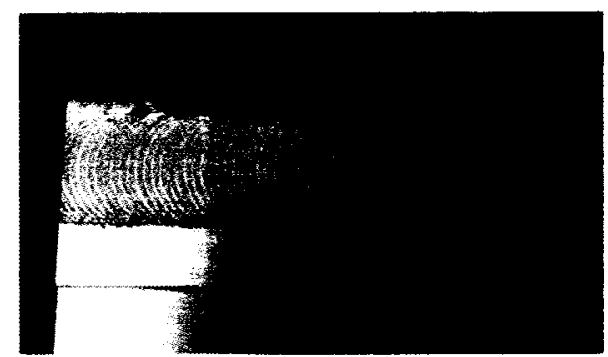

(c)

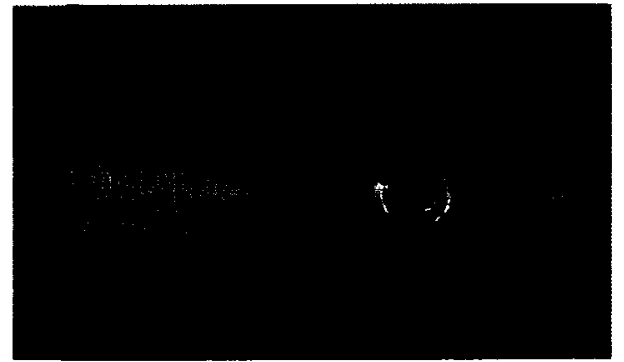

(b)

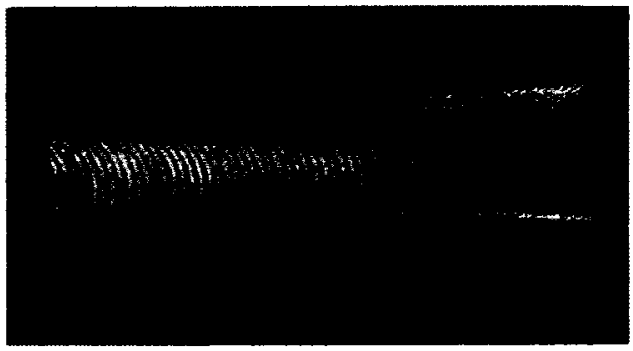

(d)

Note 1) all cracks were detected in the opposite of the red indicated crack location.

(Because the opposite 2024 base material back plate is straight plain plate, it is impossible to distinguish the location of the crack. Therefore, the red indicator means only for information of crack location)

(a) Double pass (Type I) with tool pin hole

(b) Double pass (Type II) with tool pin hole

(c) Single pass without tool pin hole

(d) Double pass (Type II) without tool pin hole

Fig. 3.16. Crack initiation place in the categorized group except single pass with tool pin hole 


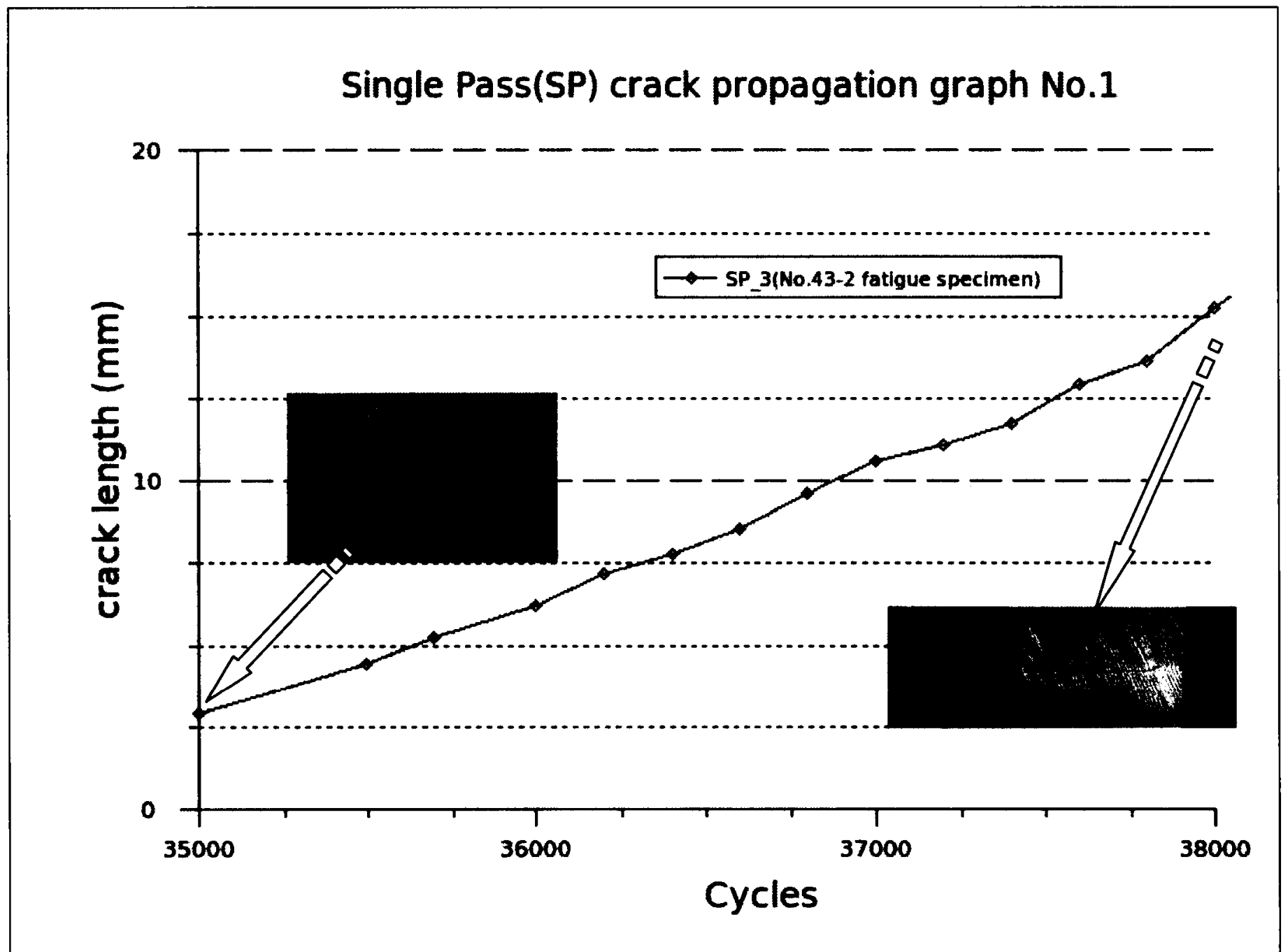

Fig. 3.17. The representative crack monitoring sample of SP 


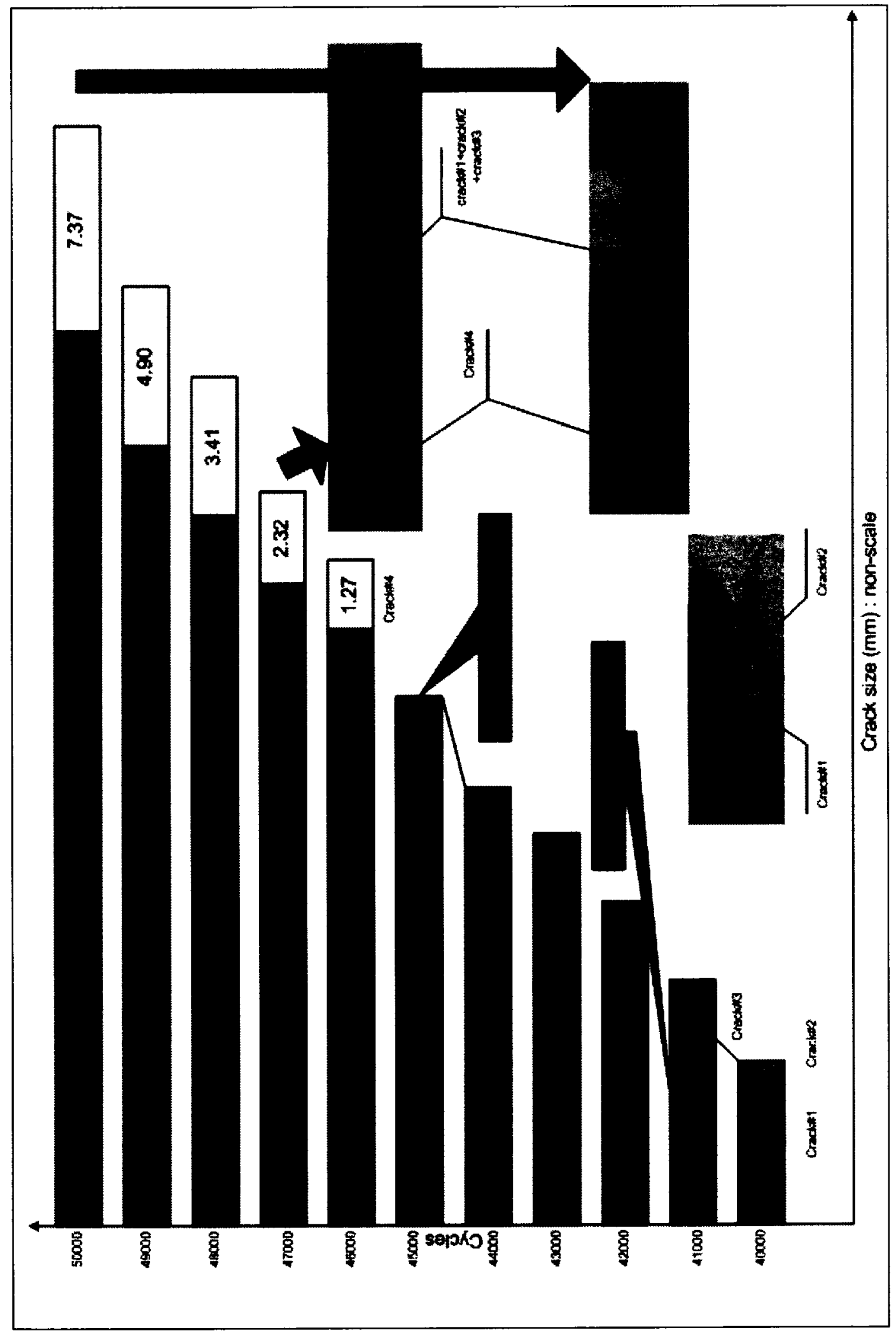

 


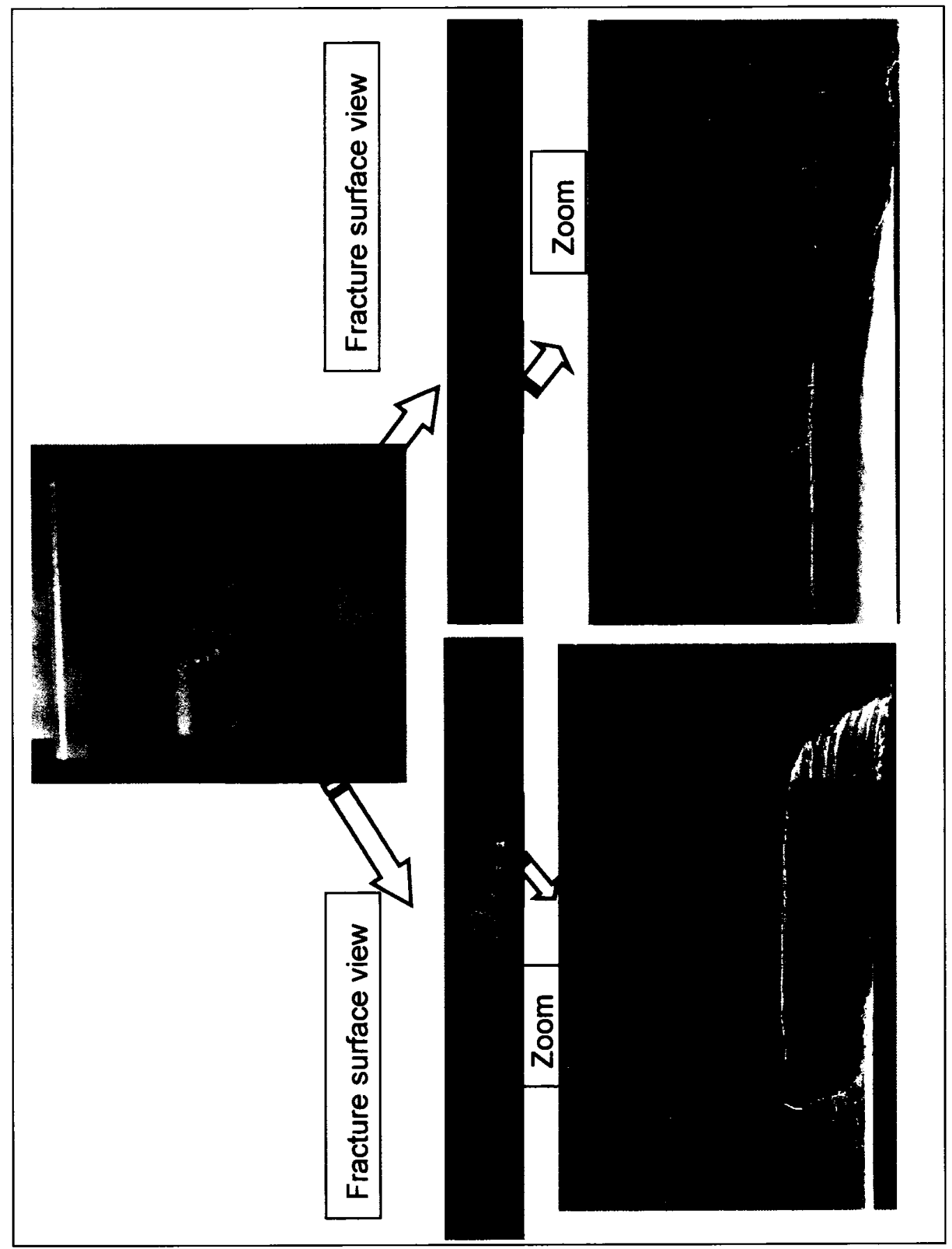

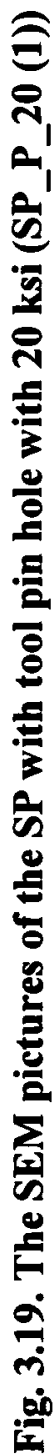




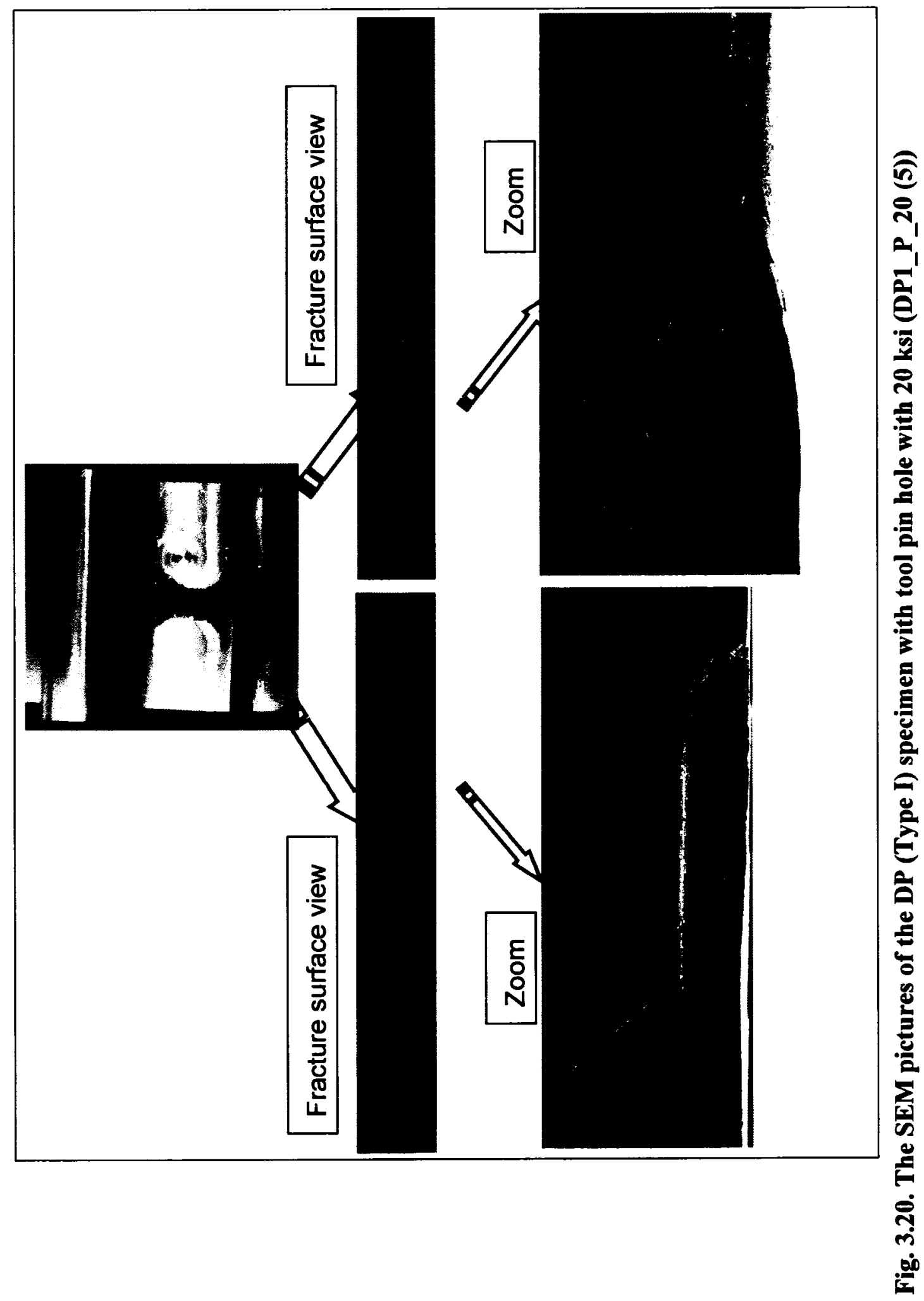




\section{CHAPTER 4}

\section{Discussion}

In this chapter, the fatigue fracture mechanism of SP and DP specimens with tool pin hole were discussed. Plus, the analyses of theses specimens were studied using SEM pictures. In the same manner, the fatigue fracture mechanism and analyses of SP and DP without tool pin hole were discussed. In addition, the fatigue crack propagation rate of the FSW specimens was compared with the 2024-T3 base material. Also, the brittleness after the FSW was investigated by comparing the fatigue crack propagation rate according to the welding method. Moreover, using metallographic analysis, the welding defects in the SP specimens indicated that some SP specimens had tool mark defects developed by tool pin and these defects may dominate the surface crack development.

\subsection{The fatigue fracture mechanism of FSW specimens}

In the first two sections, the fatigue fracture mechanisms of SP and DP specimens with tool pin hole are presented. In addition, the analysis describing this mechanism is discussed. In the following sections, the fatigue mechanism and the 
analysis of the SP and DP without tool pin hole are discussed.

\subsubsection{The fatigue fracture mechanism of the SP FSW specimens with tool pin hole.}

As mentioned at the end of 2.2.3.2, the advancing side of the weld of the SP FSW lap joint specimens is weaker than the retreating side because of the lack of mixing of two dissimilar materials (2024-T3 and 7075-T6 aluminum). This can be identified visually by the scanning electron microscopy (SEM) pictures in a SP FSW lap joint specimen. In the section view of the SEM pictures of the SP FSW specimens, the end point of the unmixed interface line of the two materials (2024-T3 and 7075-T6 aluminum) contacting the outer curve of the grey hook shape, represents that the end point and this can induce the weakness of the advancing side of the weld. The retreating side of the weld does not have such an end point.

To study the relation of the tool pin position and the end point, the graphic model developed by measuring a FSW specimen and the SEM picture of a SP specimen were overlaid in the Fig. 4.1. In the figure, the region of the mixed microstructures of 2024-T3 and 7075-T6 aluminum materials exists only nearby areas where the tool pin passed. In addition, it showed that the area under the pin shoulder did not show much mixing even with the large applied friction energy and wider area.

Therefore, the initial surface cracks for two SP fatigue test specimen (20/15 ksi ) with tool pin hole were detected in the weak end point of the advancing side of the weld near the tool pin hole. However, two other fatigue tests (12/10 ksi), as reported in the Fig. 
3.15, show that the retreating side of the tool pin pullout position of the weld for the 10 ksi specimen or the tool pin plunge position of the weld of the $12 \mathrm{ksi}$ specimen can also be the crack initiators. This may imply that porosities, welding defects, the kissing bond (explained in section 2.1.6), or the local overheat position near the tool pin pullout or the tool pin plunge position can induce the surface cracks earlier than the weak end point in the advancing side of the weld.

\subsubsection{The fatigue fracture mechanism of the DP FSW specimens with tool pin hole}

The initial surface cracks of the DP FSW specimens with tool pin hole detected two different locations according to their welding types. DP(Type I) specimens had initial surface cracks in the lower part of the $1^{\text {st }}$ tool pin pullout position while DP(Type II) specimens had cracks in the upper part of the $1^{\text {st }}$ tool pin pullout position as depicted in the Fig. 3.16. The microscopic section views of DP (Type I) specimens show that DP (Type I) specimens have two weak end points generated by FSW. The first weak point was developed by the first welding pass, already explained in the SP specimen. The second weak point was developed by the second welding pass. However, the shape of the section view is the opposite image of the first welding pass since the welding direction was changed. So, DP (Type I) specimens have the same weak end point in the both advancing sides as shown in Fig. 4.2.

In the case of DP (Type II) specimens, there is no weak end point because the both perimeters of the weld are the retreating sides due to the changing of welding 
sequences. Therefore, the advancing side of the weld in the DP (Type II) exists as a mixed zone of two individual advancing sides in the middle of two welds as can be seen in the Fig. 4.2. Thus, all initial surface cracks were detected in the upper part of the $1^{\text {st }}$ tool pin pullout position of the mixed advancing side of the weld. The microscopic pictures of DP (Type I, II) specimens can clarify the difference of two types of DP FSW specimens Fig. 4.2.

\subsubsection{The analysis of the fatigue behavior of the SP and DP FSW specimens with tool pin hole}

Upon microscopic analysis, it was found that all SP and DP FSW specimens with tool pin hole had two crack initiators. These cracks occurred in the tool pin pullout and plunge position of SP specimens and in the $1^{\text {st }}$ and $2^{\text {nd }}$ tool pin pullout position of DP specimens. However, the development of the crack initiators in the SP specimens varied since the welding defects, porosities, kissing bond, or the local overheat had an effect on the development of the cracks. Thus, the initial surface cracks were detected in a few different positions in one SP specimen. For instance, one crack was detected in the upper part of the welding plunge position while one crack was detected in the lower and the other for the upper part of the welding pullout position respectively.

Also, the $1^{\text {st }}$ and $2^{\text {nd }}$ tool pin pullout positions in the DP specimens were the crack initiators and developed into the surface cracks. Though both tool pin pullout holes could be possible crack initiators, all surface cracks in DP specimens started near the $1^{\text {st }}$ tool pin pullout position. That might result from the fact that the $1^{\text {st }}$ tool pin pullout 
position could not be removed completely by the second welding pass and the remaining defect of the $1^{\text {st }}$ tool pin pullout hole acted as crack initiator. In contrast, the $2^{\text {nd }}$ tool pin pullout hole was created on the reinforced $1^{\text {st }}$ welded area and this resulted in this hole having hole better fatigue life than that of the $1^{\text {st }}$ tool pin pullout hole. Therefore, the crack growth in the $1^{\text {st }}$ tool pin pullout hole was faster than that in the $2^{\text {nd }}$ tool pin pullout hole.

To summarize, the tool pin pullout and plunge positions of SP and DP (Type I, II) with tool pin hole are the crack initiation positions because of the porosities, welding detects, kissing bond, or local overheat. In addition, the crack initiators of the $1^{\text {st }}$ tool pin pullout position in the DP (Type I,II) specimens dominates the surface crack growth but the increase of welding area by DP can contribute to the resistance for the fatigue damage.

\subsubsection{The fatigue fracture mechanism of the SP and DP FSW specimens without tool pin hole}

All SP and DP specimens without tool pin hole started their initial surface cracks in the center of the specimens. The initial surface cracks propagated to the both side ends of the specimen. When the specimen could not endure the increased stress due to the reduction of effective loading area, it was broken before the crack reached the sides. However, the initial surface crack location is different for SP specimen and DP specimens. The initial surface crack of the SP specimens were detected in the lower part of the trace of welding tool pin in the advancing side of the weld, and that of the DP (type II) specimens were detected in the two mixed advancing sides. The detail location was 
described in Fig. 3.16 (c), (d).

\subsubsection{The analysis of the fatigue behavior of the SP and DP FSW specimens without tool pin hole}

As explained in the previous section, the initial surface cracks of SP were initiated from the weak end point in the advancing side of the weld and those of DP (type II) specimens were also created from the weak point of two mixed advancing sides. However, the fatigue life of DP (Type II) specimens was much better than that of SP specimens because of the increase of welding area by DP welding. In addition, the fracture section view of the SP specimens showed repeated tool mark defects developed by the tool pin while that of the DP specimens did not show those defects, which was most likely removed by the second weld pass Fig. 4.3. Therefore, the fatigue lives of DP (Type II) specimens were much better than that of SP specimens.

\subsection{The fatigue crack propagation rate of the FSW specimens}

Because it is impossible to remove all possibility of fatigue cracks, the damage tolerance concept was devised to assure the airframe structure can complete its mission when cracks develop during inspection intervals. Therefore, all parts in the airframe structure should fulfill the requirement of the damage tolerance standard.

One simple way to compare the damage tolerance characteristics can be the comparison of the crack propagation rate of the specimens. Thus, the fatigue crack 
propagation rate between the FSW specimens and 2024-T3 base material was compared by the surface crack propagation length per cycle.

\subsubsection{The fatigue crack propagation rate comparison between 2024-T3 base material and FSW specimens.}

The crack propagation rate data of the FSW specimens were already mentioned in the Table 3.7. To compare the fatigue crack propagation rate between 2024-T3 base material and FSW specimens, two simple surface crack propagation tests for 2024-T3 base material with an initial intentional crack were carried out at 20 and $15 \mathrm{ksi}$. The profile of the test specimen is the same as the static test specimen in Fig. 3.1 except an initial intentional crack.

The first test obtained the fatigue crack propagation rate of $2.30 \times 10^{-5} \mathrm{inch} / \mathrm{cycle}$ for $20 \mathrm{ksi}$ in the same conditions as the FSW fatigue test. However, the 2024-T3 specimen for $15 \mathrm{ksi}$ with an initial intentional crack did not break at all over 3,500,000 cycles due to low maximum applied load. Nevertheless, the fatigue crack propagation rate of 2024-T3 base material for $20 \mathrm{ksi}$ showed that it is the slowest crack propagation rate among the other $20 \mathrm{ksi}$ FSW specimens. Thus, it is assumed that the FSW specimens have a faster fatigue crack propagation rate than 2024-T3 base material because of the welding (FSW). 


\subsubsection{The fatigue crack propagation rate comparison according to the existence of tool pin hole}

Except for two DP FSW specimens [DP2_C_12(19) and DP2_C_10(20) - run out case] without tool pin hole, most SP and DP specimens without tool pin hole showed much faster crack propagation rate than SP and DP specimens with tool pin hole. This might depend on the brittleness after the FSW welding. Also, the one third unwelded area of the SP and DP specimen with tool pin hole might contribute to the resistance for the crack propagation. However, the fatigue crack propagation rate of SP without tool pin hole tested at 20 and $15 \mathrm{ksi}$ [SP_C_20 (13) and SP_C_15 (14)] is much faster than other specimens. Also, the fatigue crack propagation rate of DP without tool pin hole tested at 20 and $15 \mathrm{ksi}$ [DP2_C_20 (17) and DP2_C_15 (18)] is at least twice as fast as other specimens with tool pin hole respectively. So, it is possible to assume that this may come from the brittleness of the FSW process.

Therefore, further study for preventing the catastrophic failure by the brittleness of FSW should be considered in the near future.

\subsection{The metallographic analysis of FSW fatigue test specimens}

In section 3.3.5.4, the SEM pictures of the FSW fatigue test specimens revealed the surface crack initiations with or without tool pin hole. When the size of cracks initiated was over a certain size, the crack started to propagate faster than before. If the propagated crack becomes a critical size, the cracked specimen could no longer carry the load and it failed. Though most fracture surface of FSW specimens showed excellent 
welding quality, the defects after welding brought about the weakness of the overall strength. A SEM picture of the SP specimen with tool pin hole [SP_P_12 (3)] and a SEM picture among 4 SP specimens without tool pin hole [SP_C_20 (13) SP_C_10 (16)] in the Fig. 4.4 represented the defects by the tool pin. Thus, these defects in [SP_P_12 (3) and SP_P_10 (4)] may lead to the development of an unexpected initial surface crack location (Fig. 3.15) and these defects in [SP_C_20 (13) SP_C_10 (16)] may make a significant contribution to decide the fatigue lives of the SP specimens without tool pin hole to having similar fatigue lives (Fig. 3.13).

In contrast, the SEM pictures of DP (Type I and II) specimens with and without tool pin hole did not show the same welding defects as were present in the SP specimens. The representative SEM pictures of DP (Type I) specimen with tool pin hole [DP1_P_20 (5)] were already shown in the Fig. 3.20. So, the SEM pictures of DP (Type II) specimen with tool pin hole [DP2_P_10(12)] and DP without tool pin hole [DP2_C_20(17)] were illustrated in the Fig. 4.5 and Fig. 4.6 respectively.

\subsection{Summary}

To summarize, the FSW is an advanced joining technology, which has a high potential to replace the rivets in airframe structures, due to its simplicity, cost effectiveness, environmental friendliness, and so on. Though the FSW butt welding showed an excellent static tensile strength and fatigue characteristics in the literature, the fatigue characteristics of FSW stiffened panel structure lap joints have not developed enough to make it a viable replacement for riveted lap joints. Thus, in this study, the 
fatigue tests of the 5 categorized FSW stiffened panel structure specimens according to the welding type were carried out. Also, the fatigue crack initiation and propagation mechanisms were proposed using SEM pictures and the graphic model developed by measuring the specimen.

The DP (Type II) specimens without tool pin hole showed outstanding fatigue lives since they did not include the tool pin hole which was a major factor to developing a crack initiation. In addition, the increased welding area by DP (double pass) could improve the physical fatigue resistance and the second pass of DP specimen could contribute to reduce the microstructure defects which were frequently detected in the SP specimens.

The SP specimens with and without tool pin hole showed that they had a high possibility of initial defects which developed during the process of FSW. Therefore, these defects worked as crack initiations and reduced the fatigue lives of SP specimens. Though the tensile strength of SP specimen in the static strength test was similar to that of DP (Type I) specimen, the fatigue life of SP specimens was shorter than that of DP specimens since the welding area of SP specimens is smaller than that of DP specimens.

The two different types of DP (Type I, II) specimens with tool pin hole showed a similar result regarding the fatigue life since the crack initiation developed first in the $1^{\text {st }}$ tool pin pullout. Also, a crack developed much later at the $2^{\text {nd }}$ tool pin pullout position or in some cases was not detected. However, the tensile strength of DP(Type II) specimen is better than that of DP(Type I) specimen since the micro structural constitution of 
DP(Type I) specimen is weaker than that of DP(Type II) specimen due to the weak end point of the advancing sides of both perimeters in DP(Type I) specimen (Fig. 4.2). 


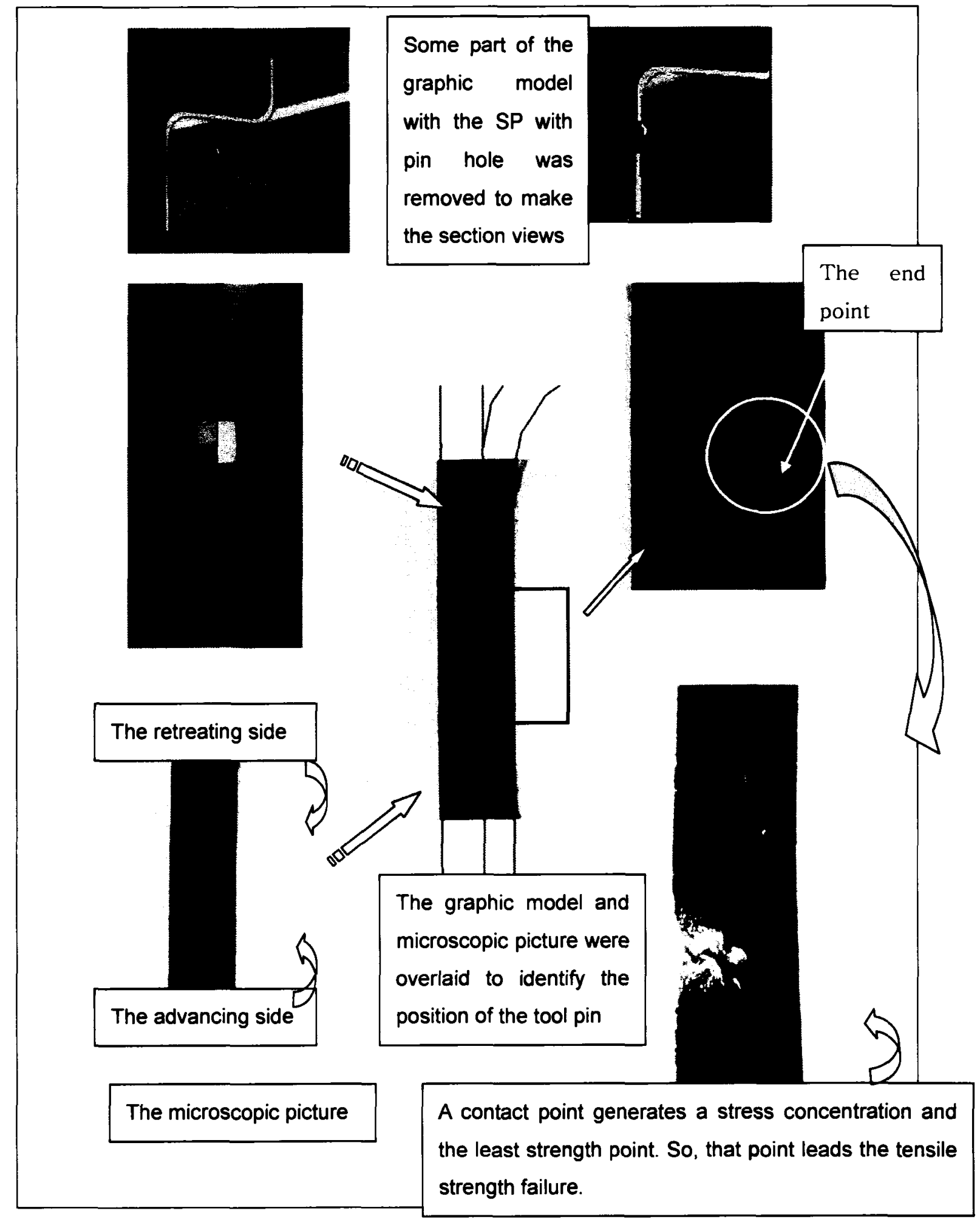

Note 1) microscopic pictures was provided by NRC-IAR (Ottawa)

2) Since the graphic model was made by measured data, some detail dimensions do not match exactly.

Fig. 4.1. The overlaid schematic of the graphic model and SEM picture for the SP specimen 


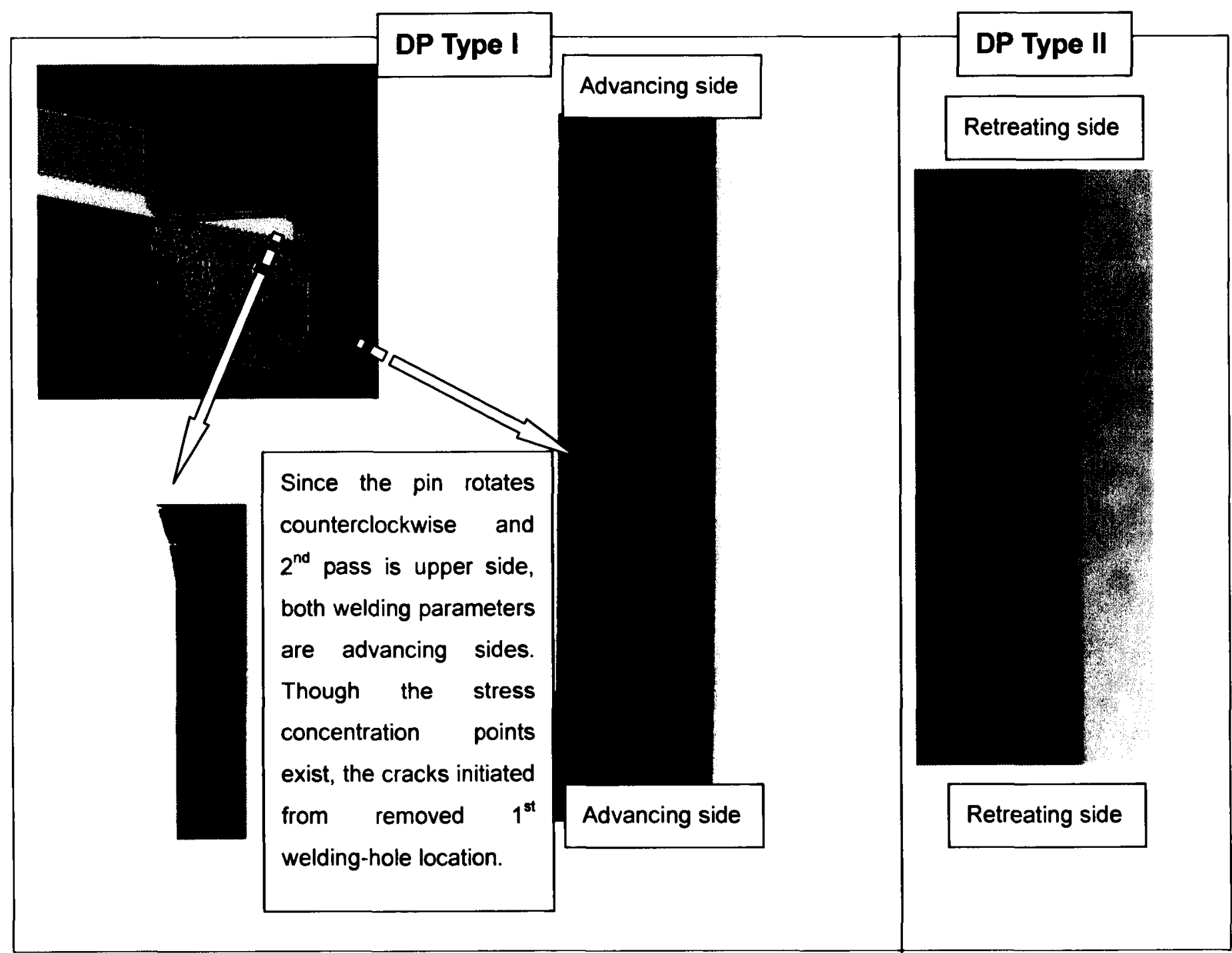

Fig. 4.2. The SEM pictures of DP I and DP II 


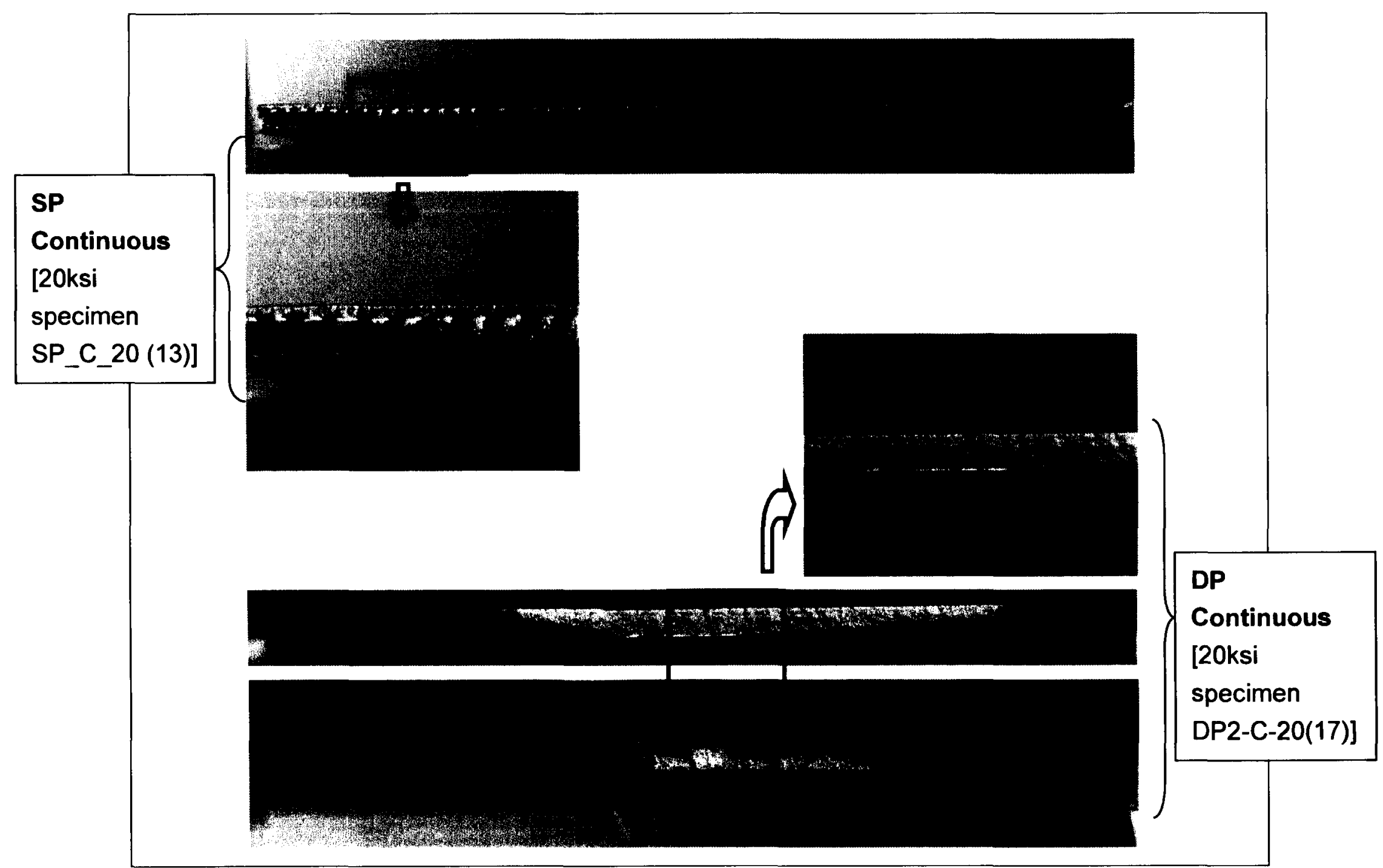

Fig. 4.3. The fracture section view of SP and DP 


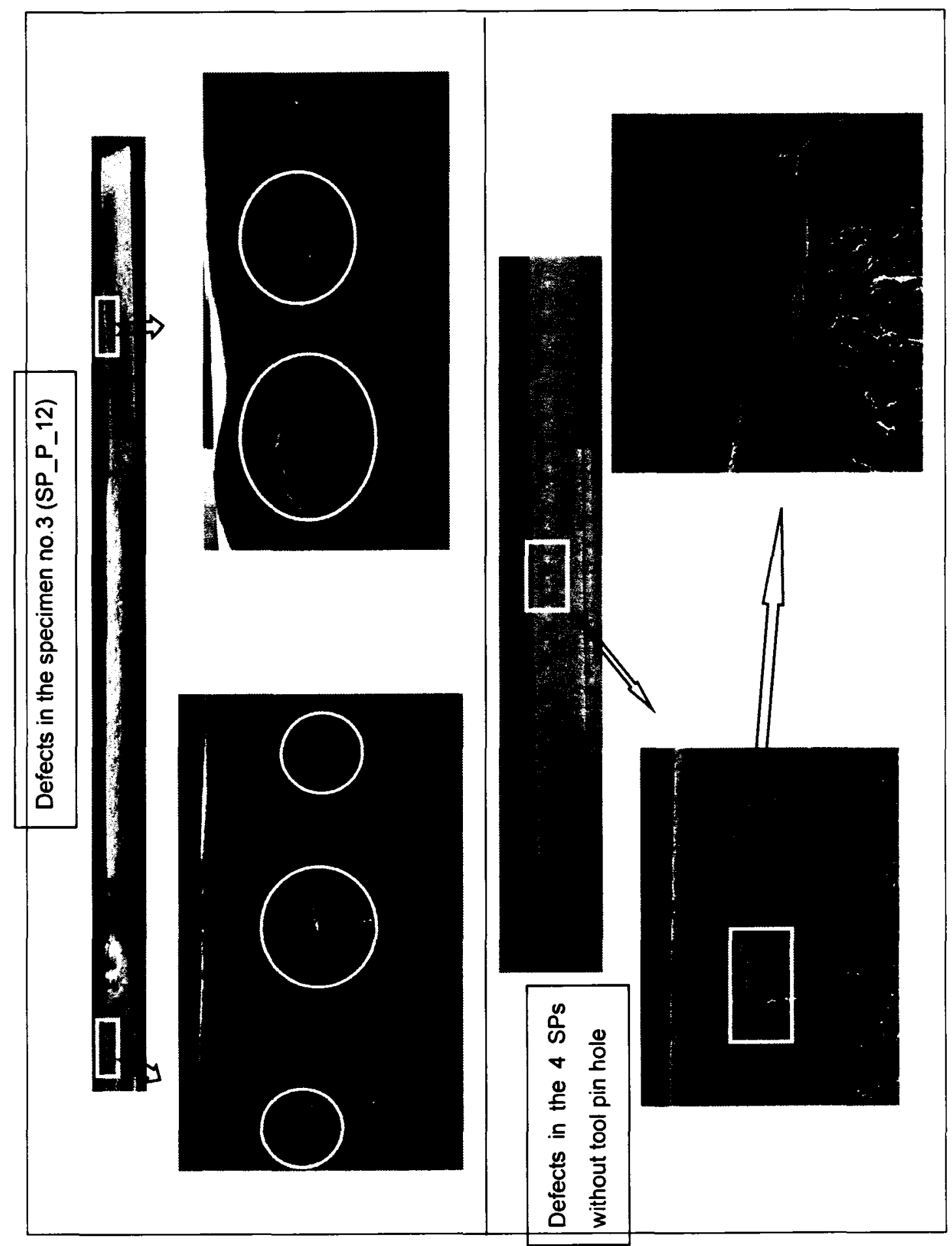




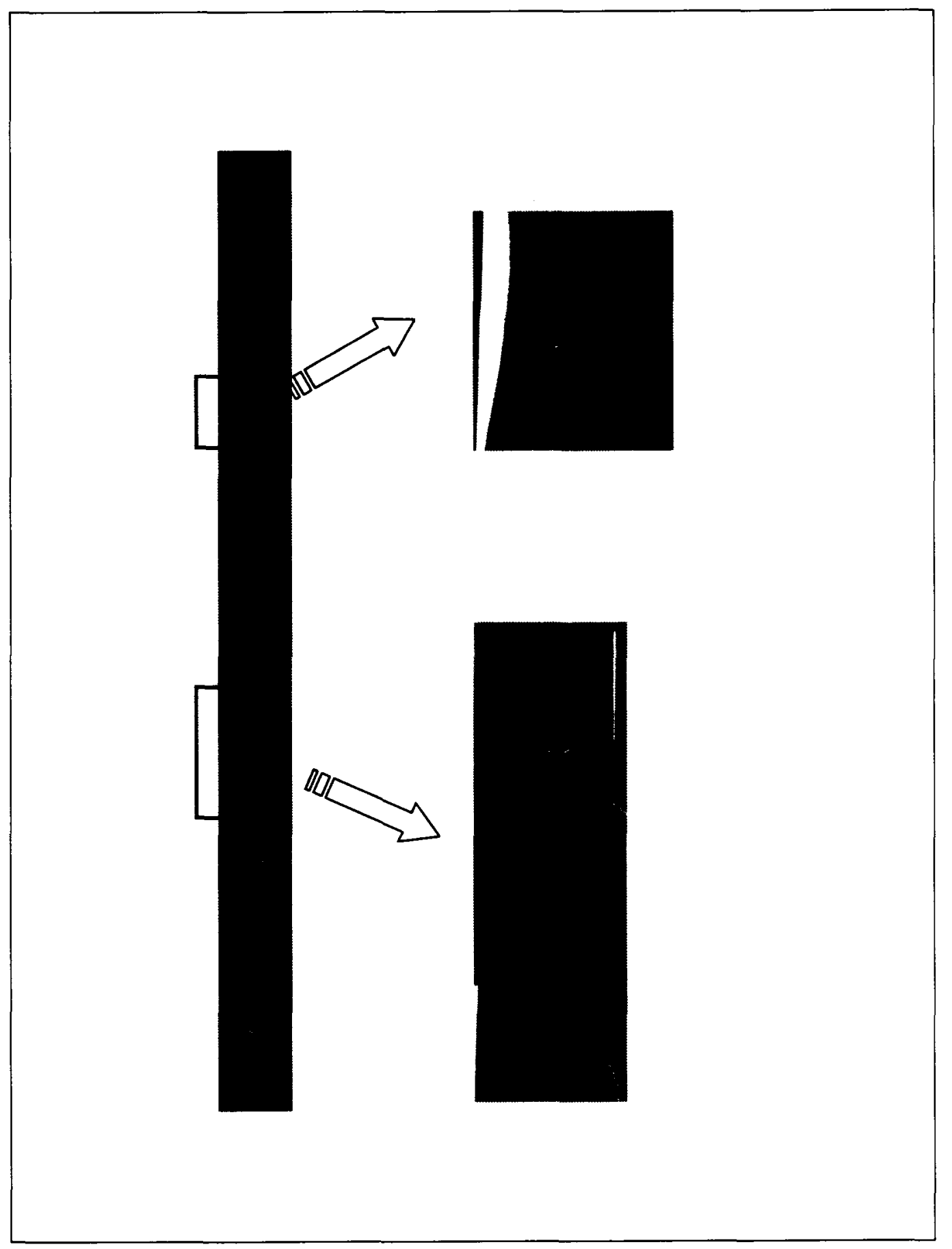

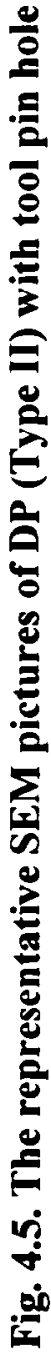




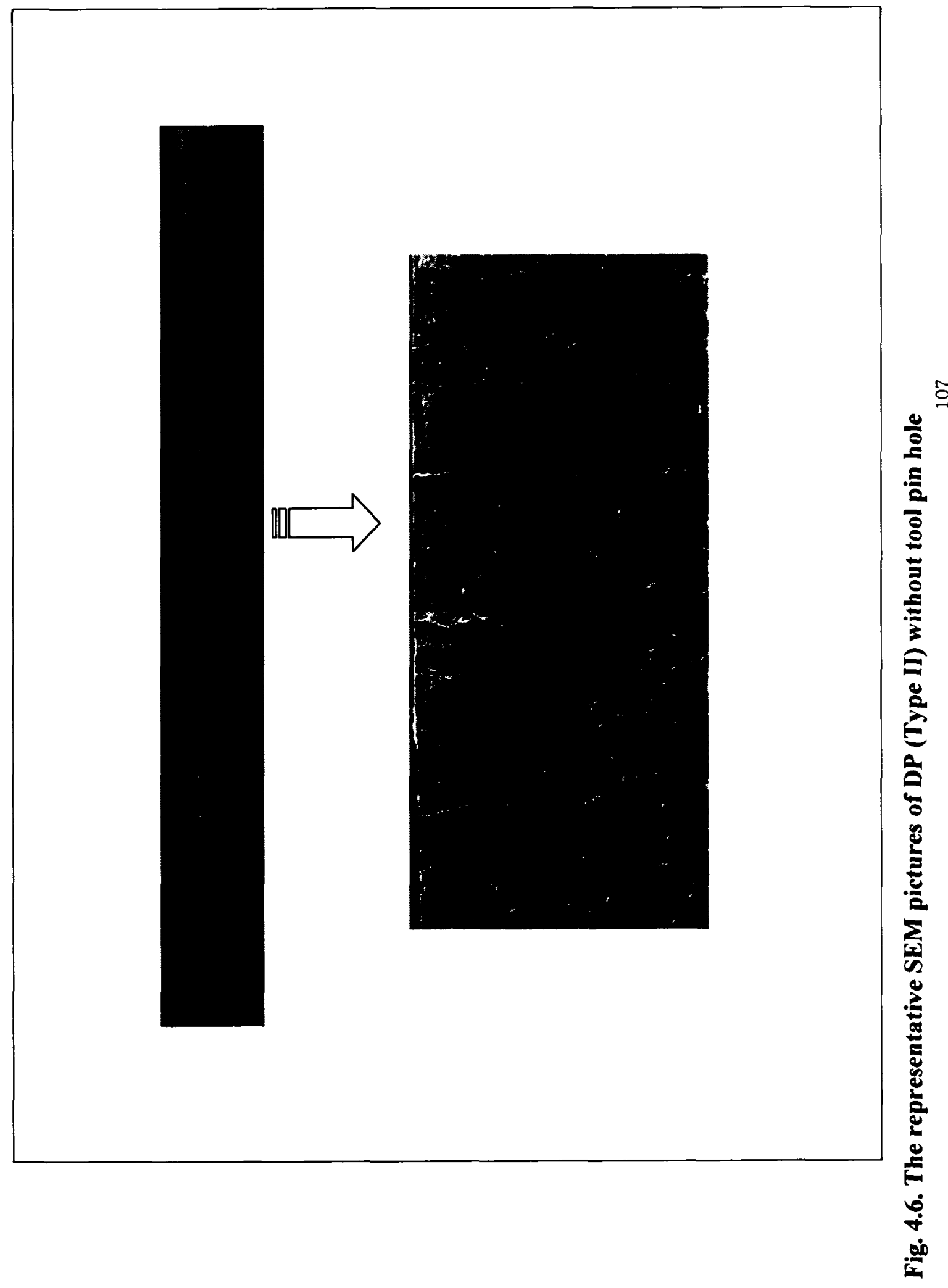




\section{CHAPTER 5}

\section{Conclusions}

In this study, the fatigue test and the static tensile strength test of the FSW stiffened panel structures were carried out to evaluate and compare the durability and static performance. Five groups FSW specimens were tested for the fatigue test and two FSW specimens were tested for the static test. The following conclusions result from analyzing the test results and SEM pictures.

1. The fatigue lives of DP (Type II) specimens without tool pin hole are much longer than those of others since they do not have crack initiation sites such as the pullout and plunge tool pin hole. Also, the specimens have better fatigue lives than SP without tool pin hole due to the welding area increased by the double pass.

2. The fatigue lives of SP without tool pin hole are similar to those of SP with tool pin hole and much shorter than DP without tool pin hole. The main reason of crack initiations in SP specimens without tool hole comes from the tool marks made by the tool pin. All 4 SP specimens without tool pin have the same tool mark 
pattern which cannot be seen in the DP specimens without tool pin hole. Also, a SP with tool pin hole has a welding defect and its crack location is different with other specimens. Thus, the SP specimens with and without tool pin hole have a high potential to possess the welding defects or tool mark defects.

3. While the microstructures of DP (Type I) and DP (Type II) specimens with tool pin hole show large difference, the fatigue lives of both specimens are quite similar since the main driving element to decide the fatigue life of the specimens is the remaining defect of the $1^{\text {st }}$ tool pin pullout hole acted as crack initiators.

4. The SP specimens with tool pin hole have a slighttly shorter fatigue life than DP (Type I and II) specimens with tool pin hole.

5. The crack propagation rate of FSW specimens is faster than 2024-T3 base material due to the brittleness of the welding.

6. In the static strength test of SP and DP (Type I) specimen with tool pin hole, the tensile strength of FSW specimens is less than 2024-T3 base material while the yield strength is similar to each other. Though there is no difference between SP and DP (Type I) specimen in static test graph, the elongation of both specimens is $10 \%$ of the elongation of 2024-T3 base material (max. elongation $=0.19$ ). 


\begin{abstract}
APPENDIX
1. Appendix (A.1 A.4); the surface crack length(Y axis) versus cycles(X axis) about all fatigue test specimens were plotted in the appendix A.
\end{abstract}

Fig. A.1 showed the plot about $20 \mathrm{ksi}$. However, the plot of the SP specimen without tool pin hole was not included since this specimen was broke in a few cycles.

Fig. A.2 showed the plot about $15 \mathrm{ksi}$. However, the plot of the SP specimen without tool pin hole was not included since this specimen was broke in a few cycles.

Fig. A.3 showed the plot about $12 \mathrm{ksi}$.

Fig. A.3 showed the plot about $10 \mathrm{ksi}$. However, the plot of the DP specimen without tool pin hole was not included since this specimen was the run-out condition. 


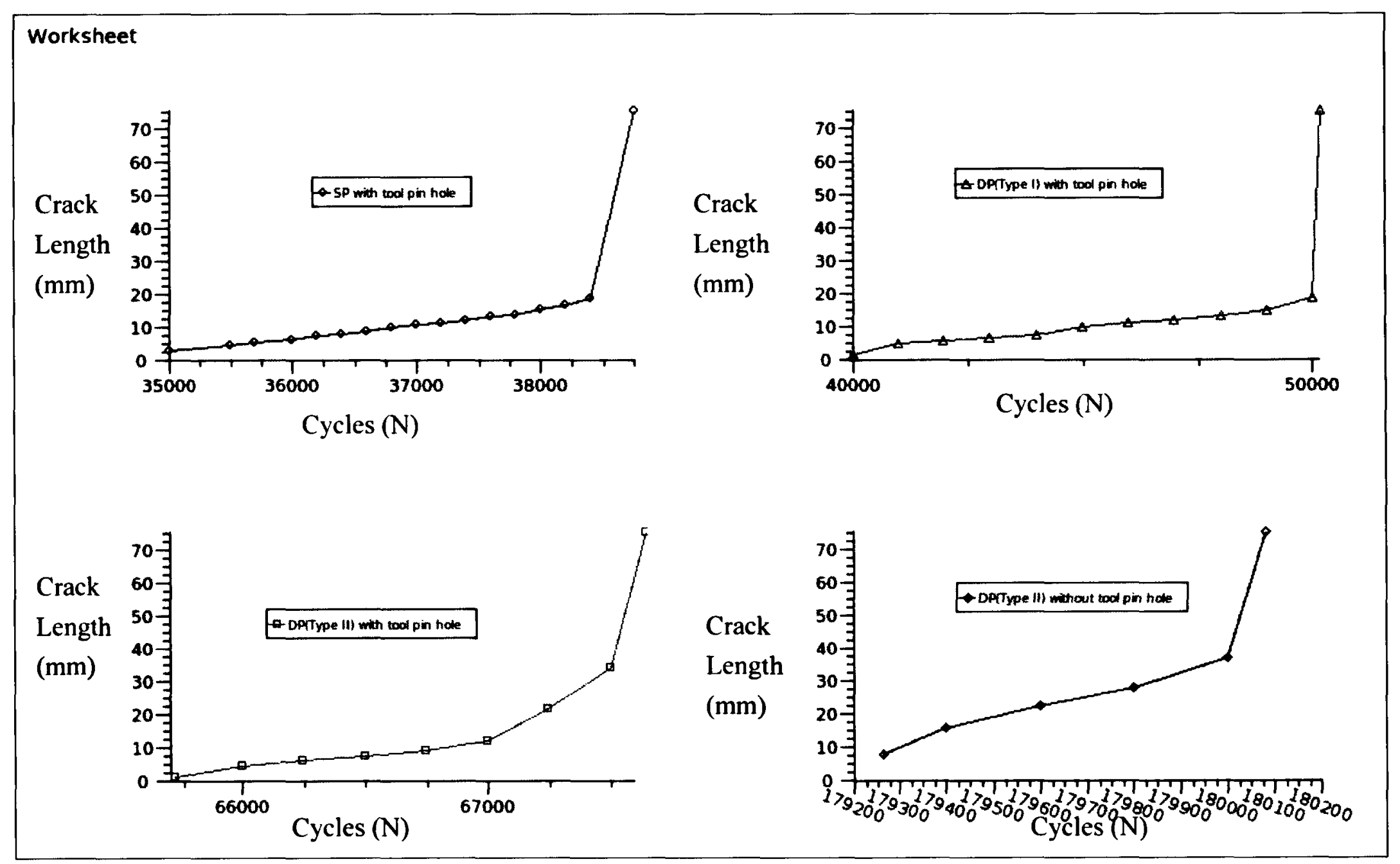

Fig. A.1 The plot of crack length versus cycles about 20 ksi fatigue test 


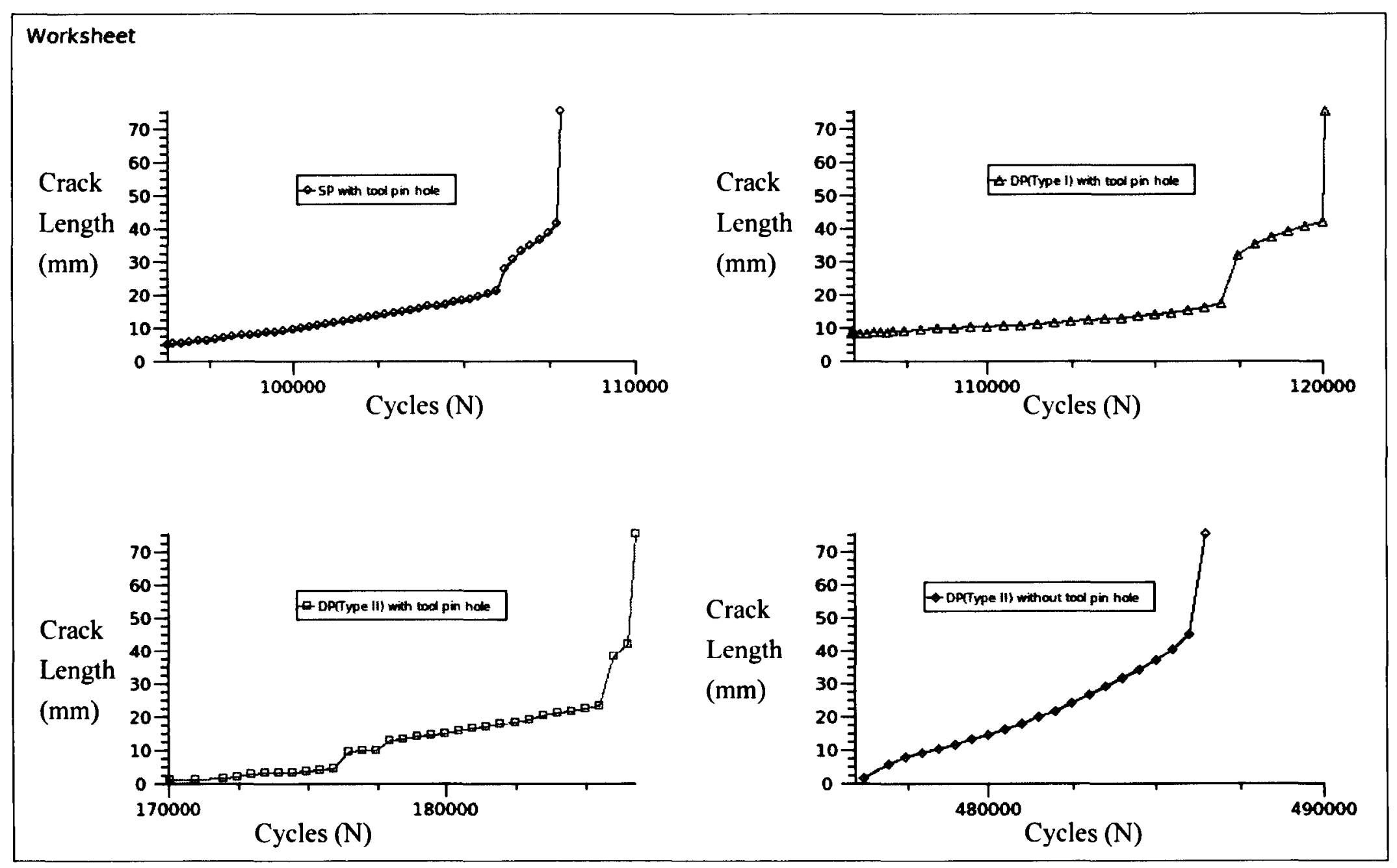

Fig. A.2 The plot of crack length versus cycles about 15 ksi fatigue test 


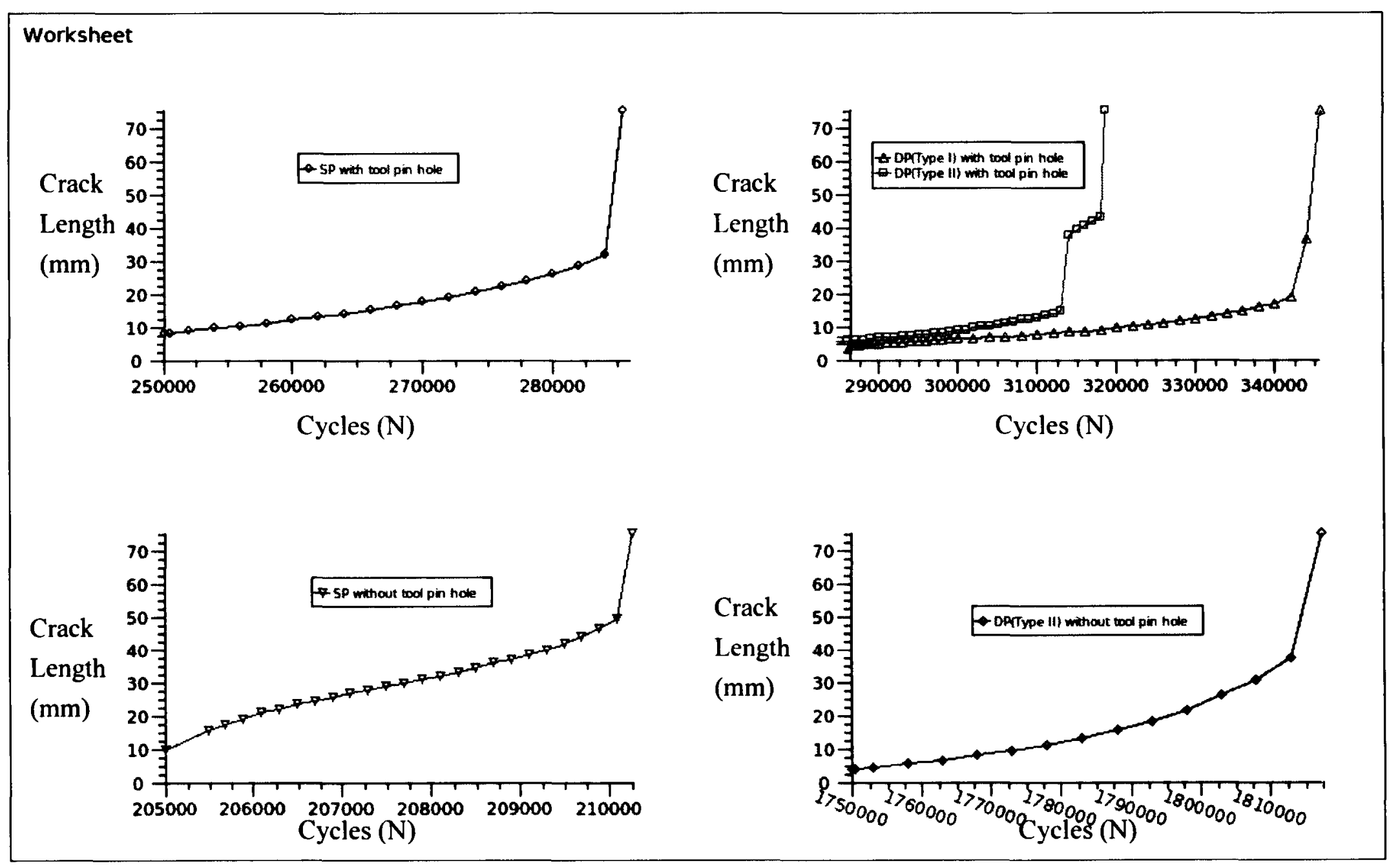

Fig. A.3 The plot of crack length versus cycles about 12 ksi fatigue test 


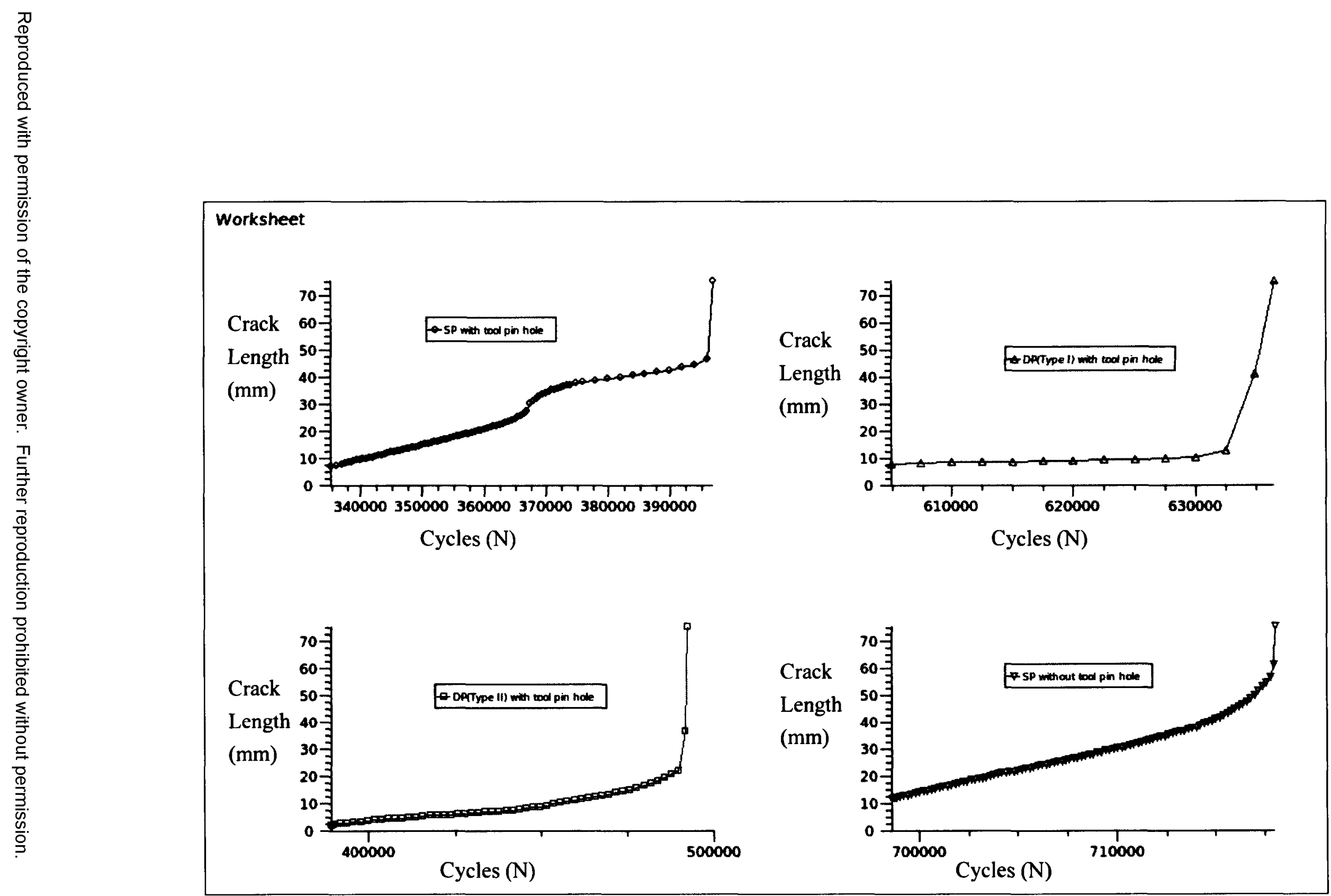

Fig. A.4 The plot of crack length versus cycles about $10 \mathrm{ksi}$ fatigue test 


\title{
REFERENCES
}

\begin{abstract}
Aluminum Now Online. 2003.
http://www.aluminum.org/ANTemplate.cfm?IssueDate=05/01/2003\&Template=/Content Management/ContentDisplay.cfm\&ContentID=7156.
\end{abstract}

(accessed September 20, 2007)

"8. material testing." In $A S M$ handbook. n.p.: Materials Park, Ohio, ASM International, pp.742, 2000.

Bhadeshia, H. K. D. H. “Friction Stir Welding," 2003. University of Cambridge. http://www.msm.cam.ac.uk/phase-trans/2003/FSW/aaa.html. (accessed September 20, 2007)

Burford, Dwight, Christian Widener, and Bryan Tweedy. "Advances in Friction Stir Welding for Aerospace Applications." 6th AIAA Aviation Technology, Integration and Operations Conference (ATIO) (25-27 September 2006).

Cook, Robert, Tito Handboy, Sean Long Fox, and William Arbegast. "Friction Stir Welding of Dissimilar Aluminum Alloys." Friction Stir Welding and Processing III, 115 
pp.35-41, 2005.

Ericsson, Mats, Kai-Zhe Jin, and Rolf Sandstroem. "Fatigue properties of friction stir overlap welds." International journal of fatigue, pp.57-68, 2007.

Farahmand, Braham, George Bockrath, and James Glassco. "2.3 Fatigue Spectrum." In Fatigue and Fracture Mechanics of High Risk Parts. : Chapman \& Hall, pp.19, 1997.

Ghidini, T. ., T. Vugrin, and C. Dalle Donne. "Residual stresses, defects and nondestructive evaluation of FSW joints." Welding International, pp.783-790, 2005).

Hitachi-rail. 2007. Hitachi-rail.

http://www.hitachi-rail.com/rail now/seminar/fsw/index.html. (accessed September 20, 2007)

Horschel, Jeff. "FSRL - Friction Stir Research Laboratory - Brigham Young University BYU," Brigham Young University.

http://www.et.byu.edu/groups/fsw/microstructure research fatigue.html. (accessed September 20, 2007)

Ir Sjoerd van der Veen, Adrian Murphy, and Rinze Benedictus. "Post-buckling failure of welded aluminium panels." 47th AIAA/ASME/ASCE/PHS/ASC structures, Structural Dynamics, and material conference (1-4 May 2006). 
J.A.Baumann, Lederich, Bolser R.J., D.R., and R. Talwar. "Property Characterization of 2024AL/7075AL Bi-alloy Friction Stir Welded Joints." Friction Stir Welding and Processing II (2003).

Kumar, Brijesh, Adam Jahn, Bryan Tweedy, Dale Cope, and Ryan Lee. "Review of the Applicability of FSW Processing to Aircraft Applications." 46th AIAA/ASME/ASCE/AHS/ASC Structures, Structural Dynamics\&Materials Conference (18-21 April 2005).

L. Cederqvist, and A.P. Raynolds "Factors Affecting the Properties of Friction Stir Welded Aluminum Lap Joints." Welding Journal, vol 80, no. 12, pp.281-287, 2001.

Mercado, U. Alfaro, T. Ghidini, and C. D. Donne. "Fatigue of Pre-corroded 2024-T3 Friction Stir Welds:Experiment and Prediction." Friction Stir Welding and Processing $I I I$, pp.43-53, 2005.

Messler, Robert W., Jr. “3 Mechanical Fasteners, Integral Attachments, and Other Mechanical Joining Methods." In Joining of materials and structures. , pp.134-145, Elsevier, 2004.

Mishra, R.S., and Ma, Z.Y. "Friction stir welding and processing." Materials Science and Engineering, vol. 50, pp.1-78, 2005. 
Murphy, A, F lynch, M Price, and A Gibson. "Modified stiffened panel analysis methods for laser beam and friction stir welded aircraft panels." Proceedings of the Institution of Mechanical Engineers, Part G: Journal of Aerospace Engineering , vol. 220, no. 4, 2006.

Oosterkamp, A., L. Djapic oosterkamp, and A. Nordeide. "'Kissing Bond Phenomena in Solid-State Welds of Aluminum Alloys.” Welding Journal , pp.225-s - 231-s, 2004.

Ouyang, J.H., and R. Kovacevic. "Material Flow and Microstructure in the Friction Stir Butt Welds of the Same and Dissimilar Aluminum Alloys." Journal of Materials Engineering and Performance, vol.11, pp.51-63, 2002.

Pao, P.S., E. Lee, C.R. Feng, H.N. Jones, and D.W. Moon. "Corrosion Fatigue in FSW Welded Al 2519." Friction Stir Welding and Processing II, pp.113-122, 2003.

Pao, P.S., R.W. Fonda, H.N. Jones, C.R. Feng, B.J. Connolly, and A.J. Davenport. "Microstructure, Fatigue Crack Growth, and Corrosion in Friction Stir Welded A15456." Friction Stir Welding and Processing III (2005).

Qian, M., and J.C. Lippold. "Liquation Phenomena in the Simulated Heat-Affected Zone of Alloy 718 after Multiple Postweld Heat Treatment Cycles." Welding Journal , pp.145$\mathrm{s}-150-\mathrm{s}, 2003$. 
Schmidt, H J, C, Voto, and Hansson J. "Metallic Fuselage Barrel, Validation of Advanced Technologies." Proceedings of the 21st Symposium of the International Committee on Aeronautical Fatigue, vol.2, pp.273-289, 2001.

Schmidt, Hans-juergen, and Biank Schmidt-Brandecker. "Damage tolerance design and analysis of current and future aircraft structure." Damage tolerance design and analysis of current and future aircraft structure (2003).

The communications Department of the Boeing company. "Delta Incorporates Friction Stir Welding." INSIDE DELTA, August 1998 [magazine on-line]; available from http:// www.boeing.com/defense-space/space/delta/id/inde0898.pdf; Internet. (accessed January $20,2007)$

Tweedy, Bryan, Scott Sellmeyer, Adam Jahn, and Dwight Burford. "Static Strength Comparison of Riveted versus Friction Stir Welded Stiffened Panels." 47th AIAA/ASME/ASCE/AHS/ASC Structures, Structural Dynamics, and Material Conference, 2006.

TWI. "Microstructure Classification of Friction Stir Welds," 2007. TWI. http://www.twi.co.uk/j32k/unprotected/band 1/fswqual.html. (accessed September 20, 2007) 
. "Friction Stir Welding at TWI," 2006. TWI.

http://www.twi.co.uk/j32k/unprotected/band 1/fswintro.html. (accessed September 20, 2007)

wikipedia. "Friction stir welding - Wikipedia, the free encyclopedia," 2007. wikipedia. http://en.wikipedia.org/wiki/Friction stir welding. (accessed September 20, 2007)

Zhou, Caizhi, Xinqi Yang, and Guohong Luan. "Effect of roots flaws on the fatigue property of friction stir welds in 2024-T3 aluminum alloys." Material Science and Engineering $A$, vol.418, pp.155-160, 2006. 